

\section{DISCLAIMER}

This report was prepared as an account of work sponsored by an agency of the United States Government. Netther the United States Government nor any agency thereof, nor any of the:r employees, makes any warranty, express or implied, or assumes any legal liability or responsibility for the accuracy, completeness, or use. fulness of any information, apparatus, product, or process disclosed, or represents that its use would not infringe privately owned rights. Reference herein to any specific commercial product, process, or service by trade name, trademark, manu. facturer, or otherwise, does not necessarily constitute or imply its endorsement, recommendation, or favoring by the United States Government or any agency thereof. The views and opinions of authors expressed herein do not necessarily state or reflect those of the United States Government or any agency thereof. 
Dist: UC-505, Mathematics and Computers

DE92 000149

\title{
PROJECT RECORDS INFORMATION SYSTEM (PRIS)
}

\section{USER'S MANUAL}

P. S. Smith

J. A Nations

R. D. Short

Engineering Design Information Systems Section

Engineering and Production Management Systems

\author{
August 1991 \\ COMPUTING AND TELECOMMUNICATIONS DIVISION \\ at \\ Oak Ridge K-25 Site \\ Post Office Box 2003 \\ Oak Ridge, Tennessee 37831 \\ Oak Ridge K-25 Site \\ Oak Ridge Y-12 Plant \\ under Contract No. DE-AC05-84OR21400 \\ for the
Department of Energy \\ for the
Department of Energy \\ rietta Energy Systems, Inc.
managing the \\ Oak Ridge National Laboratory \\ Paducah Gaseous Diffusion Plant
}




\section{TABLE OF CONTENTS}

Page

1.0 INTRODUCTION $\ldots \ldots \ldots \ldots \ldots \ldots \ldots \ldots \ldots \ldots \ldots \ldots \ldots \ldots \ldots$

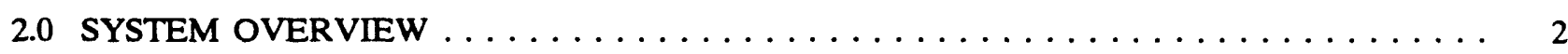

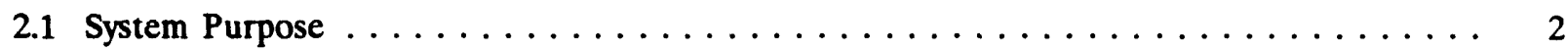

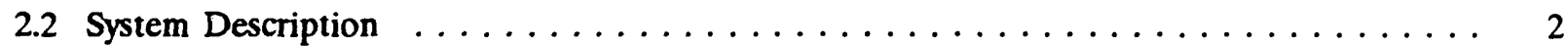

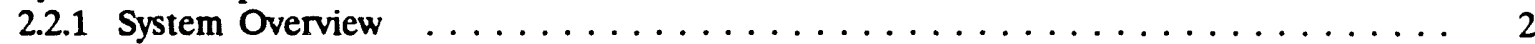

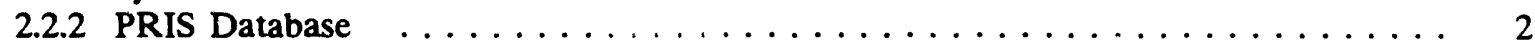

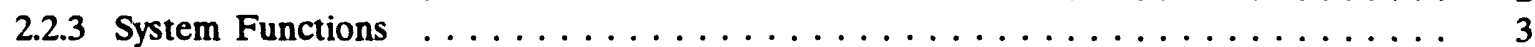

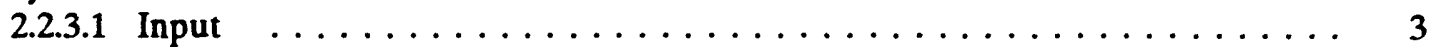

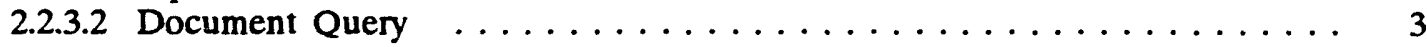

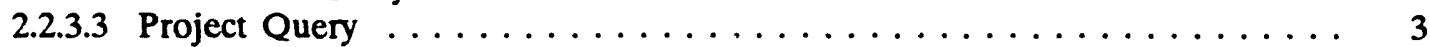

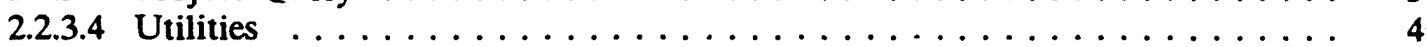

2.3 System Requirements $\ldots \ldots \ldots \ldots \ldots \ldots \ldots \ldots \ldots \ldots \ldots \ldots \ldots \ldots \ldots \ldots$

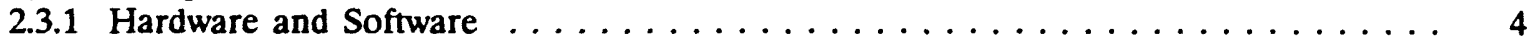

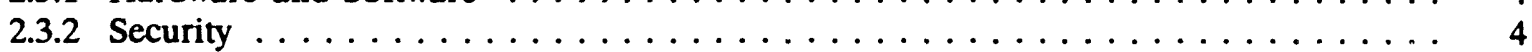

2.4 Help Screens and Error Messages $\ldots \ldots \ldots \ldots \ldots \ldots \ldots \ldots \ldots \ldots \ldots \ldots$

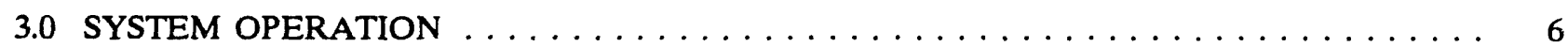

3.1 Conventions in System Commands and Keys $\ldots \ldots \ldots \ldots \ldots \ldots \ldots \ldots \ldots \ldots$

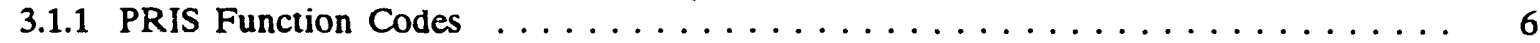

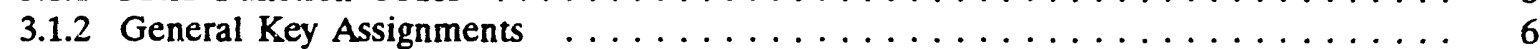

3.1.3 General Processing and Commands $\ldots \ldots \ldots \ldots \ldots \ldots \ldots \ldots \ldots \ldots$

3.2 Accessing PRIS $\ldots \ldots \ldots \ldots \ldots \ldots \ldots \ldots \ldots \ldots \ldots \ldots \ldots \ldots \ldots$

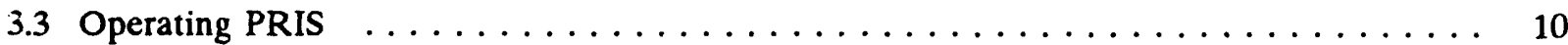

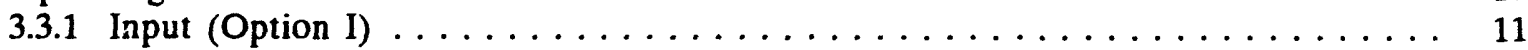

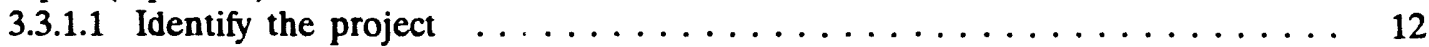

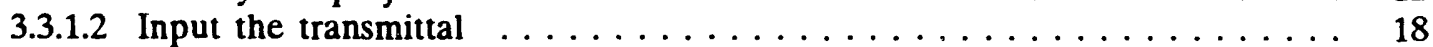

3.3.1.3 Input document index information $\ldots \ldots \ldots \ldots \ldots \ldots \ldots \ldots \ldots$

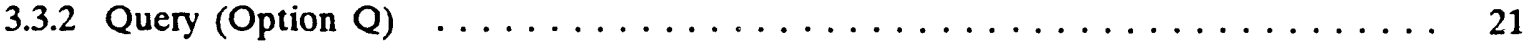

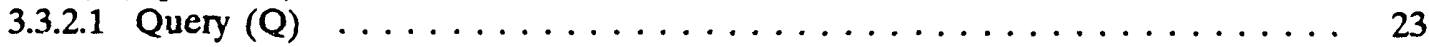

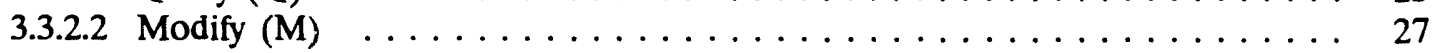

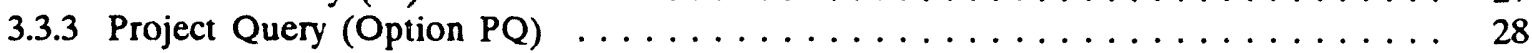

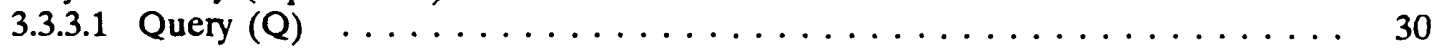

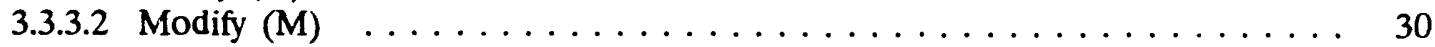

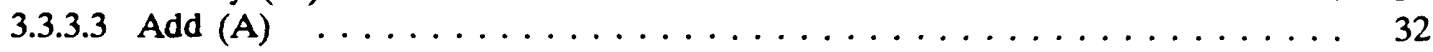


TABLE OF CONTENTS (Continued)

Page

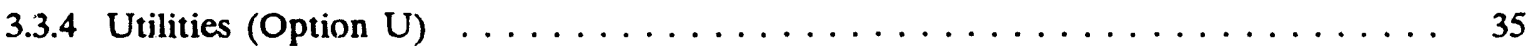

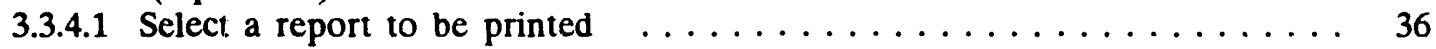

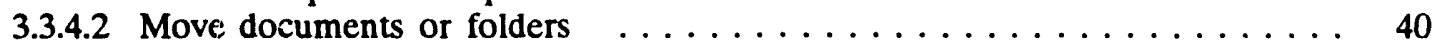

3.3.4.3 Select a project to be archived $\ldots \ldots \ldots \ldots \ldots \ldots \ldots \ldots \ldots \ldots \ldots$

APPENDIX A: FRIS DATA DICTIONARY

APPENDIX B: HELP AND ERROR SCREENS

APPENDIX C: FRIS REPORT FORMATS

APPENDIX D: FRIS PRIMARY MENU STRUCTURE DIAGRAM

iii 


\subsection{INTRODUCTION}

The Project Records Information System (PRIS) is an interactive system developed for the Information Services Division (ISD) of Martin Marietta Energy Systems, Inc., to perform indexing, maintenance, and retrieval of information about Engineering project record documents for which they are responsible. This PRIS User's Manual provides instruction on the use of this system.

Section 2.0 of this manual presents an overview of PRIS, describing the system's purpose; the data that it handles; functions it performs; hardware, software, and access; and help and error functions.

Section 3.0 describes the interactive menu-driven operation of PRIS.

Appendixes A, B, C, and D contain the data dictionary, help screens, report descriptions, and a primary menu structure diagram, respectively. 


\subsection{SYSTEM OVERVIEW}

\subsection{SYSTEM PURPOSE}

The American National Standards Institute (ANSI) has assigned responsibility for development and maintenance of nuclear power quality assurance standards to the American Society of Mechanical Engineers (ASME). The ASME Committee on Nuclear Quality Assurance has established ANSI/ASME NQA-1, Quality Assurance Program Requirements for Nuclear Power Plants. This standard is to be implemented and followed within the Department of Energy (DOE) Oak Ridge facilities operated by Martin Marietta Energy Systems, Inc. One implementation of this standard is described in Engineering Procedure EP-B36, which requires that project files be maintained that contain the record copy of certain Engineering Project documents. The Information Services Division (ISD), which has the responsibility of maintaining these files, has requested that the Engineering Projects Records Information System (PRIS) be developed to meet these requirements.

\subsection{SYSTEM DESCRIPTION}

\section{System Overview}

PRIS is an interactive system developed for the ISD to perform indexing, maintenance, and retrieval of information about Engineering project record documents for which they are responsible. Engineering project information and information about documents associated with these projects are entered into the system by ISD personnel via interactive screens. This information is taken from the Engineering Transmittal forms that are attached to documents transmitted to ISD. All documents received with a given transmittal are indexed and physically stored in a unique folder associated with the appropriate project. Based on information entered on the screens, the system generates project indexing numbers and organizes a series of indexed folde's for each project. These folders are physically set up by ISD personnel for the hardcopy storare of the project documents, except for design drawings. Design drawings are physically stored at the ISD Drawing Centers, and only information about the drawings are stored in their project folders.

PRIS has been incorporated into the Engineering Design Information System (EDIS) as a separate user interface to the EDIS Index. The EDIS Index contains information about Engineering design documents released by ISD.

Information may be retrieved from PRIS using interactive query screens that allow searches on both document and project related fields. The information resulting from the queries can be viewed on the terminal screen. In addition, hard-copy reports may be selected from a list of predefined reports displayed on interactive selection screens. The selected hard-copy reports are delivered to requesters via the plant mail system. A diagram of the primary menu structure for PRIS is shown in Appendix D. The diagram depicts the functional flow of the screens that are described in this manual.

\subsection{PRIS Database}

The index information about Engineering design documents entered through PRIS is only a subset of the total index information entered into EDIS through other systems, which include the CADAM system and the ISD update program. The index information in the EDIS Index and PRIS is stored in the same set of tables regardless of the source of the information. For this reason, PRIS users may obtain additional index information about design documents that were originally entered into the Index through systems other than PRIS and then later entered through PRIS as a project document. In these instances, the physical document does not reside in the project folder but is maintained by the ISD Design Center or the repository 
associated with the system that entered the document into the consolidated database.

A dictionary defining PRIS data elements is presented in Appendix A.

\section{System Functions}

PRIS functions are accessed through a Primary Option Menu that lists the Input, Document Query, Project Query, and Utilities functions available for the system. Section 3.0 describes the screens and user actions for each of the PRIS functions. The following sections describe these major functions.

\subsection{Input}

This function allows you to enter the necessary data into the system to establish a new project or to enter document index information for an existing project. The indexing of documents into PRIS is accomplished by associating the document index information with a unique folder, which is further associated with a unique project. Documents received by ISD are accompanied by an Engineering transmittal, which identifies, among other things, the project with which the accompanying documents are to be associated. The project is identified by name (ISD Project No.) or by an Engineering Service Order (ESO) number. Each transmittal received and entered into the system is assigned a sequential folder number and is associated with the appropriate project as it is entered.

To enter document information into the system, you are expected to first identify an existing project with which the document is to be associated or to supply information necessary to create a new project. Once a project has been identified or a new one has been created, you are expected to enter required transmittal data that will be associated with a folder within the identified project. The project and transmittal data are entered into the system using the Project/Transmittal Entry Screen. After the required project and transmittal data have been entered, the Document Entry Screen will be displayed for entry of the document index information for each document received with the transmittal. All documents associated with this transmittal should be indexed during the same Input session. Once the Input session has been ended for a particular transmittal, no further documents can be associated with the transmittal using the Input function. However, the Add subfunction of the Project Query function described below may be used for this purpose.

\subsection{Document Query}

This function allows you to obtain an abbreviated listing of documents that meet certain criteria you enter into a query screen. You may select one or more of the documents from the list and perform Query or Modify functions concerning the document using any of the available PRIS commands. The Query function displays additional detail information concerning the document, and the Modify function allows you to modify certain index data fields associated with the selected document.

\subsubsection{Project Query}

This function allows you to obtain an abbreviated listing of projects that meet certain criteria you enter into a query screen. You may select one of the listed projects and perform other Query, Modify, and Add functions concerning the project using any of the available PRIS commands.

If the Query function is selected, the system will display an abbreviated listing of documents associated with the selected project, and you may select one of these documents to query or modify as described for the Document Query function above. The Modify function allows you to either change project related data or add additional ESOs to the list of valid ESOs for the selected project. The Add function allows you to enter additional documents to a selected project transmittal. 


\subsubsection{Utilities}

This function allows you (1) to select from a list of predefined hard-copy reports of project and document information contained in the PRIS database, (2) to archive, deactivate, and change the storage location of an active project (this function has not been implemented into PRIS but will be completed at a later date), and (3) to move documents from one project folder to another or move a folder from one project to another.

\section{SYSTEM REQUIREMENTS}

\subsection{Hardware and Software}

PRIS is located on the IBM 3084 unclassified processor located at the Oak Ridge K-25 Site.

PRIS is accessed via asynchronous communication over the unclassified DCA network using VT-100type terminals or microcomputers equipped with VT-100 emulation software as follows:

1. An ASCII terminal connection to the IBM 7171 (System Select 47) through the unclassifieci DCA network for the 3084 unclassified system or a microcomputer with communications software (e.g., SmarTerm).

2. An IBM 3270-type terminal or a microcomputer equipped with 3270 emulation, such as IRMA, connected through coaxial cable or an IBM token ring network. are used:

PL/I is the primary programming language used for PRIS. The following vendor software packages

1. ISPF Dialog Manager - User interface screens

2. DB2 relational database - Repository for PRIS data

All vendor software packages currently reside on the IBM 3084 .

\subsubsection{Security}

Users must have a user ID, a computer password, and an authorized TSO account on the IBM 3083 computer at K-25 to access the system. Security is enforced through user identification at the time of logon and through authorization tables that exist within EDIS to define the functions that are permitted to be performed by each user of the system.

User access control information is obtained from the Engineering Management Information System (EMIS). A PRIS user must first be a valid EMIS user. Engineering information, including EMIS user IDs, is written to a DB2 table that is used to control access to the PRIS data.

ISPF tables and VSAM files of EDIS are used for data validation. Certain EDIS modules are called by this system to validate certain data elements, which include building numbers, ESO numbers, and EMIS user IDs.

\section{HELP SCREENS AND ERROR MESSAGES}


Help screens are available throughout the system to prompt you for valid codes for buildings, engineering personnel, companies, classifications, plants, and document functions. These screens may be accessed by placing a "?" in the code field and pressing <ENTER>. The help screens are displayed in Appendix B of this user's manual.

A help screen of valid PRIS command and selection codes can be obtained by typing "?" in the command line of any screen and pressing <ENTER> (see Appendix B).

Error screens for certain special cases are also displayed in Appendix B.

Error messages are displayed to you on the system screens just below the command line whenever an invalid command or information is entered. Messages that confirm the system's execution of functions you have requested are also displayed on the screen just below the Command line. 


\subsection{SYSTEM OPERATION}

\subsection{CONVENTIONS IN SYSTEM COMMANDS AND KEYS}

System operations are performed using a series of data display, selection, and/or entry screens. The primary screen structure is shown in Appendix D. The system will perform the tasks you request by guiding you from one screen to the next based upon your responses to the prompts. You can make selections from a displayed menu by entering requested data and pressing the $<$ ENTER $>$ key or by entering one of the PRIS function command codes (shown below) in the indicated command field and pressing the <ENTER> key. Section 3.1.1 lists the PRIS function codes and their associated system response. Section 3.1.2 lists the general key assignments and their associated functions.

The system screens are operated from a command line, which is the second line of each screen. The commands that may be entered on this line are listed below. Command keys are enclosed in angle brackets (e.g., <ENTER >) that indicate you should press a single key to perform the action.

\subsubsection{PRIS Function Codes}

\begin{tabular}{|c|c|c|c|}
\hline Command o & & and Press & Action \\
\hline ADD & $\overline{\mathbf{A}}$ & $<$ ENTER $>$ & Adds a document to an existing folder. \\
\hline END & E & $<$ ENTER $>$ & $\begin{array}{l}\text { Terminates the present screen or function and returns the user } \\
\text { to the previous screen or function accessed. }\end{array}$ \\
\hline UP & UP & $<$ ENTER $>$ & $\begin{array}{l}\text { Scrolls the screen image up to reveal text that is above the } \\
\text { displayed list. ("UP } n \text { " scrolls " } n \text { " lines up.) }\end{array}$ \\
\hline DOWN & DN & $<$ ENTER $>$ & $\begin{array}{l}\text { Scrolls the screen image down to reveal text that is below the } \\
\text { displayed list. ("DOWN } n^{n} \text { scrolls " } n \text { " lines down.) }\end{array}$ \\
\hline EXIT & $\mathbf{x}$ & $<$ ENTER $>$ & $\begin{array}{l}\text { Returns to the Primary Option Menu from any other system } \\
\text { screen. }\end{array}$ \\
\hline MODIFY & $\mathbf{M}$ & $<$ ENTER $>$ & Modifies an existing document or project. \\
\hline QUERY & Q & $<$ ENTER $>$ & Displays document information. \\
\hline HELP & $\mathbf{H}$ & $<$ ENTER $>$ & Calls the PRIS on-line tutorial. (Not currently available.) \\
\hline
\end{tabular}

\subsubsection{General Key Assignments}

Command keys and their functions to operate cursor movement on the screen are listed below:

Command Key

<ARROW-DOWN >

<ARROW-LEFT>

<ARROW-RIGHT>

$<A R R O W-U P>$

<BACKSPACE>

$<$ DELETE $>$

$<$ ENTER $>$

$<$ RESET $>$

$<$ SHIFT $><\mathrm{TAB}>$

$\langle\mathrm{TAB}>$

\section{Function}

Moves cursor down one line directly below the current cursor position. Moves cursor one space to the left of the current cursor position. Moves cursor one space to the right of the current cursor position. Moves cursor up one line directly above the current cursor position. Moves cursor one space to the left of the current cursor position. Deletes character on which the cursor currently rests and moves all characters on the right of the cursor one space to the left.

Tells system to execute the command that the user has entered. Unlocks keyboard when the system displays the locked symbol in the lower-left corner of the screen.

Moves cursor back to the previous sequential field on the screen. Moves cursor to the next sequential field on the screen. 


\subsubsection{General Processing and Commands}

You may enter "?" in some of the input fields of the screens to receive a help screen listing valid input options for that field. These help screens may also be displayed if you enter an invalid entry in these fields. These fields include classification, building, company, document type, and plant. See Appendix B for examples of these list screens. In most cases, you may select from the list in one of two ways, either by placing an $\mathrm{X}$ beside the desired option or by entering the indicated response code. The system will return you to the original screen, and the data for the input option selected will be placed in the original screen's input field just as if you had entered the characters directly into the field manually. If you press <ENTER > while one of these list screens is displayed vrithout having made a selection, the system will display a message requesting a selection. If you enter END in the command field of any of these list screens, the system will redispiay the screen where the "?" was originally entered, place the cursor at that field, and continue processing as required.

NOTE: When using Help screens to find valid search entries while using one of the system's search screens, do not select directly from the help screen if you have not completed entering search criteria on the search screen. Return to the search screen using the END command, and then, type the chosen value directly on the search screen. If the code and <ENTER> are entered on the help screen, the search will be executed with only the search criteria existing at that time.

For input fields that require EMIS IDs to be entered, you may enter "?" and press <ENTER > to receive the Engineering Personnel Help screen. This screen allows you to enter search criteria consisting of a portion of a person's name and to receive a second screen listing the EMIS IDs and the associated names that meet the search criteria you entered. You may then select an entry from this list for the needed EMIS ID.

For the entry of partial search criteria on search screens, a "\%" sign can be used as a wild-card to represent unknown characters located before, after, or in the middle of a known string of characters. The system will search all records that contain the search string in the indicated position. 


\subsection{ACCESSING PRIS}

To access PRIS, you must have a user ID, a computer password, and an authorized TSO account on the IBM 3084 machine.

Several types of terminal connections may be used to access the 3084 , as described in Sect. 2.3.1. To log on the K-25 IBM 3084 unclassified system using one of these terminal connections, follow one of the procedures described below. Responses enclosed in parentheses ( ) indicate that you should fill in the appropriate variable information.

NOTE: Whenever the system displays *** at the bottom of text, you must press <ENTER> to continue.

1. For the 7171 connection to the K-25 system, answer the following prompts with the indicated responses:

\section{Prompt}

Which System (1 thru 55)?

enter terminal type:

THIS TERMINAL IS ATTACHED TO ...

\section{Response}

$47<$ ENTER > $<$ ENTER $>$

(type) $<$ ENTER >*

TSOK <ENTER >

"The (type) response for this terminal type is almost always VT100.

2. For the 3270-type terminal with coaxial or token ring connection, respond to the prompt as shown below:

\section{Prompt}

THIS TERMINAL IS ATTACHED TO THE ...

\section{Response}

TSOK <ENTER >

After entering the TSOK command for each of these log-on sequences, you will receive prompts for user ID and password:

Prompt

ACF82003 ACF2, ENTER LOGON ID

ACF82004 ACF2, ENTER PASSWORD

ACF82012 ACF2, ENTER ACCOUNT

(Displayed if no default account

has been set up.) *** $\underline{\text { Response }}$

(user ID)

<ENTER >

(user password)

$<$ ENTER >

(account number)

$<$ ENTER > 
If the log-on session is successful, you will receive TSO log-on messages followed by the TSO prompt: READY

To access PRIS, type

PRIS <ENTER>

The PRIS Primary Option Menu shown on the next page will be displayed. 


\subsection{OPERATING PRIS}

When you have gained access to PRIS, the following menu will be displayed from which you may select the system functions.

\section{PRIMARY OPTION MENU}

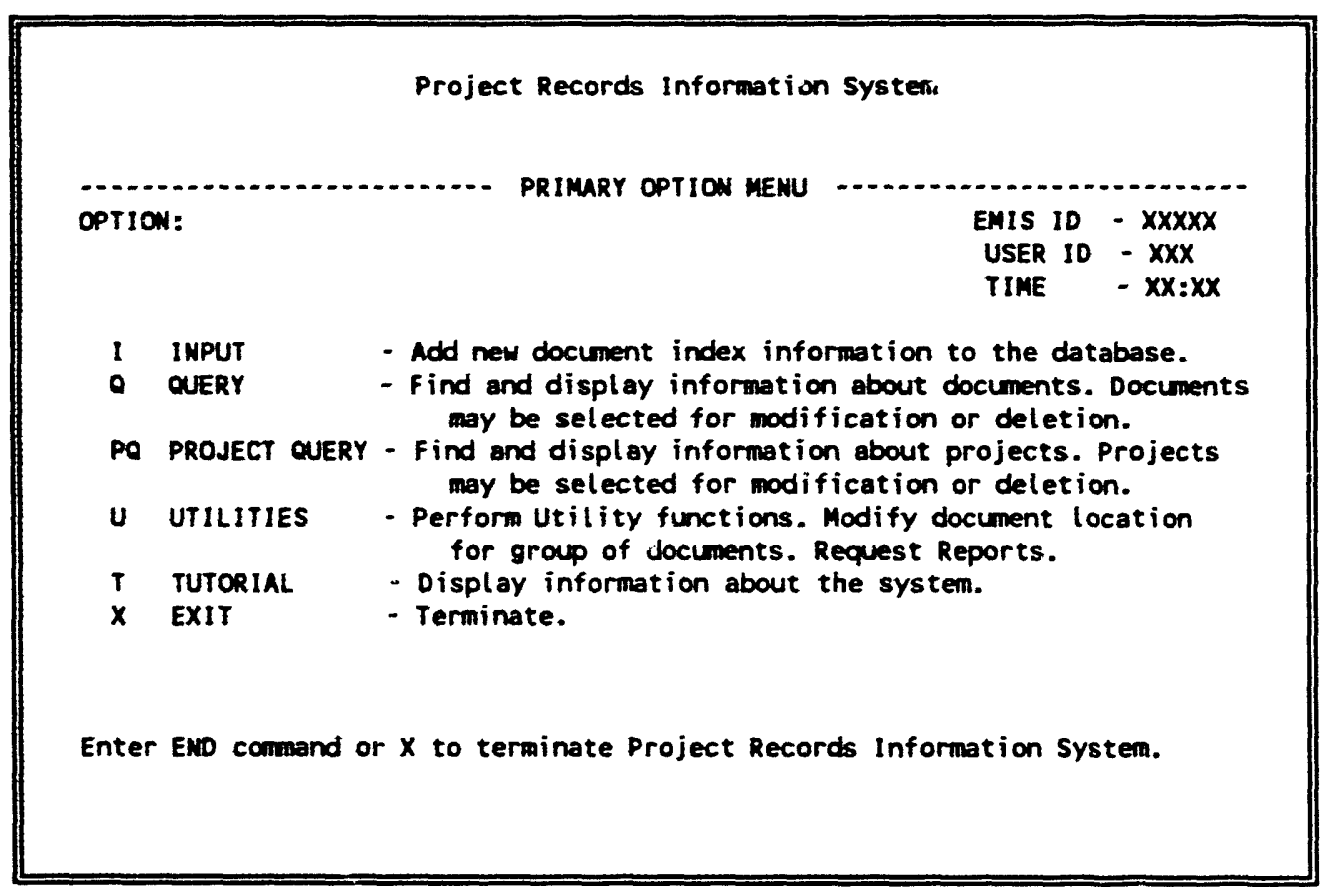

You can indicate the function to be performed by typing the option character(s) on the OPTION line and pressing <ENTER>. The following sections of this manual describe the operation of the Primary Option Menu options. Refer to the table below to find the manual section that covers each option.

\begin{tabular}{ll} 
Option & \multicolumn{1}{c}{ Action } \\
I & INPUT (see Sect. 3.3.1). \\
Q & QUERY (see Sect. 3.3.2). \\
PQ & PROJECT QUERY (see Sect. 3.3.3). \\
U & UTILITIES (see Sect. 3.3.4). \\
T & TUTORIAL (This option is not currently available.)
\end{tabular}

Entering option $\mathrm{X}$ or the command END and pressing <ENTER $>$ will exit PRIS and return you to the system READY prompt. 


\subsubsection{Input (Option I)}

To enter document and transmittal information into the system, you must perform three basic steps:

1. Identify the project to which the document(s) belong. This may be an existing project or require entry of a new project (see Sect. 3.3.1.1).

2. Input the transmittal to which the document(s) are associated. PRIS will generate a separate folder number for each transmittal (see Sect. 3.3.1.2).

3. Input document index information for all the document(s) associated with the identified transmittal (see Sect. 3.3.1.3). PRIS will index each document with the project, transmittal, and folder numbers that have been identified. All documents associated with this transmittal should be entered during the same Input session. Once the Input function has been ended for a particular transmittal, no further documents can be associated with the transmittal using the Input function option. However, an Add function, described in Sect. 3.3.3.3, may be used for adding additional documents to a transmittal.

When Option I is selected from the Primary Option Menu, the Project/Transmittal Entry screen will be displayed to allow you to perform the first two input steps.

\section{PROJECT/TRANSMITTAL ENTRY SCREEN}

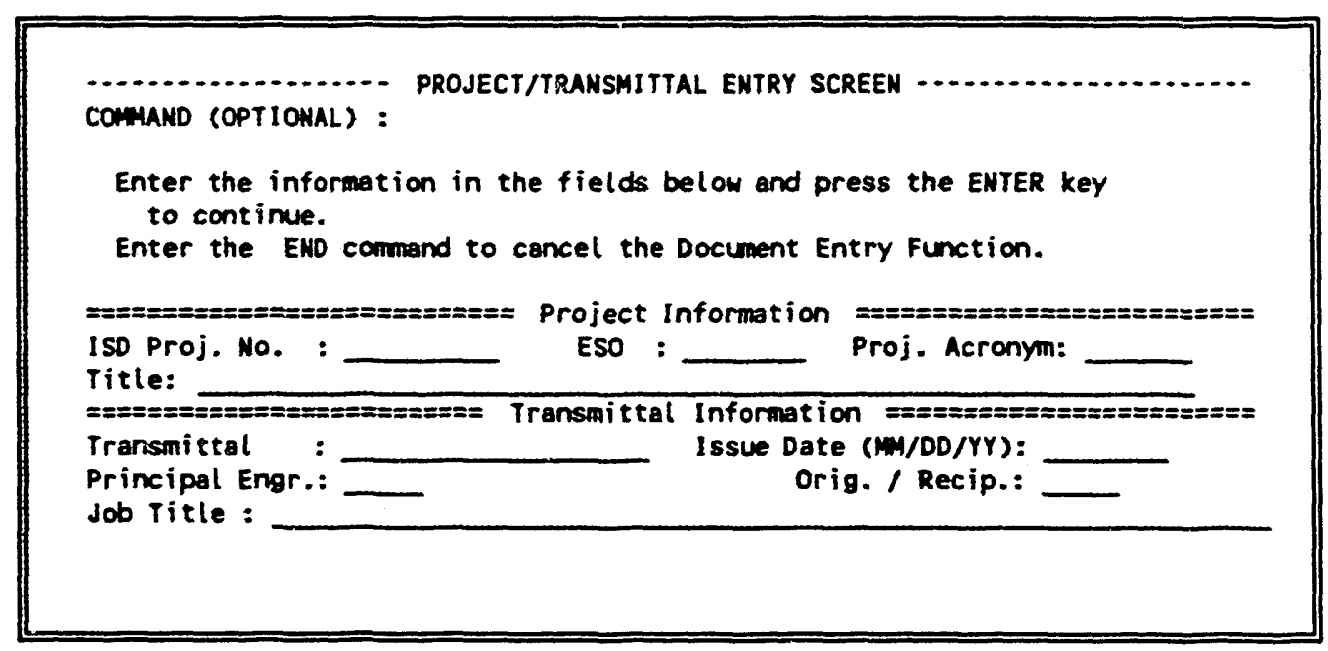

Two input areas are defined on this screen: one for project information and one for transmittal information. If all the valid information for input fields on both portions of this screen are known, $<\mathrm{TAB}\rangle$ to each field, enter the data, and press <ENTER>. The system will proceed directly to the Document Entry Screen to input document index information. For detailed information about entry of project and transmittal information see Sects. 3.3.1.1 and 3.3.1.2, respectively. Additional screens to help you enter this information are described in these sections.

Entry of document information is described in Sect. 3.3.1.3. 


\subsubsection{Identify the project}

To enter project information, follow either option 1 or 2 below depending upon whether (1) the project for this document transmittal already exists in the database or (2) the project does not exist in the database.

1. Select existing project. An existing project can be identified by entering a valid (valid only in terms of format) 8 digit ESO and/or an existing ISD Project Number into the Project/Transmittal Entry Screen and pressing <ENTER $>$. Entry of an existing Project Acronym and a Project Title is optional.

The system will check the validity of the data you entered and, if valid, will either advance the cursor to the Transmittal Information part of the screen to allow you to enter transmittal data (see Sect. 3.3.1.2) or to the Document Entry Screen to enter document index information (see Sect. 3.3.1.3). (You may add transmittal information at the same time you enter project information on this screen and press <ENTER $>$ to process the entire screen's data at once.) If you enter more than one of the data elements listed on the screen and the information entered is inconsistent with that stored in the database, you will be warned and the data entered will be rejected.

This function will display two additional screens to help you identify a project number and/or an ESO (a) if you enter a valid ESO that has not previously been assigned to a project and (b) if you do not know the project number and/or the ESO number you wish to use. The use of these screens is described below.

a. The first screen will be displayed if you enter an ISD project number and a new valid ESO number that has not been assigned to that ISD Project Number. This ESO may have been previously assigned to other ISD Projects. This screen allows you to confirm that the ESO entered should be assigned to the project number you have entered. If an attempt is made to associate an ESO number with multiple ISD projects, a warning message will be displayed on this screen to indicate that other projects are associated with the entered ESO number.

\section{ADD ESO TO EXISTING PROJECT SCREEN}

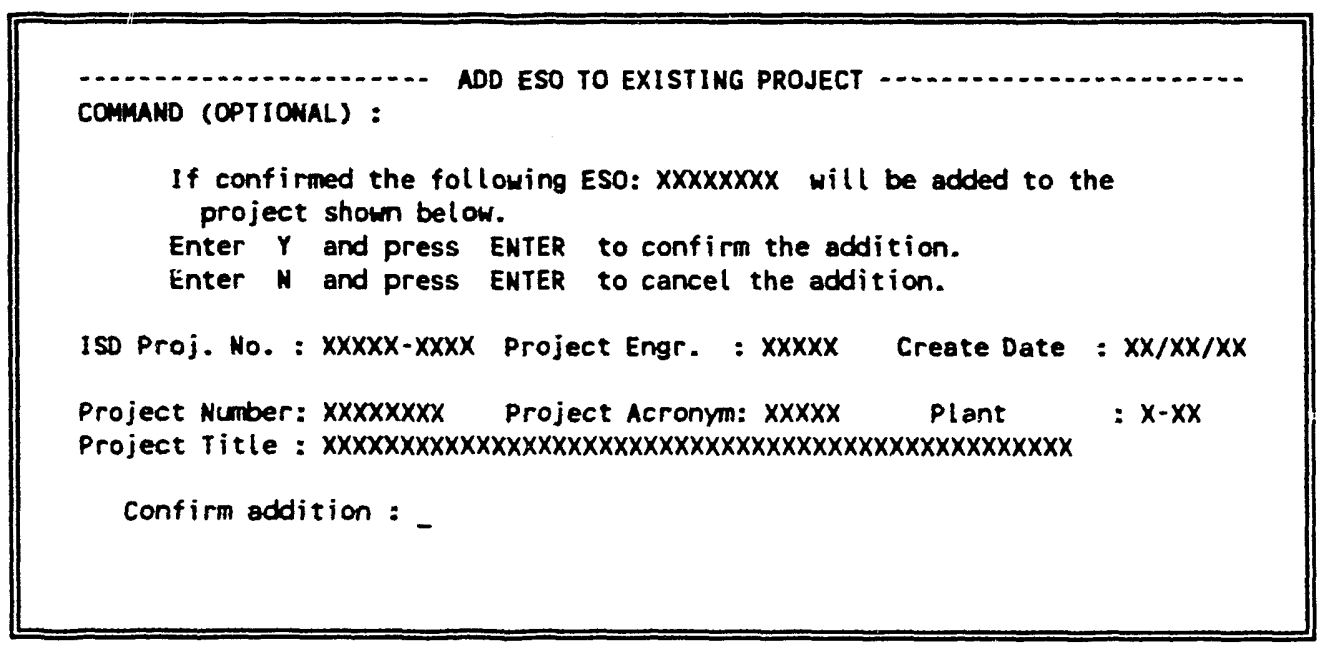


Enter $\mathrm{Y}$ to confirm the assignment, and the system will add the ESO to the project and either return you to the Project/Transmittal Entry screen to input transmittal data (see Sect. 3.3.1.2) or advance you to the Document Entry Screen (Sect. 3.3.1.3) if you have already entered the transmittal information.

If you answer $\mathrm{N}$ to the confirmation screen, the Project/Transmittal Entry screen will be redisplayed with an error message, and you must either change the input information or exit.

b. The second screen allows you find a valid ISD project number under the following situations:

i. If you wish to assign a new ESO to an existing project but do not know the ISD project number.

ii. If you wish to find an ISD project number and use the ESO already assigned to the project.

Enter partial phrases in either the ISD Project Number, ESO, Project Acronym or Project Title field of the Project/Transmittal Entry screen to receive a list of existing projects that contain the project number, ESO, acronym or title phrase you entered. If you know the ESO you wish to use with the project, enter this number at the same time that you enter the search phrase.

NOTE: For the entry of partial search phrases on search screens, a "\%" sign can be used as a wild-card to represent unknown characters located before, after, or in the middle of a known string of characters. The system will search all records that contain the search string in the indicated position of the field.

If only one project exists that contains the entered phrase, this project will be selected, and you will be returned to the Project/Transmittal Entry Screen (or the Add ESO to Existing Project Screen described above) with the project information entered into the appropriate fields.

If more than one project is found, a list of projects will be displayed on the Project Selection Screen shown on the following page.

If no projects are found containing the entered phrase, the Project/Transmittal Entry screen will be redisplayed with an error message, and you must enter new project values. 


\section{PROJECT SELECTION SCREEN}

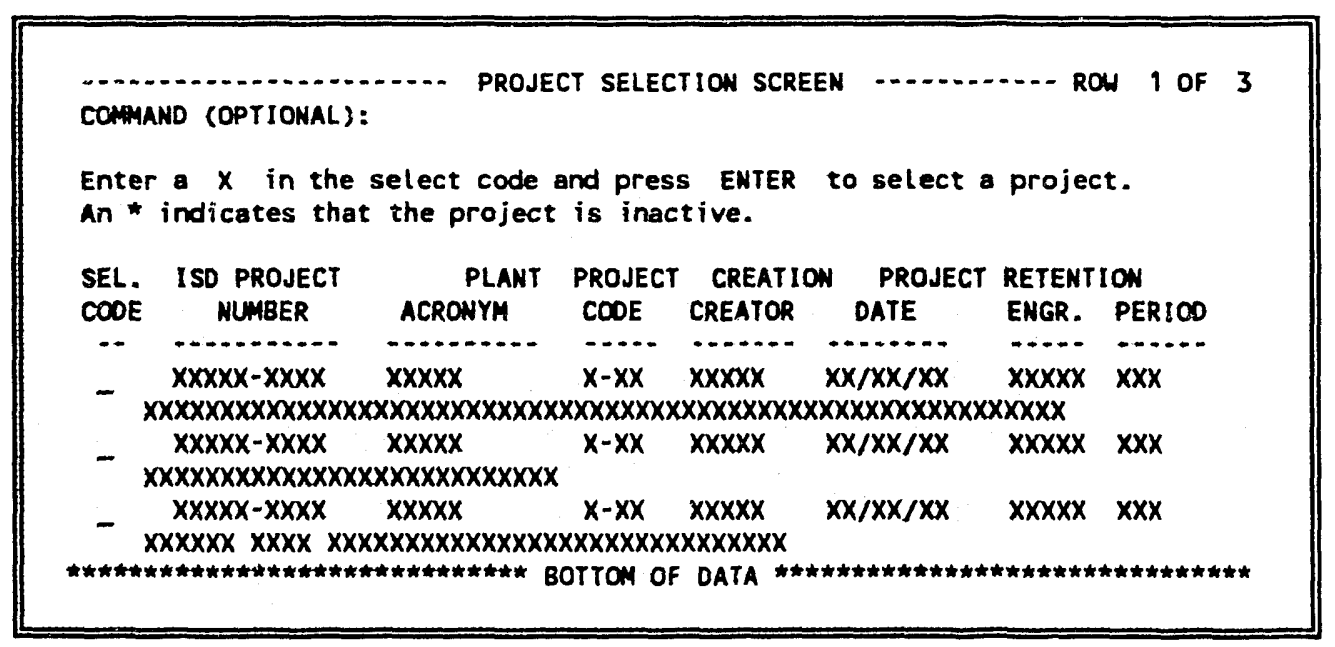

Select one of the listed projects by entering an $\mathrm{X}$ in the associated SEL. CODE field and pressing <ENTER $>$.

If you have not specified the ESO to be used for this project, the system will assign to it the first ESO listed in the database for the selected project. The system will next display a screen for entry of either transmittal or document information as appropriate, and the project you selected and the ESO selected will be entered in the respective fields of these screens.

If you specified an ESO for the selected project, the system will next display the Add ESO to Existing Project Screen described in (a) above to allow you to confirm this assignment. You will then be allowed to continue to enter either transmittal or document information as appropriate.

If no projects are selected from the above Project Selection Screen, the Project/Transmittal Entry Screen will be redisplayed with an error message. 
2. Enter new project. To enter a new project into the database, enter the valid ISD project number (Validity will be checked in format and plant identifier, i.e. ZYYYY-NNNN, where $\mathrm{Z}$ is the plant identifier, YYYY is the year identifier, and NNNN is a four digit identifier. The plant identifier must be one of the three plant codes; $\mathrm{X}, \mathrm{Y}$, or $\mathrm{K}$.) and the 8 digit ESO listed on the transmittal or ESO form in the ISD Project Number and ESO fields of the Project/Transmittal Entry Screen. The project acronym and project title for the new project are optional. If the data entered is not valid, an error message will be issued. If the data entered is valid the following screen will be displayed.

\section{ADD NEW PROJECT INFORMATION SCREEN}

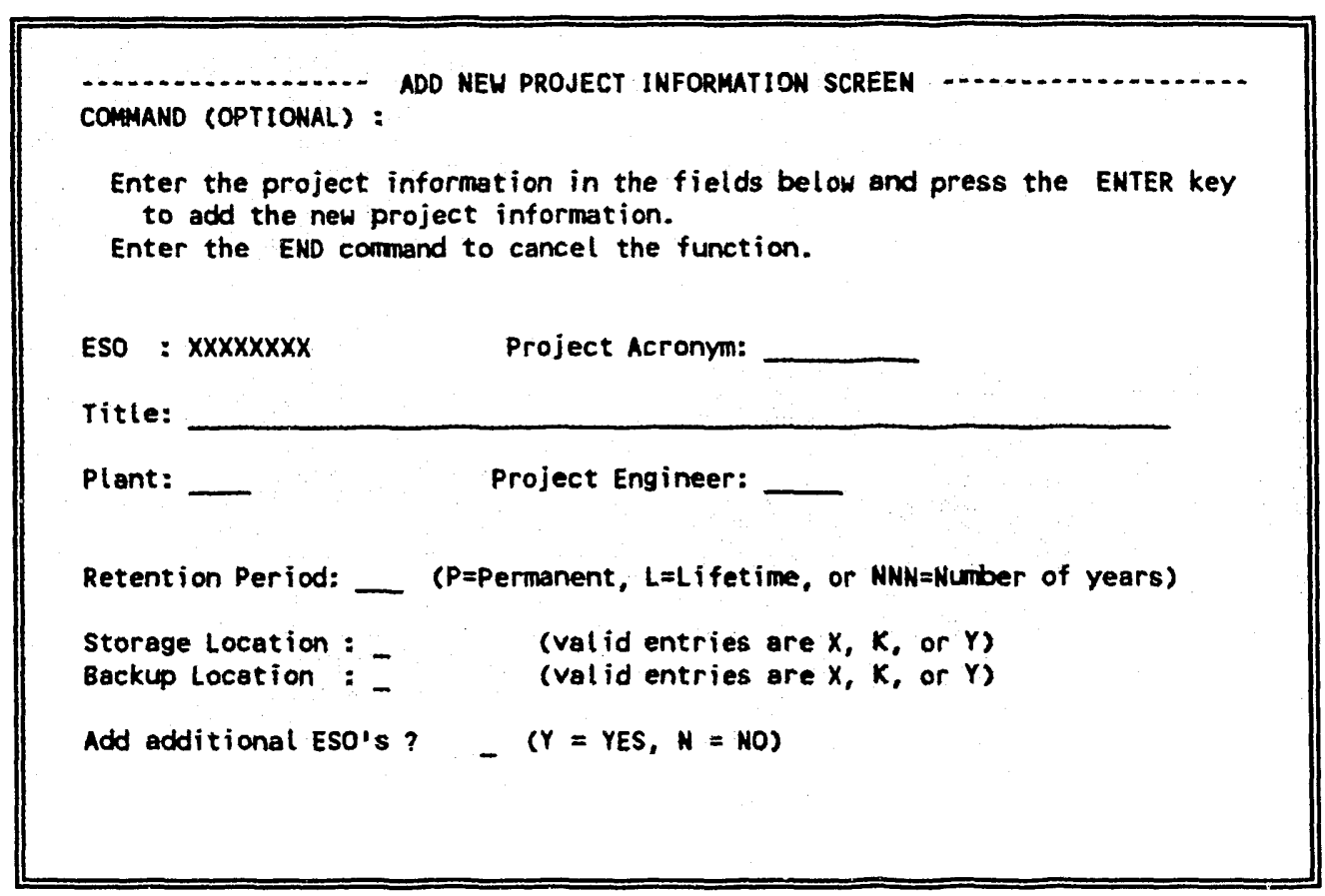

The ESO, project acronym, and the project title will be defaulted to those just entered on the previous screen, and the plant value will be defaulted to the plant with which you are associated. The project primary storage location is defaulted to your plant location, and the backup location is defaulted to the assigned backup location for the primary location. A list of backup locations for each plant is maintained by the system.

If an attempt is made to associate the entered ESO number with multiple ISD Projects a warning message will be displayed indicating that the entered ESO number is currently associated with other ISD projects.

Enter the additional information requested and press $<$ ENTER $>$. With the exception of the ESO and ISD Project Number, you may change any of the default entries on the screen before pressing <ENTER>. 
The system will no longer generate the next sequential project number for the new project, but rather accept the number entered. Upon successful completion of this screen, a new project will have been created, and a project record will exist regardless of whether transmittal and document information is entered or you choose to exit the system by entering END or $\mathrm{X}$ in the command line.

If you requested the assignment of additional ESOs to the new project by entering $\mathrm{Y}$ in the field prompt "Add additional ESO's," the following screen will be displayed, allowing you to add up to 50 additional ESOs.

\section{ADDITIONAL ESO ENTRY SCREEN}

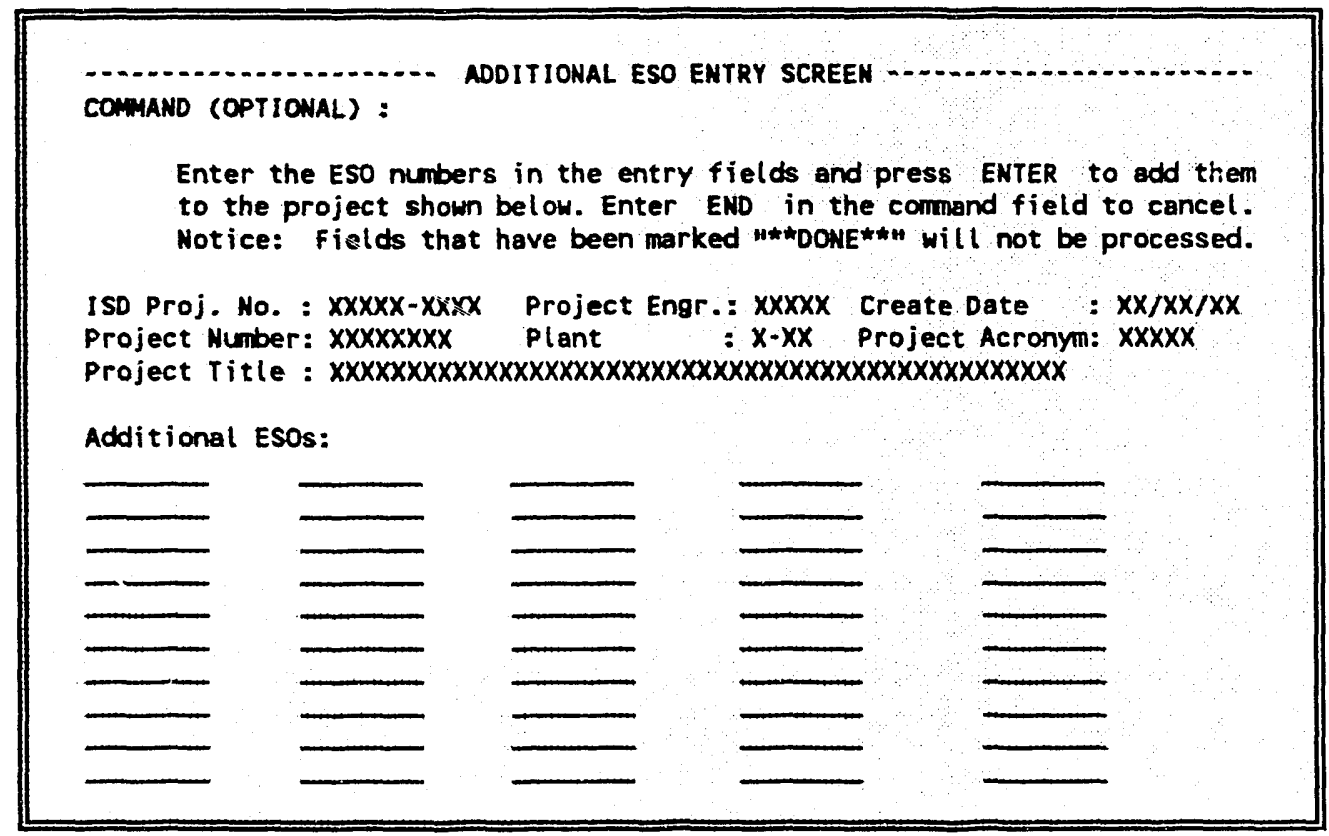

Enter the ESO numbers in the entry fields and press <ENTER> to add them to the project. Enter END in the command field and press <ENTER> to cancel this function.

Sequentially, each ESO entered will be checked only to determine if it is of a valid format (8 digits) and to determine if it is currently associated with other IDS Projects. If any of the ESOs entered fail the verification, the screen will be redisplayed with **DONE*** displayed in the fields for ESOs already checked, an error message displayed indicating invalid format or the existence of other ISD Projects with the same associativity with this ESO, and the cursor placed on the ESO that failed the verification. You must either correct the invalid entry if invalid, press <ENTER > to allow assignment if valid, or use the END command to exit the assignment of additional ESOs.

If you enter an ESO in the last field and press $<$ ENTER $>$, the screen will be redisplayed with empty fields, allowing you to enter additional ESOs. The entry process will continue until you press <ENTER > without making an entry in the last field or until you enter END in the command field. 
When you have completed the entry of ESOs on this screen and pressed <ENTER>, the system will allow you to continue with entry of either transmittal or document information, as appropriate. 


\subsubsection{Input the transmittal}

Once an existing project has been identified or a new project has been defined, if transmittal information has not already been entered on the screen, the system will redisplay the following Project/Transmittal Entry screen to allow you to enter transmittal information on the lower half of the screen:

\section{PROJECT/TRANSMITTAL ENTRY SCREEN}

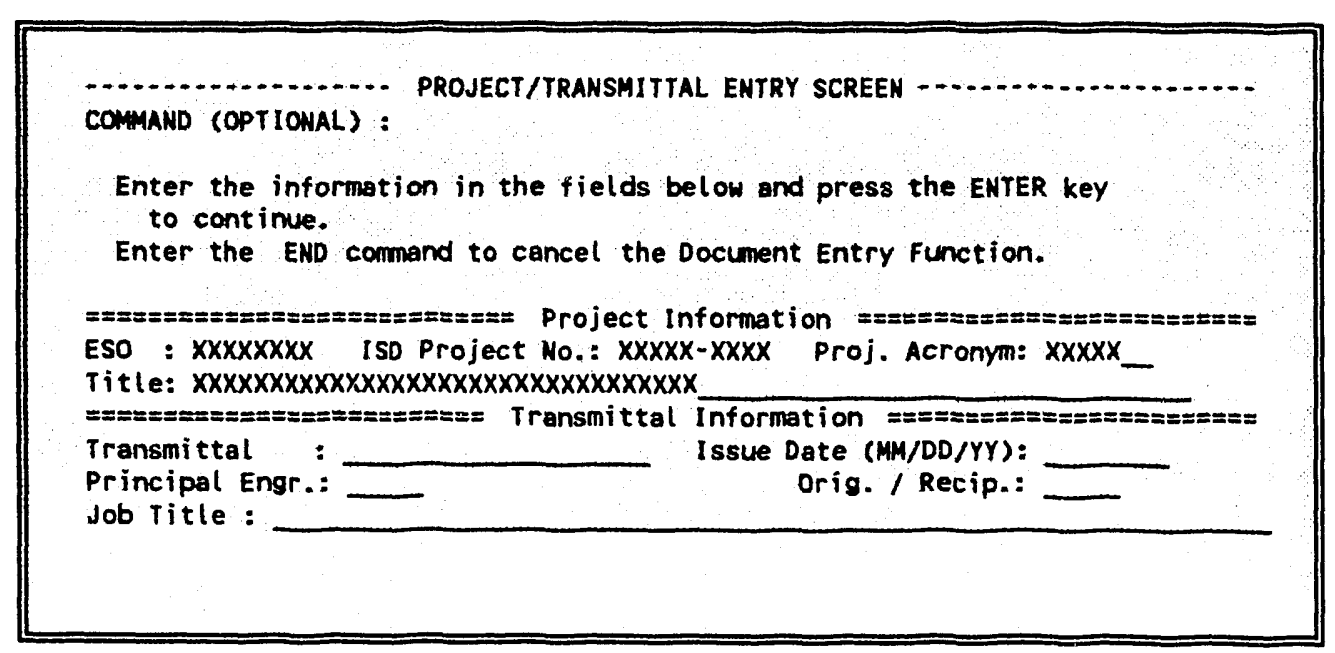

You are required to enter a valid transmittal number and Issue Date. The Principal Engr., Orig./Recip., and Job Title fields are optional. You may obtain help in identifying the correct EMIS ID for the Principal Engineer and the Originator/Recipient by invoking the Engineering Personnel Help Screen as described in Sect. 3.1.3. 


\subsubsection{Input document index information}

When you have completed entering project and transmittal data in the Project/Transmittal Entry screen, the following screen will be displayed, showing the information you previously entered along with the EMIS project number and the transmittal ESO.

\section{DOCUMENT ENTRY SCREEN}

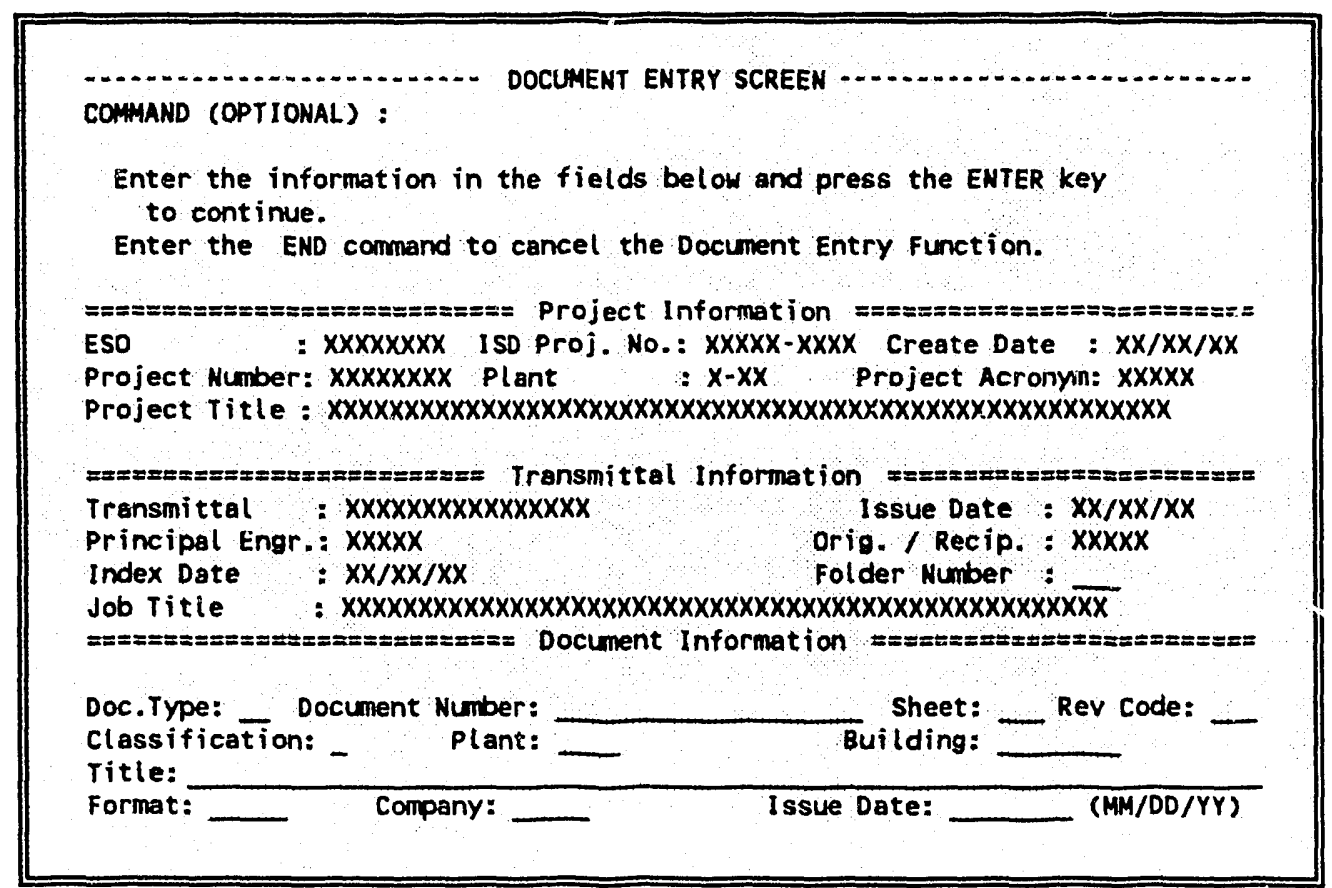

The bottom portion of the screen provides entry fields for indexing the first document associated with the transmittal. Several conventions for entry of this information are listed below:

1. A valid document type must be entered. You may obtain a list of valid document types, classifications, plants, buildings, and company codes by entering "?" in the specific code field and pressing <ENTER>, as described in Sect. 3.1.3 (see also Appendix B).

2. A document number must be entered for documents of type DD, BM, DS, JS, and DC. Document numbers should also be entered for other document types if they are available. If a document number is not known, enter the letters UNKNOWN, and the system will generate a unique number according to the format lyyyy-xxox-zzzz-nnn (where 1 is plant, yyyy is year, $x x x x$ is the ISD Project sequence number to which the document is to be associated, zzzz is the folder number in which the document is to be filed, and $\mathrm{nnn}$ is the next highest four-digit number sequentially generated by the system for the current project and folder).

3. A valid entry in the classification field is required. The field will be initially displayed with a code of $U$. If you enter a classification code other than $U$ and a title, the system will display the following screen, warning you that the title entered must not contain classified information. 
TITLE CLASSIFICATION VERIFICATION SCREEN

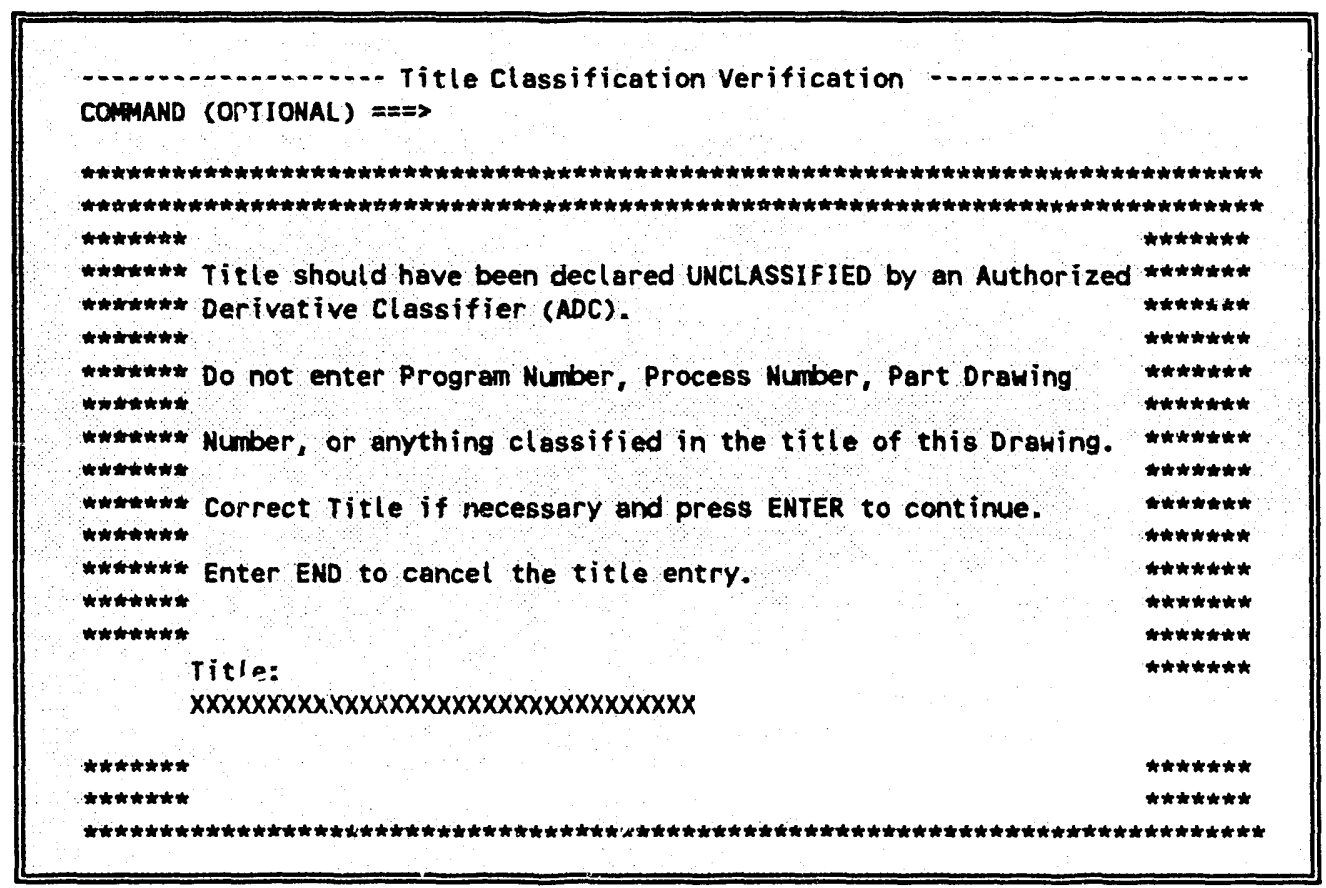

4. A building code is required only for document types other than DD. If the document does not pertain to a specific building, enter KAREA, YAREA, or XAREA as appropriate in the building field, and a listing of the specified "AREA" will be displayed from which you can identify the correct location. For document type DD, the building field should be left blank.

5. The company code will be defaulted to MMES but may be changed.

6. A revision code is required. If the revision is an original issue or does not apply, enter 0 (zero).

When you press <ENTER > upon completion of the document index information, the data will be verified before acceptance into the database. Once accepted, the document will be identified in the system with the transmittal and project indicated on the screen. The folder number will then be calculated by the system. The screen will then be redisplayed with the calculated folder number and with blank document index fields, ready for entry of the next document associated with the current transmittal being entered. This process will be repeated until you enter END in the command line and press <ENTER $>$, at which time the Project/Transmittal Entry Screen will be redisplayed with a message verifying the number of documents that have been added to the indicated project.

At least one document must be accepted and entered for a project and folder before a new folder will be established. If the user enters END or $\mathrm{X}$ in the command line before at least one document has been accepted, the new folder associated with the transmittal being entered will not exist. This implies that emnty folders may not be created using the Input function. 


\subsubsection{Query (Option Q)}

The Query option on the PRIS Primary Menu allows you to find and display index information for documents that exist in the PRIS Index based on data element values you enter into a query screen. Once you locate a document index record(s), you may select to do further query or modification on the document information.

When you select option Q from the PRIS Primary Menu, the following screen will be displayed for you to enter search criteria:

\section{DOCUMENT QUERY SCREEN}

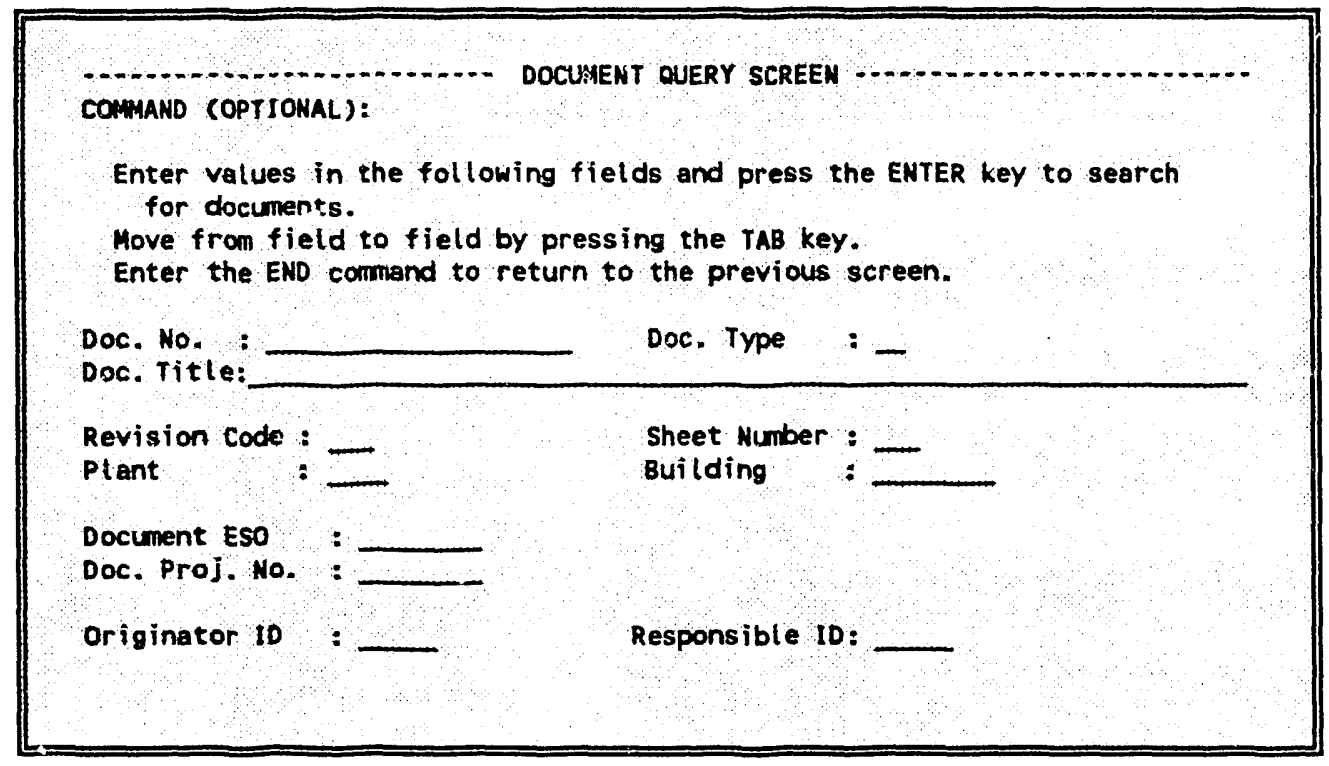

You can $\angle \mathrm{TAB}>$ to any of the blank fields on the screen, enter values into the fields, and press $<$ ENTER >. Five fields on this screen will accept partial entries if the whole value is not known: Doc. No., Doc. Title, Bldg Number, Doc. ESO Number, and Doc. Projert No. A "\%" sign can be used as a wildcard to represent unknown characters located before, after, or in the middle of a known string of characters. The system will search the database for any documents that fulfill the values you enter and either show you the document information (Detail Document Information Screen) or a list of the documents that are found (Abbreviated Document Information Screen). (These screens are described in the following text.)

If no documents are found that match the entered values, the Document Query screen will be redisplayed with a message stating that no documents meet the search criteria. If you press <ENTER> without entering values in any of the input fields, the screen will be redisplayed with a message requesting entry of search fields. Enter END in the command field and press <ENTER > to cancel this function and return to the Primary Option Menu.

When more than one document satisfies the search criteria you enter, the system will display the partial index information for the documents on the following Abbreviated Document Information Screen in order by document number and revision. 


\section{ABBREVIATED DOCUMENT LISTING SCREEN}

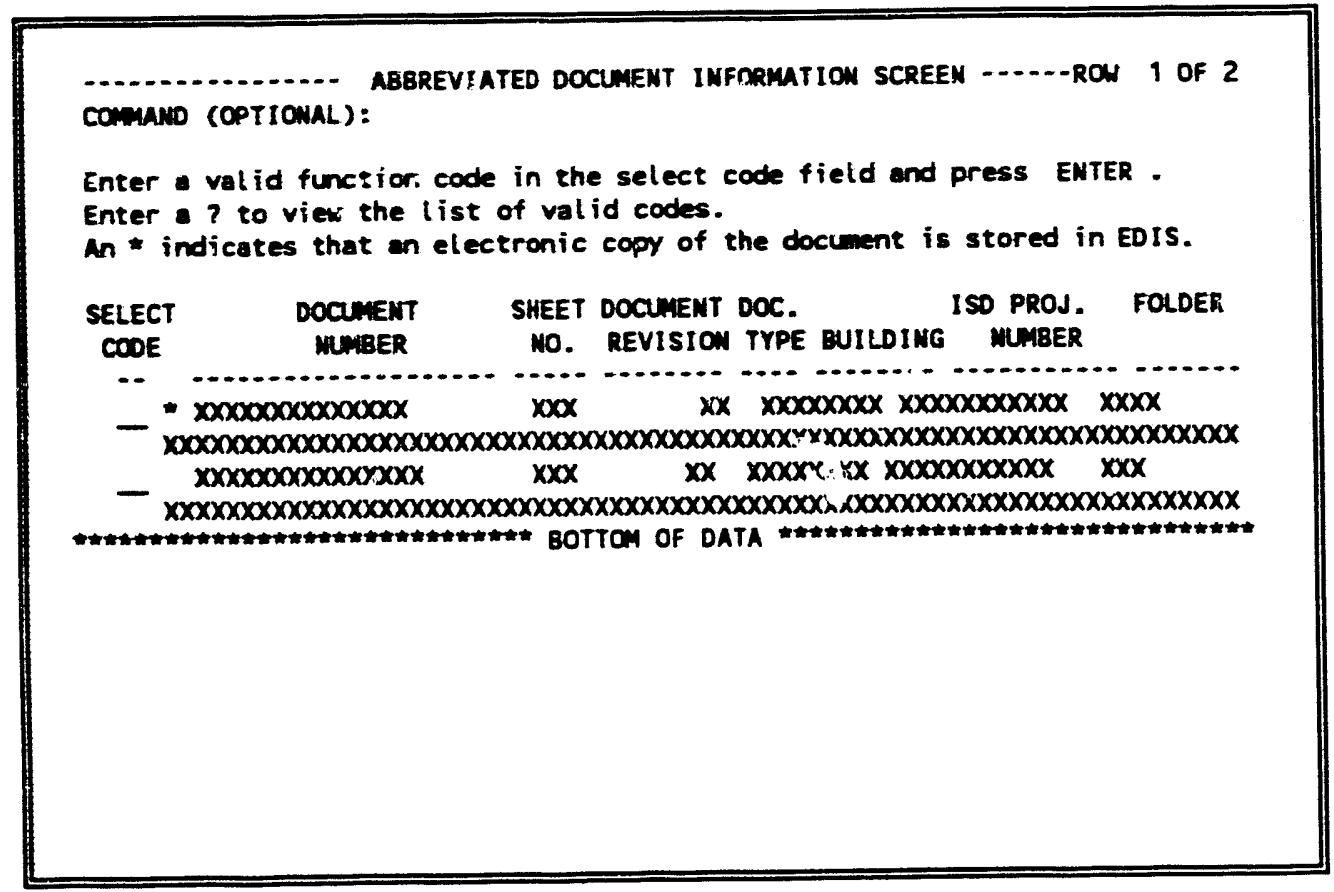

If more documunts are listed than can be viewed on one screen, enter UP or DOWN on the COMMAND line and press <ENTER> to scroll the rest of the list onto the screen. The prompt "ROW _ OF _" in the upper right corner of the screen tells you how many rows are included on the list.

You may select one or more of the listed documents for further query or modification by entering a command in the SELECT CODE field directly beside the document(s) and pressing $<$ ENTER $>$. A help screen of valid PRIS codes will be displayed if you type "?" in the COMMAND line and press <ENTER> (see Appendix B).

The Query (Q) and Modify $(M)$ codes are valid entries in the SELECT CODE field of this screen. The $Q$ option displays a screen of more detailed index information, and the $M$ option displays a screen of the document's index information for which you may change the existing values.

NOTE: You may also select one or more documents from the list using an $X$ instead of a letter in the SELECT CODE field. Then, enter the $Q$ or $M$ command on the COMMAND line and press $<$.... STER $>$.

If multiple documents are selected from this list, the system will process them, one by one, in the order in which they are listed and then return you to the Abbreviated Document Information Screen winen finished.

The Query and Modify functions are presented in Sects. 3.3.2.1 and 3.3.2.2 along with the screens that are displayed for each function. 


\subsubsection{Query (Q)}

When a search from the Document Query Screen finds only one document or when you enter the $Q$ command for a specific document on the Abbreviated Document Information Screen, the following screen is displayed containing detailed index information for the selected document:

\section{DETAII DOCUMENT INFORMATION SCREEN}

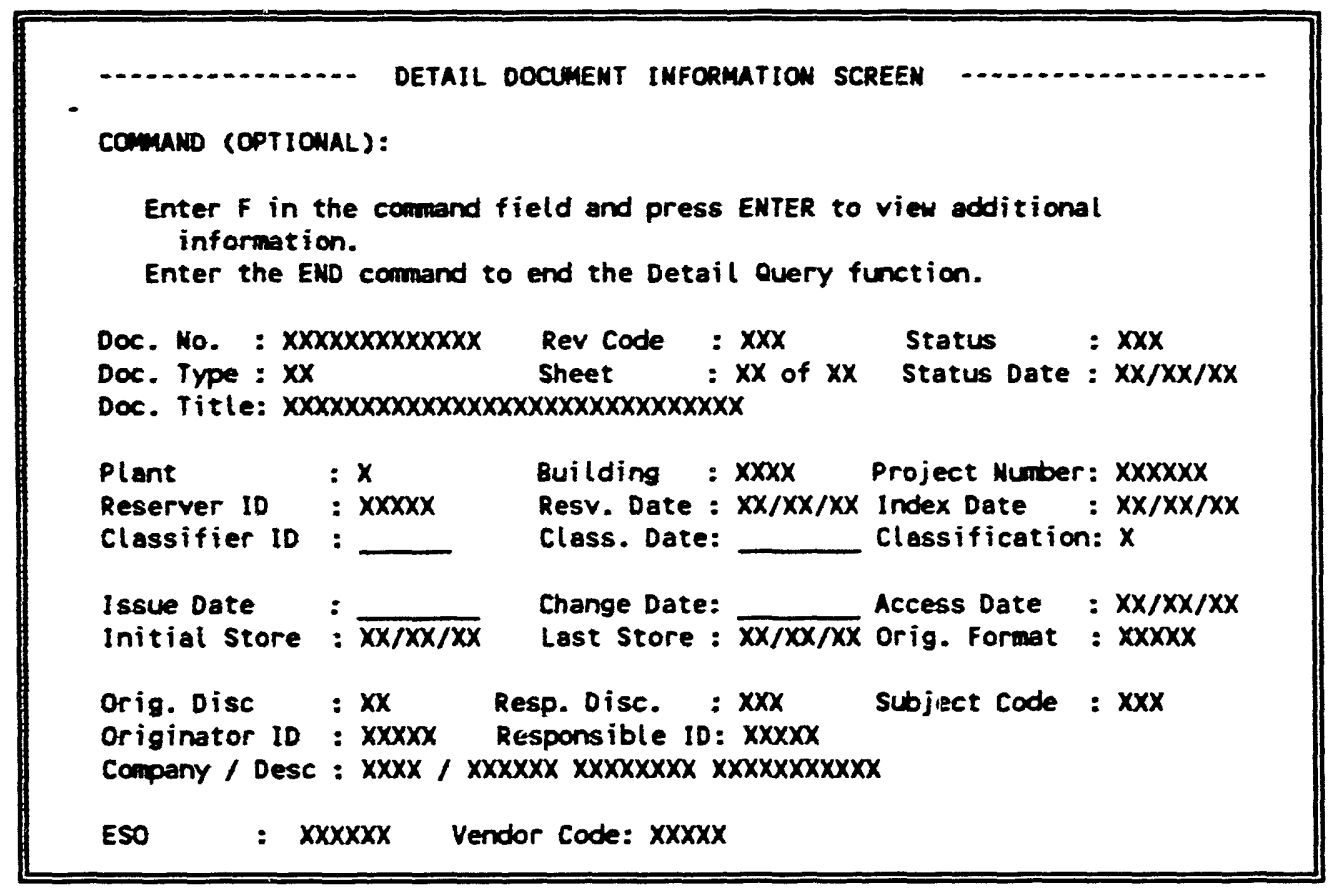

The information supplied on this screen is standard for all document types in the PRIS Index. If you wish to exit the Detail Query function, enter END on the COMMAND line to return to the previous screen (Abbreviated Document Information Screen or the Document Query Screen).

Two commands can be entered on this screen to further query this document:

$$
\begin{aligned}
& \text { M - To modify selected information. } \\
& \text { F - To display more index information. }
\end{aligned}
$$

Selected information for this document may be modified by entering $M$ in the COMMAND line of this screen and pressing <ENTER>. (This function is described in Sect. 3.3.2.2. below.) If the selected document was initially entered by some other system or information about the document was added by some other system, you will receive a message stating that you are not allowed to modify this information.

More information can be displayed for this document by entering an $F$ in the COMMAND line and pressing <ENTER>. Additional screens of information are displayed containing (1) drawing information for design documents (type DD), (2) a list of formats associated with the document, and (3) a list of folders in which the document is filed. (These three screens are described in the following text as numbered.) 
1. If you request additional information and the document is a design drawing (document type DD), the system will display the additional index information for this document on the Detail Document Information Screen 2.

\section{DETAIL DOCUMENT INFORMATION SCREEN 2}

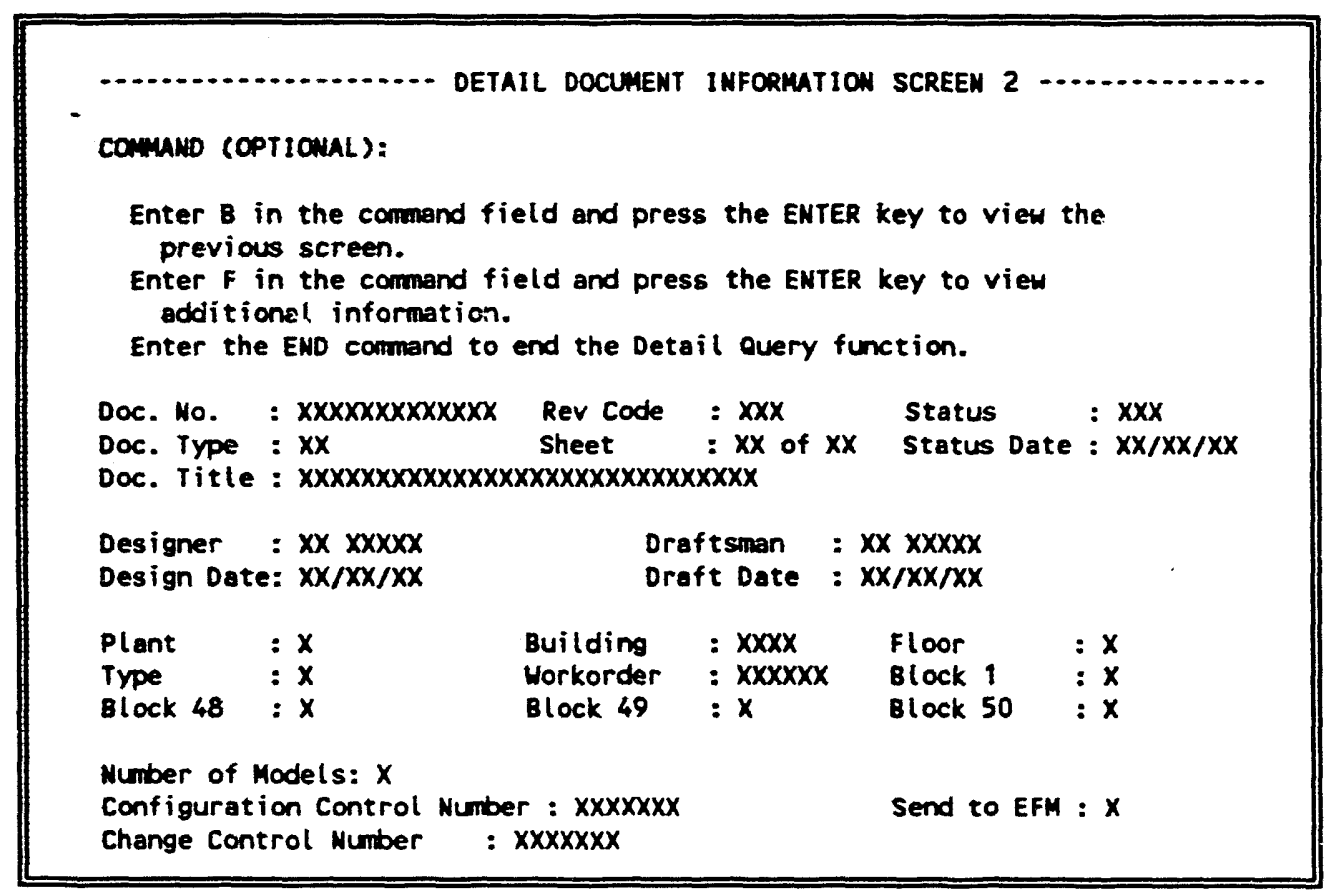

The END command will end the Detail Query function and return you to either the Abbreviated Document Information Screen or the Document Query Screen.

Three commands can be entered on this screen to further query this document:

B - To return to the prior screen of information

M - To modify selected information.

F - To display more index information.

The prior screen of information for this document can be redisplayed by entering $B$ and $<$ ENTER $>$ in the COMMAND line of the screen.

Selected information for this document may be modified by entering $M$ in the COMMAND line of this screen and pressing <ENTER >. (This function is described in Sect. 3.3.2.2. below.) If the selected document was initially entered by some other system or information about the document was added by some other system, you will receive a message stating that you are not allowed to modify this information.

If you enter an $F$ in the COMMAND line and pressing <ENTER $>$, the system will display the Query Function - Document Format Listing Screen described below. 
2. The Query Function - Doc -ment Format Listing Screen displays a listing of all the formats in which this document is stored and their associated storage locations. It is displayed when you enter an F on either of the two previous Detail Document Information screens.

QUERY FUNCTION - DOCUMENT FORMAT LISTING SCREEN

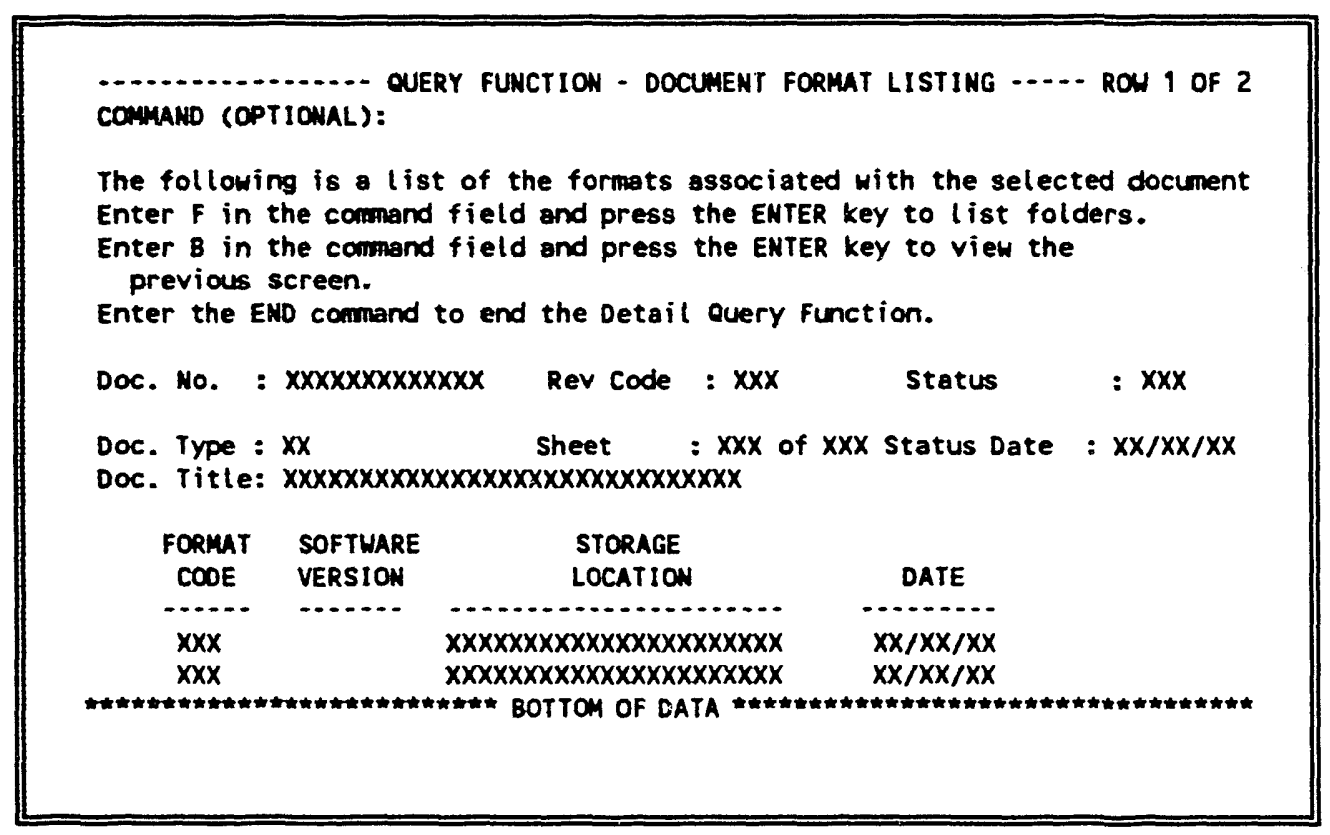

If more formats are listed than can be viewed on one screen, enter UP or DOWN on the COMMAND line and press <ENTER> to scroll the rest of the list onto the screen. The prompt "ROW _ OF _" in the upper right corner of the screen tells you how many rows are included on the list.

The END command will end the Detail Query function and return you to the Abbreviated Document Information Screen.

Two commands can be entered on this screen to further query this document:

B - To return to the prior screen of information

F - To display more index information.

The prior screen of information for this document can be redisplayed by entering $B$ and $<$ ENTER > in the COMMAND line of the screen.

If you enter an $F$ in the COMMAND line and press <ENTER>, the system will display the Query Function - Document Folder Listing Screen described below. 
3. If you request additional information on the Document Format Listing Screen, the Document Folder Listing Screen is displayed with a list of the folders in which the selected document has been filed.

\section{DOCUMENT FOLDER LISTING SCREEN}

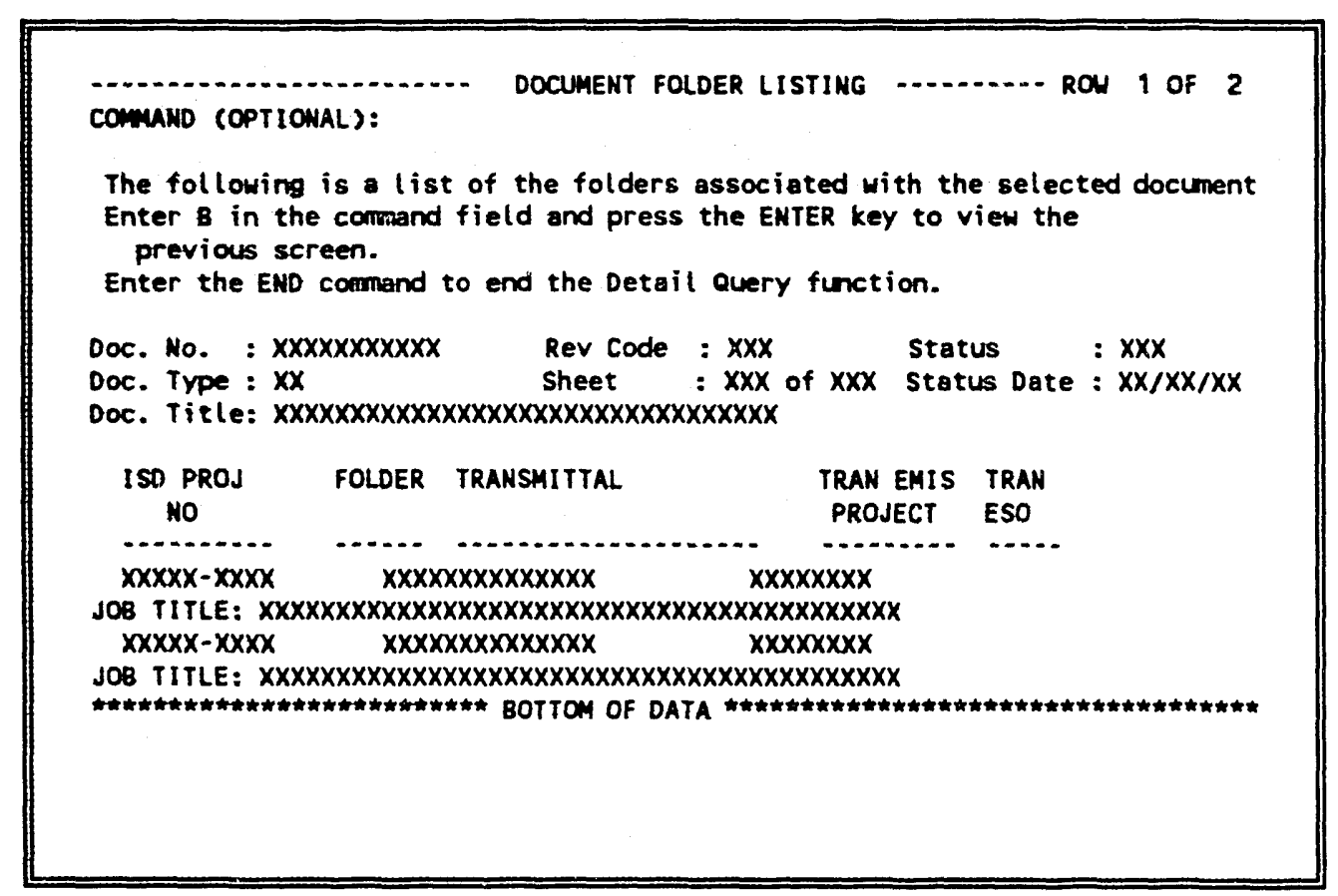

If more folders are listed than can be viewed on one screen, enter UP or DOWN on the COMMAND line and press <ENTER> to scroll the rest of the list onto the screen. The prompt "ROW _ OF _" in the upper right corner of the screen tells you how many rows are included on the list.

The END command will end the Detail Query function and return you to the Abbreviated Document Information Screen. No further document information is available beyond this screen. You may enter a $B$ in the COMMAND line and press $<E N T E R>$ to return to the previous screen. 


\subsubsection{Modify (M)}

The Modify function is available from the abbreviated document listing or detail information screens described in the previous sections. It is requested by entering a $M$ in the COMMAND line of an information screen or in the SELECT CODE field beside the desired document on the Abbreviated Document Information Screen. In either case, the system will respond by displaying the Modify Document Index Screen shown below.

\section{MODIFY DOCUMENT INDEX SCREEN}

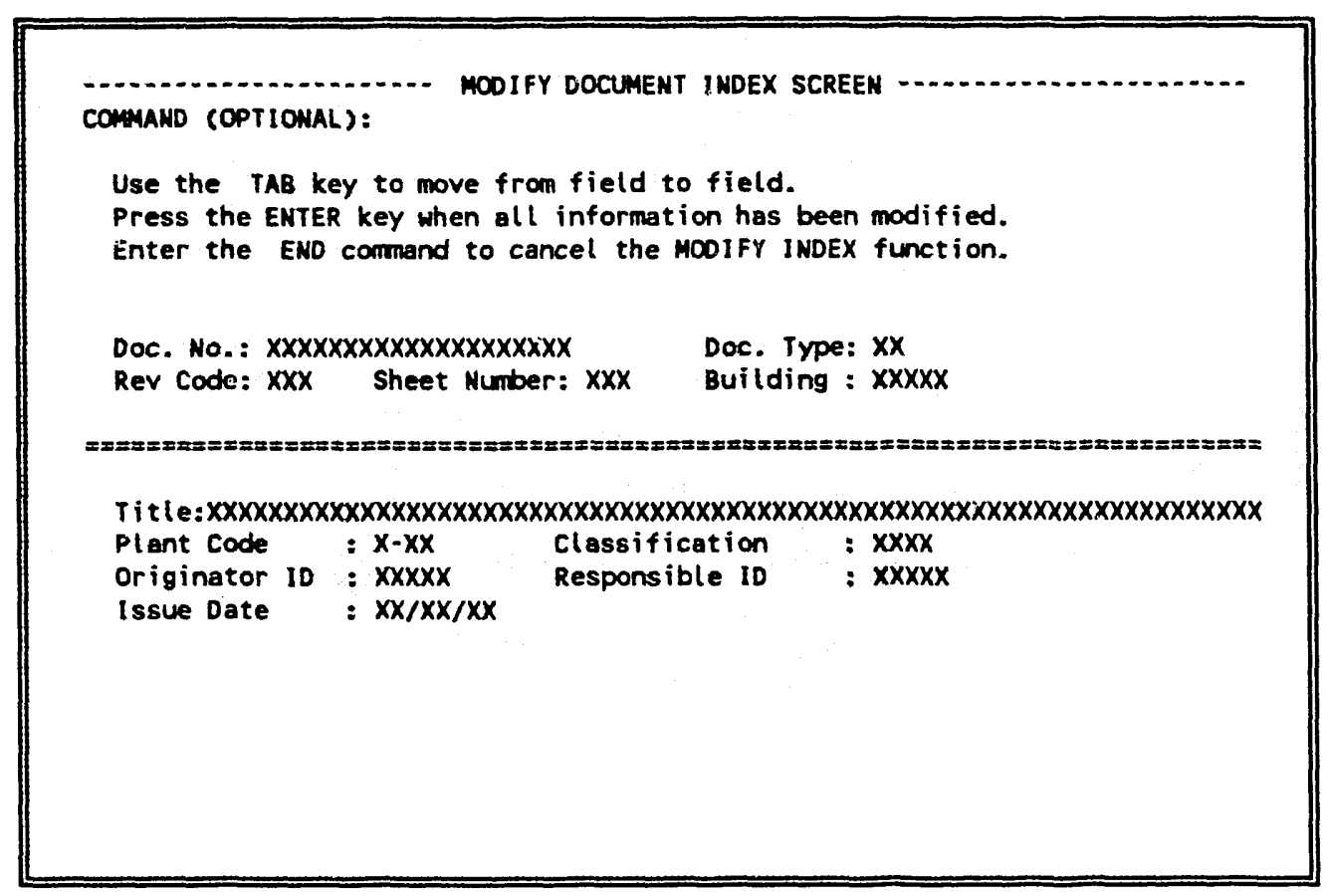

The lower part of the screen contains data fields with existing document information. You may $<\mathrm{TAB}>$ to the input fields, modify any of the indicated values, and press $<$ ENTER $>$. The fields on the top part of the screen are for display only and cannot be modified.

If you enter END in the COMMAND line of this screen, the system will redisplay the previous screen without making any modifications. 


\subsubsection{Project Query (Option PO)}

The Project Query option on the PRIS Primary Menu allows you to find and display project information that exists in the PRIS Index based on data element values you enter into a query screen. Once you locate a project index record(s), you may select to do further query, addition, or modification on the project information.

When you select option PQ from the PRIS Primary Menu, the following screen will be displayed for you to enter search criteria:

\section{PROJECT QUERY SCREEN}

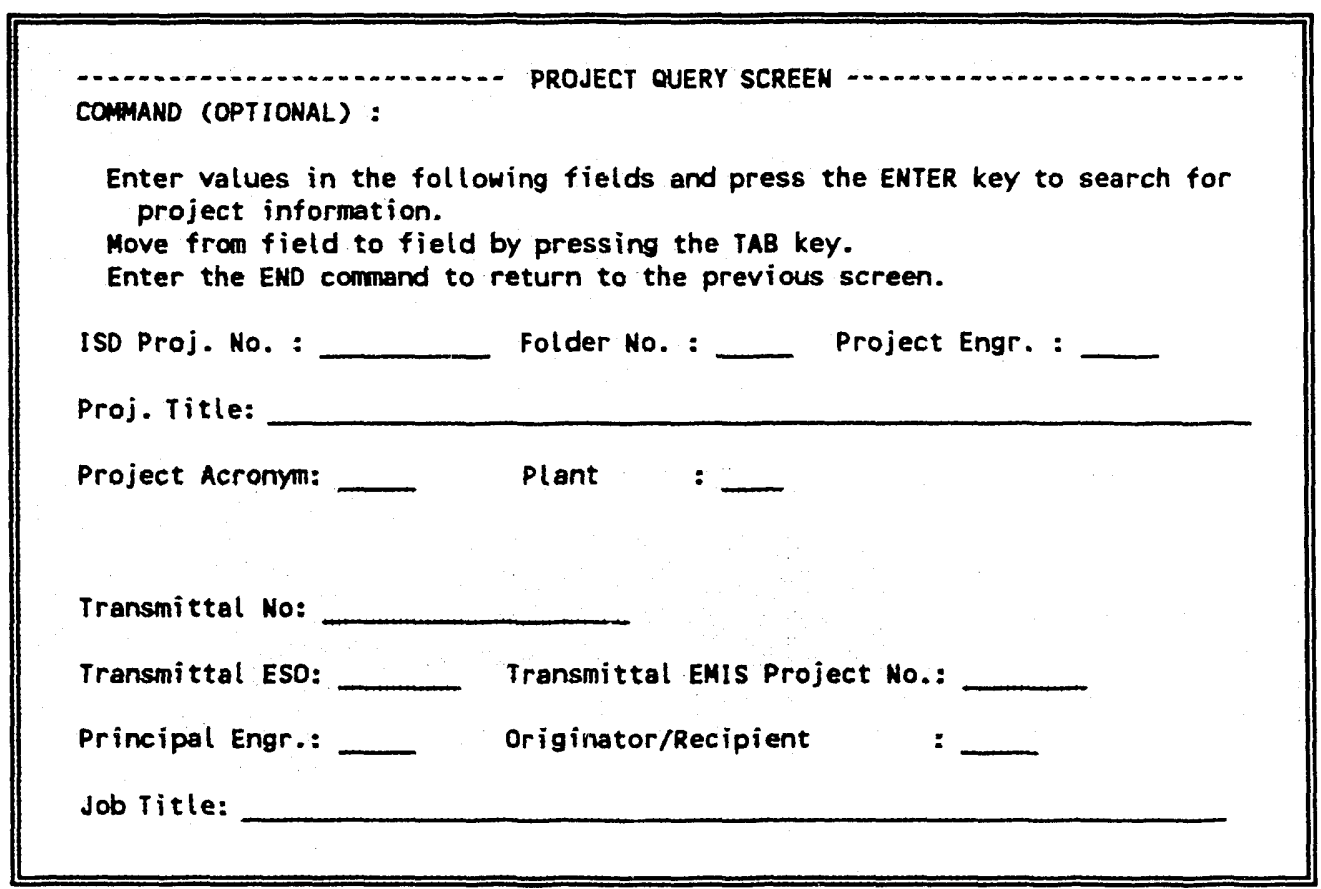

You can $\angle \mathrm{TAB}>$ to any of the blank fields on the screen, enter values into the fields, and press $<$ ENTER>. Six fields on this screen will accept partial entries if the whole value is not known: ISD Project No, Proj. Title, Project Acronym, Transmittal ESO, Transmittal EMIS Project No., and Job Title. A "\%" sign can be used as a wild-card to represent unknown characters located before, after, or in the middle of a known string of characters. The system will search the database for any projects that fulfill the values you enter and display them on the Project Information Listing screen shown on the next page.

If no projects are found that match the entered values, the Project Query screen will be redisplayed with a message stating that no projects meet the search criteria. If you press <ENTER $>$ without entering values in any of the input fields, the screen will be redisplayed with a message requesting entry of search fields. Enter END in the command field and press <ENTER > to cancel this function and return to the Primary Option Menu.

The Project Information Listing Screen shown below lists all the projects found in the database that match the query values entered on the Project Query Screen. 
PROJECT INFORMATION LISTING SCREEN

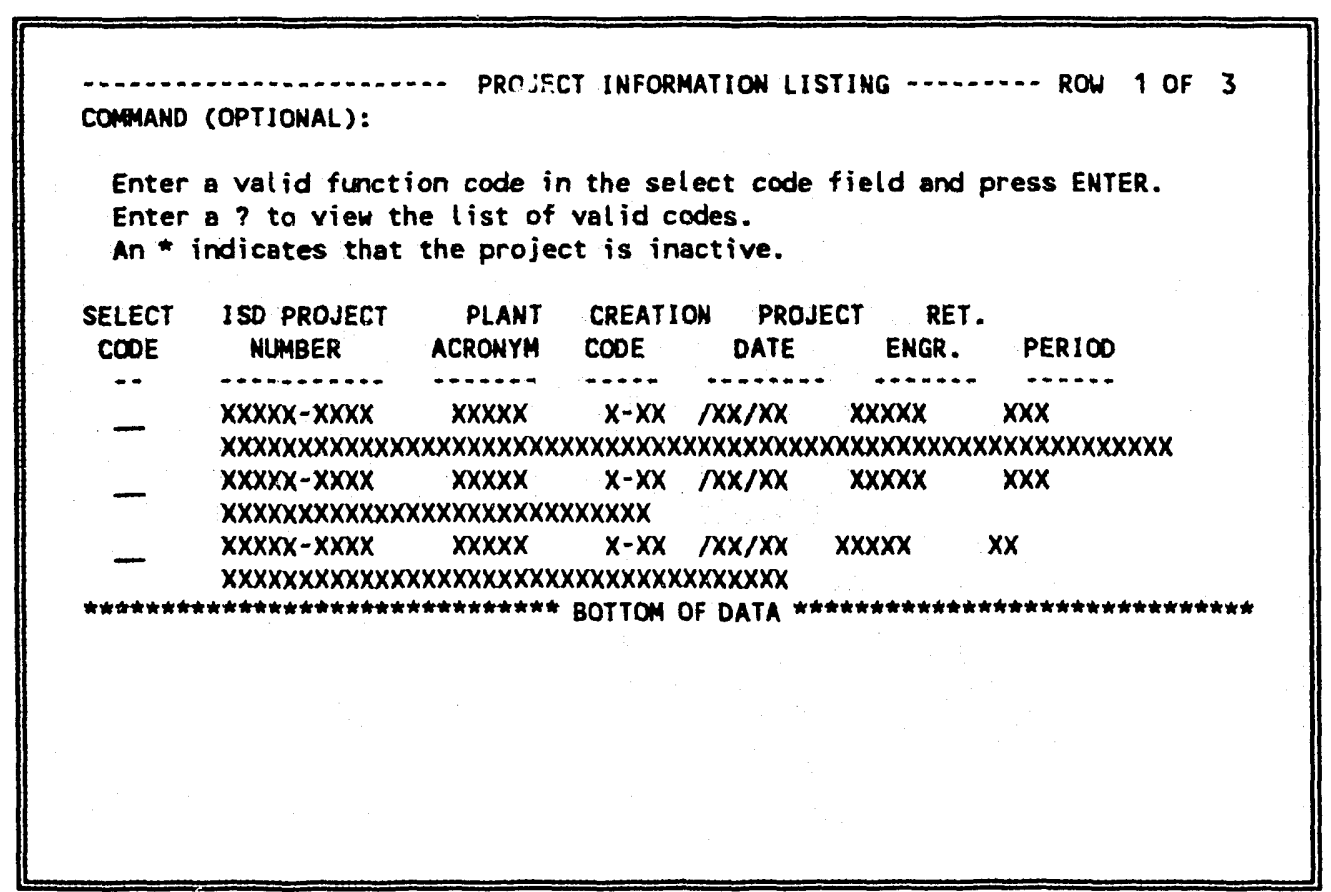

If more projects are listed than can be viewed on one screen, enter UP or DOWN on the COMMAND line and press <ENTER> to scroll the rest of the list onto the screen. The prompt "ROW _ OF _ " in the upper right corner of the screen tells you how many rows are included on the list.

You may select one or more of the listed projects for further query, modification, or addition of documents by entering a function code in the SELECT CODE field directly beside the document(s) and pressing <ENTER>. A help screen of valid PRIS codes will be displayed if you type "?" in the COMMAND line and press <ENTER> (see Appendix B).

The Query (Q), Modify (M), and Add (A) codes are valid entries in the SELECT CODE field of this screen. These three codes and their functions are summarized below. The operation of these three functions is described in the indicated section.

Code

Q

M

A

\section{Function}

Displays the Abbreviated Document Information Screen, which lists all of the documents in the database for the selected project (see Sect. 3.3.3.1).

Displays the Modify Project Information Screen, which displays information about the selected project that may be modified (see Sect. 3.3.3.2).

Displays the Project Folder Selection Screen, which lists all of the folders for the selected project so you may select the folder to which you wish to add a document (see Sect. 3.3.3.3).

NOTE: You may also select one or more projects from the list using an $\mathrm{X}$ instead of a letter 
in the SELECT CODE field. Then, enter the function code on the COMMAND line and press <ENTER>.

If multiple documents are selected from this list, the system will process them, one by one, in the order in which they are listed and then return you to the Project Information Listing Screen when finished.

\subsubsection{Query (Q)}

If you wish more information about one or more of the projects listed on the Project Information Listing Screen, enter a $Q$ in the SELECT CODE field beside each of the projects for which the information is desired. For each project selected, the system will display the Abbreviated Document Information Screen, listing all the documents that exist for the selected project. Additional query and modification of information can be performed for the documents listed on the Abbreviated Document Information Screen using the same functions described in Sect. 3.3.2 for the Query function.

\subsubsection{Modify (M)}

If you wish to modify the project information associated with one or more of the projects listed on the Project Information Listing Screen, place an M in the SELECT CODE field beside the projects you wish to select for modification. For each project marked, the system will display the Modify Project Information Screen shown below, which will list the project data element values that may be modified.

\section{MODIFY PROJECT INFORMAT:ON SCREEN}

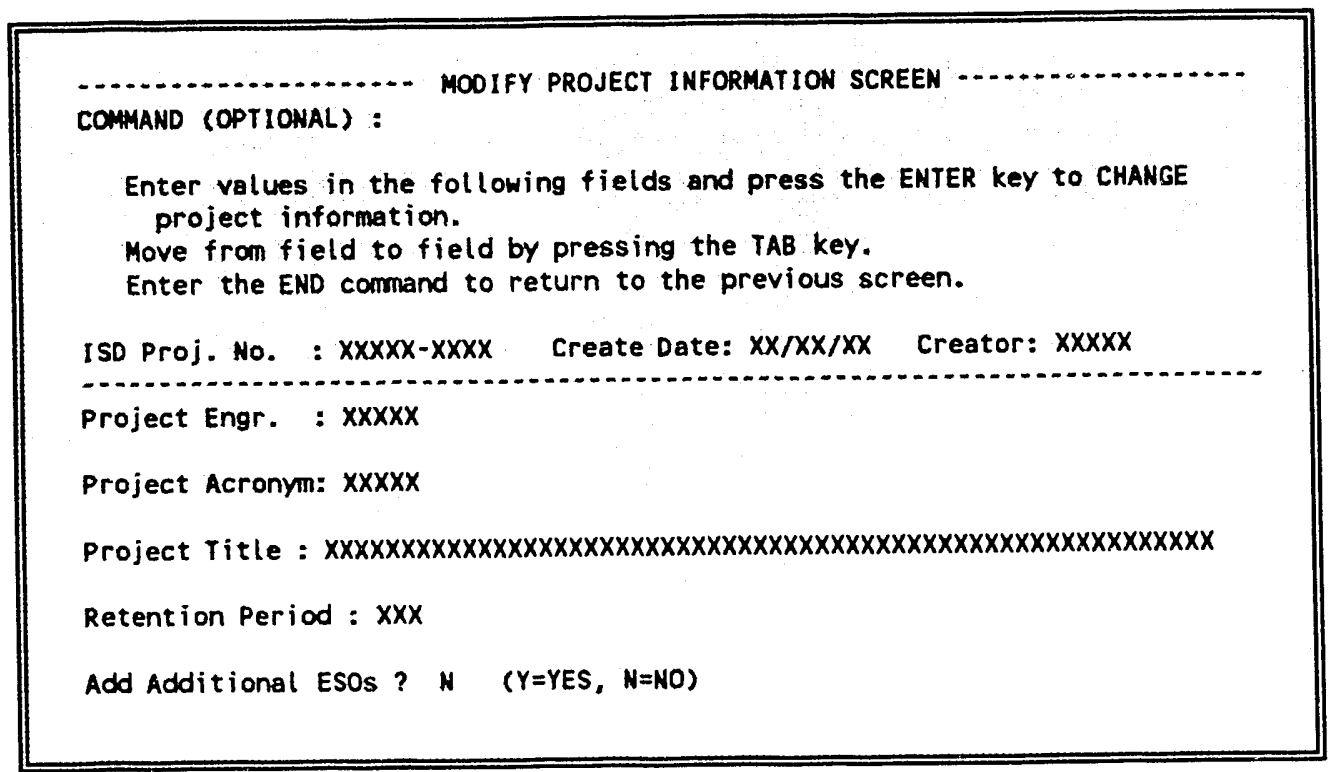

The lower part of the screen contains data fields with existing project information. You may $<\mathrm{TAB}>$ to the data fields, modify any of the indicated values, and press $<$ ENTER $>$. The fields on the top part of the screen are for display only and cannot be medified.

The END command will feturn you to the Project Information Listing Screen without saving any of the changes entered on the screen. 
If you requested the assignment of additional ESOs to the project by entering $\mathrm{Y}$ in the field prompt "Add additional ESO Numbers?" the following screen will be displayed, allowing you to add up to 50 additional ESOs. If you did not enter a $\mathrm{Y}$ before pressing <ENTER>, the system will return you to the Project Information Listing Screen after making the desired changes to all of the projects you selected.

\section{ADDITIONAL ESO ENTRY SCREEN}

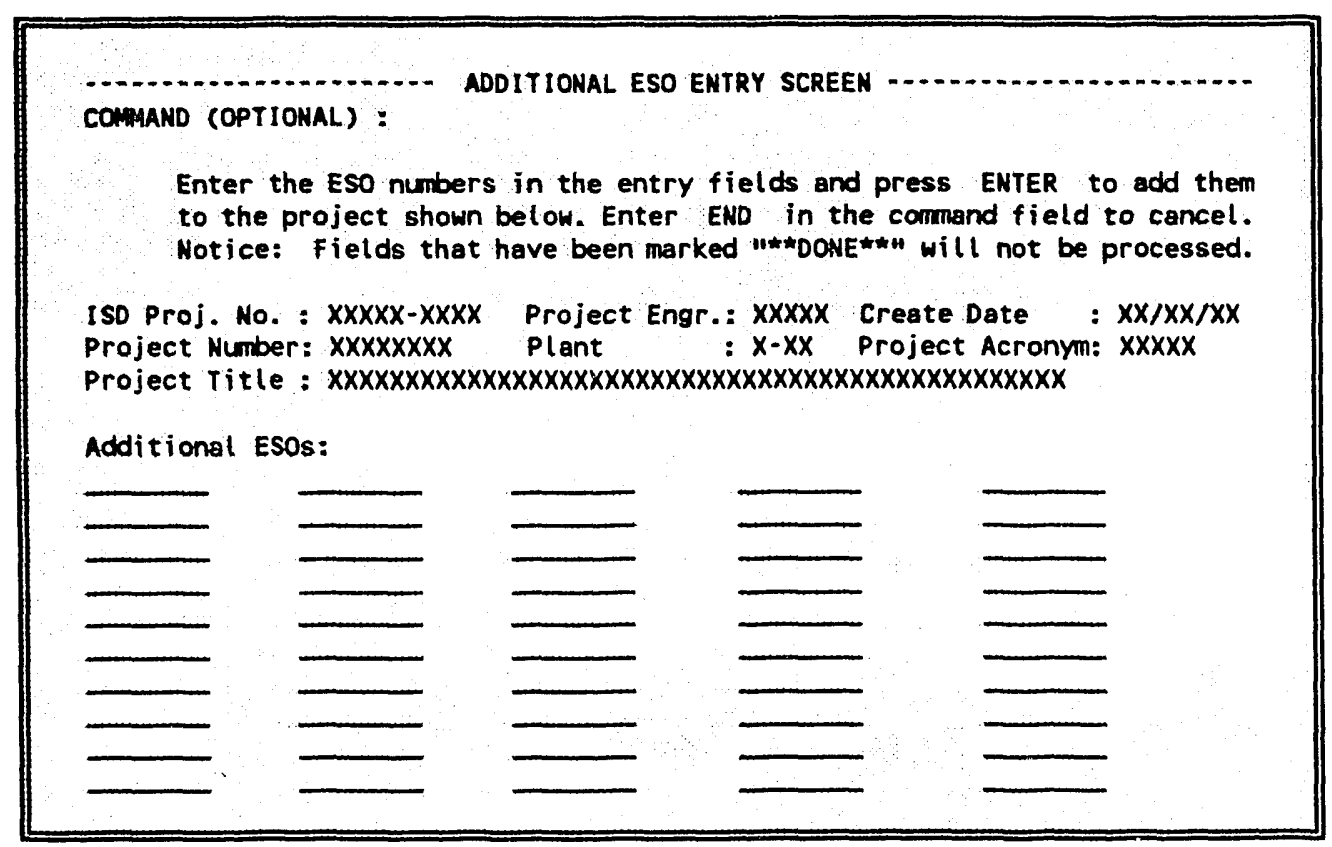

Enter the ESO numbers in the entry fields and press <ENTER $>$ to add them to the project. Enter END in the command field and press <ENTER> to cancel this function.

Sequentially, each ESO entered will be checked only to determine if it is of a valid format (8 digits) and to determine if it is currently associated with other ISD Projects. If any of the ESOs entered fail the verification, the screen will be redisplayed with **DONE*** displayed in the fields for ESOs already checked, an error message displayed indicating invalid format or the existence of other ISD Projects with the same associativity with this ESO, and the cursor placed on the ESO that failed the verification. You must either correct the invalid entry if invalid, press <ENTER> to allow assignment if valid, or use the END command to exit the assignment of additional ESOs.

If you enter an ESO in the last field and press <ENTER >, the screen will be redisplayed with empty fields, allowing you to enter additional ESOs. The entry process will continue until you press <ENTER> without making an entry in the last field or until you enter END in the command field. 


\subsubsection{Add (A)}

If you wish to add additional documents to an existing folder contained in one of the listed projects, you may enter an $A$ in the SELECT CODE field of the Project Information Listing Screen beside the project for which the addition is to apply. The Project Folder Selection Screen wil! be displayed, listing all of the available folders currently contained in the selected project.

\section{PROJECT FOLDER SELECTION SCREEN}

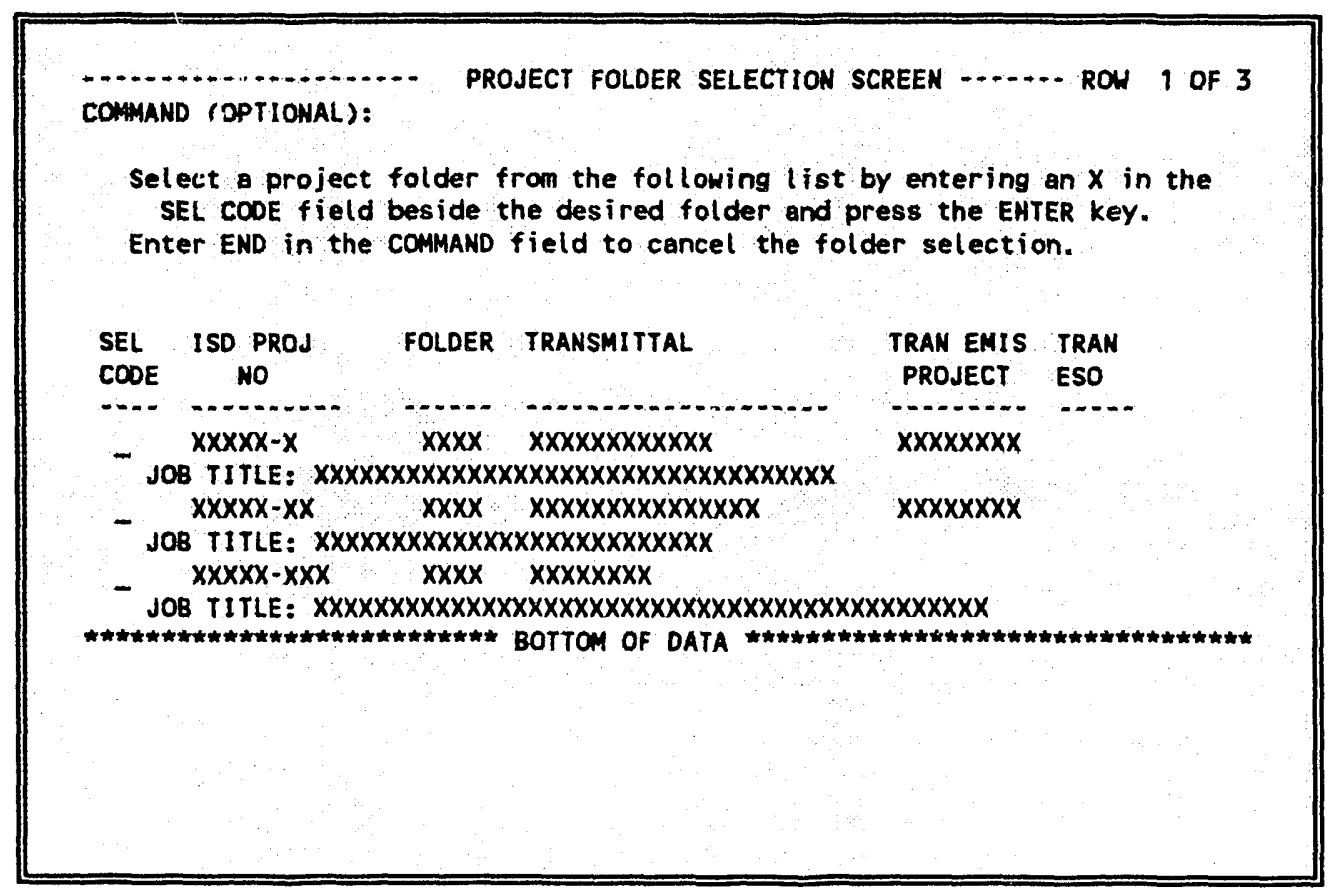

If more folders are listed than can be viewed on one screen, enter UP or DOWN on the COMMAND line and press <ENTER> to scroll the rest of the list onto the screen. The prompt "ROW _ OF _ in the upper right corner of the screen tells you how many rows are included on the list.

Select a folder for which the addition of documents will apply by entering an $\mathrm{X}$ in the SEL CODE field beside the desired folder and pressing <ENTER >. Only one folder selection is allowed. If you enter END in the COMMAND line, the system will return to the Project Information Listing Screen.

If a folder has been moved to another project using the Move Folder utility (see Sect. 3.3.4.2), the message "MOVED TO PROJECT _ FOLDER _ " will be displayed in the Job Title field of the folder. This folder cannot be selected from this list; if selected, the system will redisplay this screen with an error message.

When you mark a desired folder with an X, the system will display the Document Entry Screen with the project and transmittal information defaulted to that associated with the selected folder. 


\section{DOCUMENT ENTRY SCREEN}

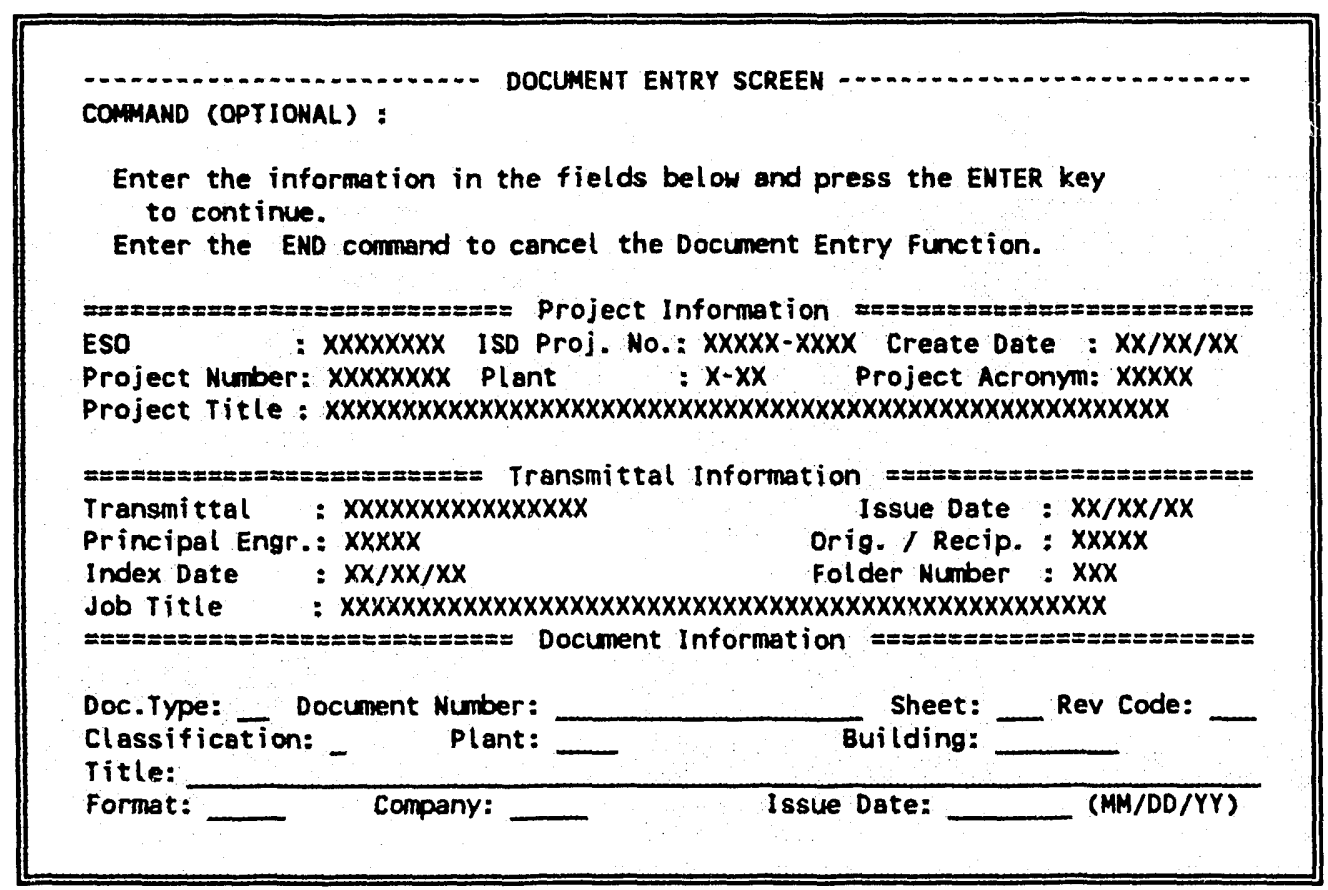

The bottom portion of the screen provides entry fields for adding index information for a new document associated with the selected project and folder. Several conventions for entry of this information are listed below:

1. A valid document type must be entered. You may obtain a list of valid document types, classifications, plants, buildings, and company codes by entering "?" in the specific code field and pressing <ENTER>, as described in Sect. 3.1.3 (see also Appendix B).

2. A document number must be entered for documents of type DD, BM, DS, JS, and DC. Document numbers should also be entered for other document types if they are available. If a document number is not known, enter the letters UNKNOWN, and the system will generate a unique number according to the format lyyyy-xxxx-zzzz-nnn (where 1 is plant, yyyy is year, $x x x$ is the ISD Project sequence number to which the document is to be associated, zzzz is the folder number in which the document is to be filed, and nnn is the next highest four-digit number sequentially generated by the system for the current project and folder).

3. A valid entry in the classification field is required. The field will be initially displayed with a code of $U$. If you enter a classification code other than $U$ and a title, the system will display the following screen, warning you that the title entered must not contain classified information. 


\section{TITLE CLASSIFICATION VERIFICATION SCREEN}

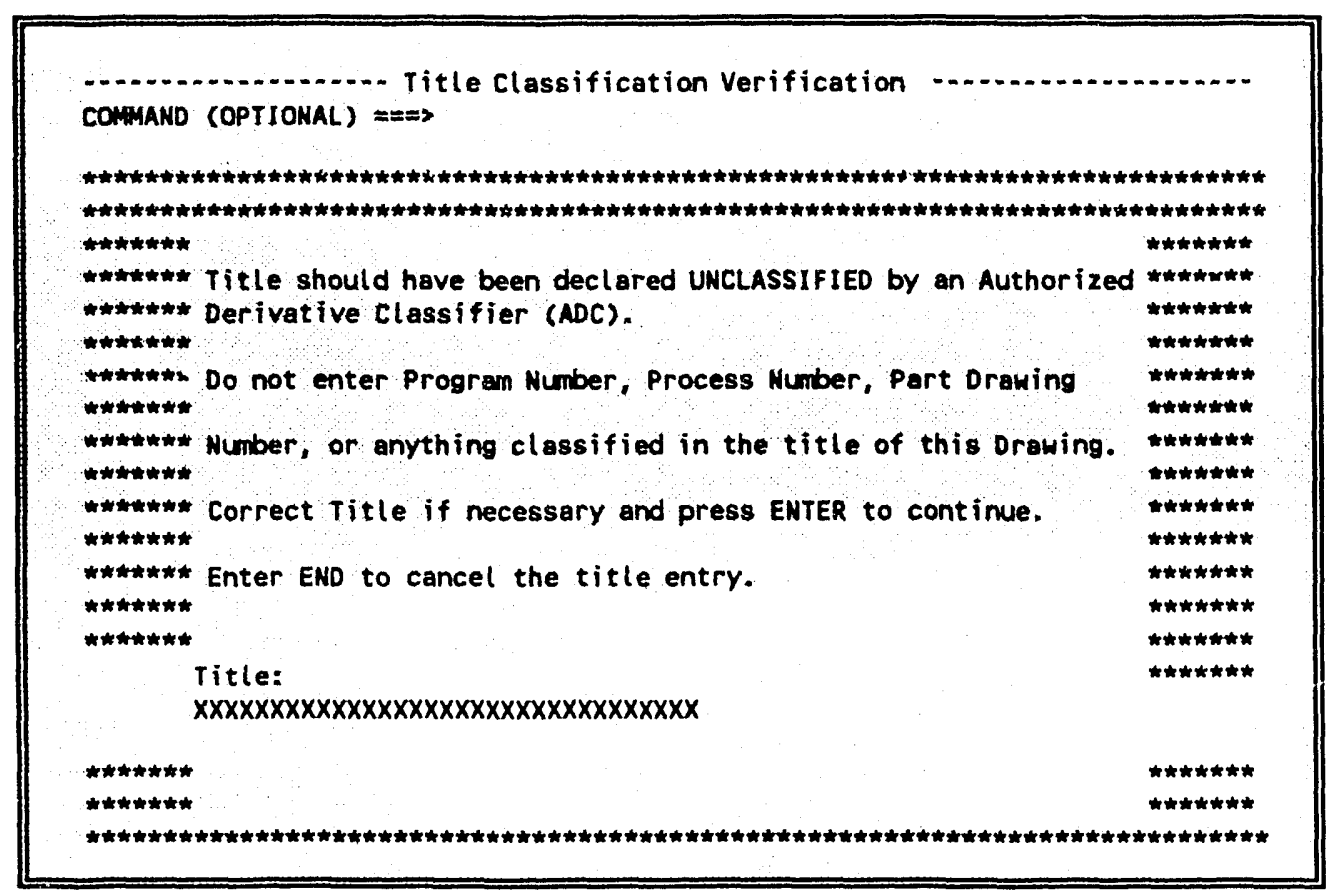

4. A building code is required only for document types other than DD. If the document does not pertain to a specific building, enter KAREA, YAREA, or XAREA as appropriate in the building field, and a listing of the specified "AREA" will be displayed from which you can identify the correct location. For document type DD, the building code should be left blank.

5. The company code will be defaulted to MMES but may be changed.

6. A revision code is required. If the revision is an original issue or does not apply, enter 0 (zero). If UNKNOWN is entered in the document number field, only revision 0 will be accepted.

When you press <ENTER> upon completion of the document index information, the data will be verified before acceptance into the database. Once accepted, the document will be identified in the system with the transmittal, project, and folder numbers indicated on the screen. The screen will then be redisplayed with blank document index fields, ready for entry of another document. This process will be repeated until you enter END in the command line and press <ENTER>, at which time the Project Information Listing Screen will be redisplayed. 


\subsubsection{Utilities (Option U)}

This option provides you with the capability (1) to select from a list of hard-copy reports, (2) to move documents from one project folder to another or move a folder from one project to another, and (3) to archive, deactivate, and change the storage location of an active project (this function is not available for PRIS but will be incorporated into EDIS).

When you select Option U from the Primary Option Menu, the following PRIS Utilities Menu will be displayed:

\section{PROJECT RECORDS UTILITIES MENU SCREEN}

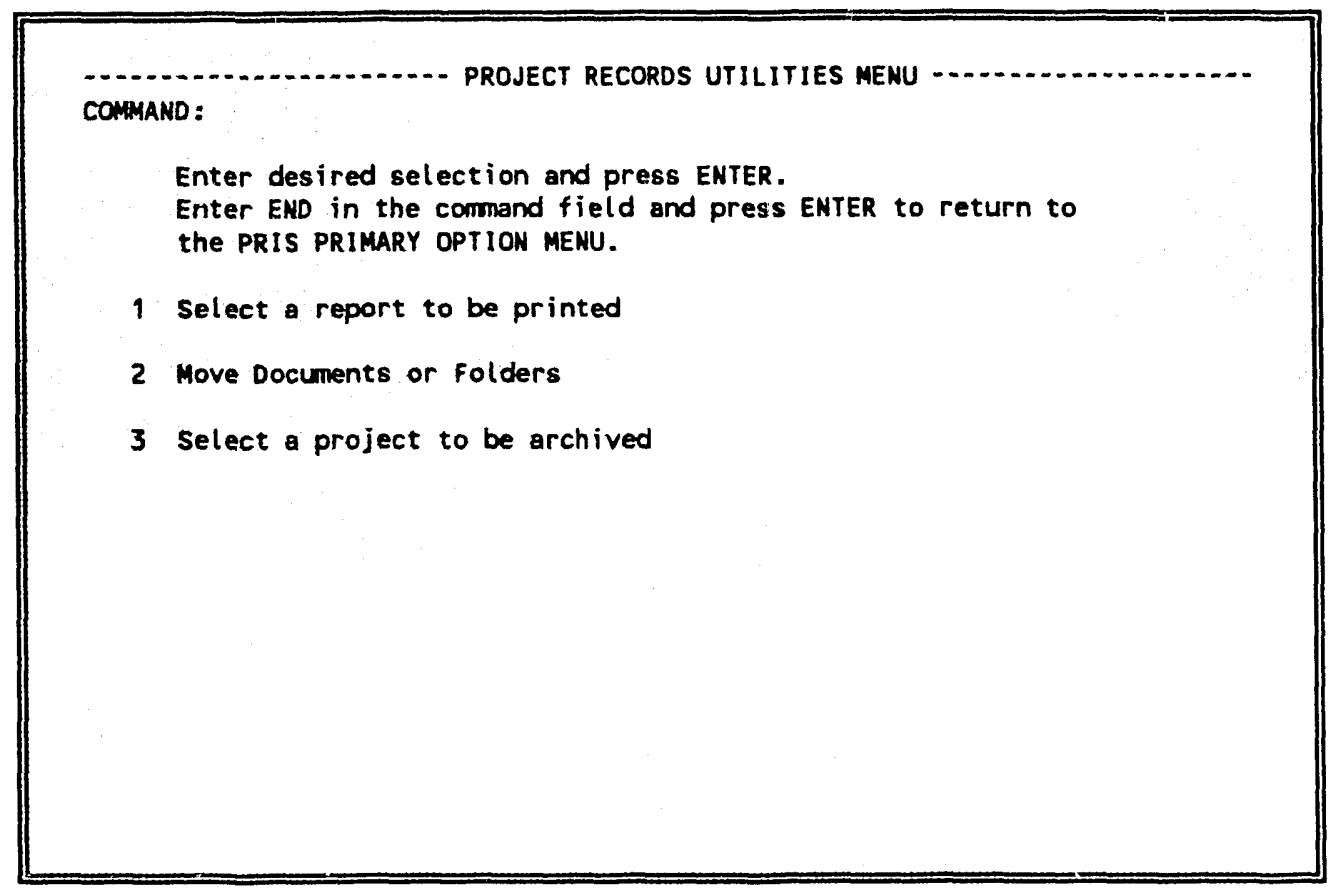

To sclect a utility you wish to perform, enter the option number on the COMMAND line and press $<$ ENTER>. If you enter END and <ENTER > in the COMMAND line, the Utilities function will be cancelled and you will be returned to the Primary Option Menu.

Instructions for performing these utility functions are given in the next three sections of this manual. 


\subsubsection{Select a report to be printed}

If you select option 1 from the Project Records Utilities Menu, the following screen will be displayed:

PROJECT RECORDS P.EPORTS MENU SCREEN

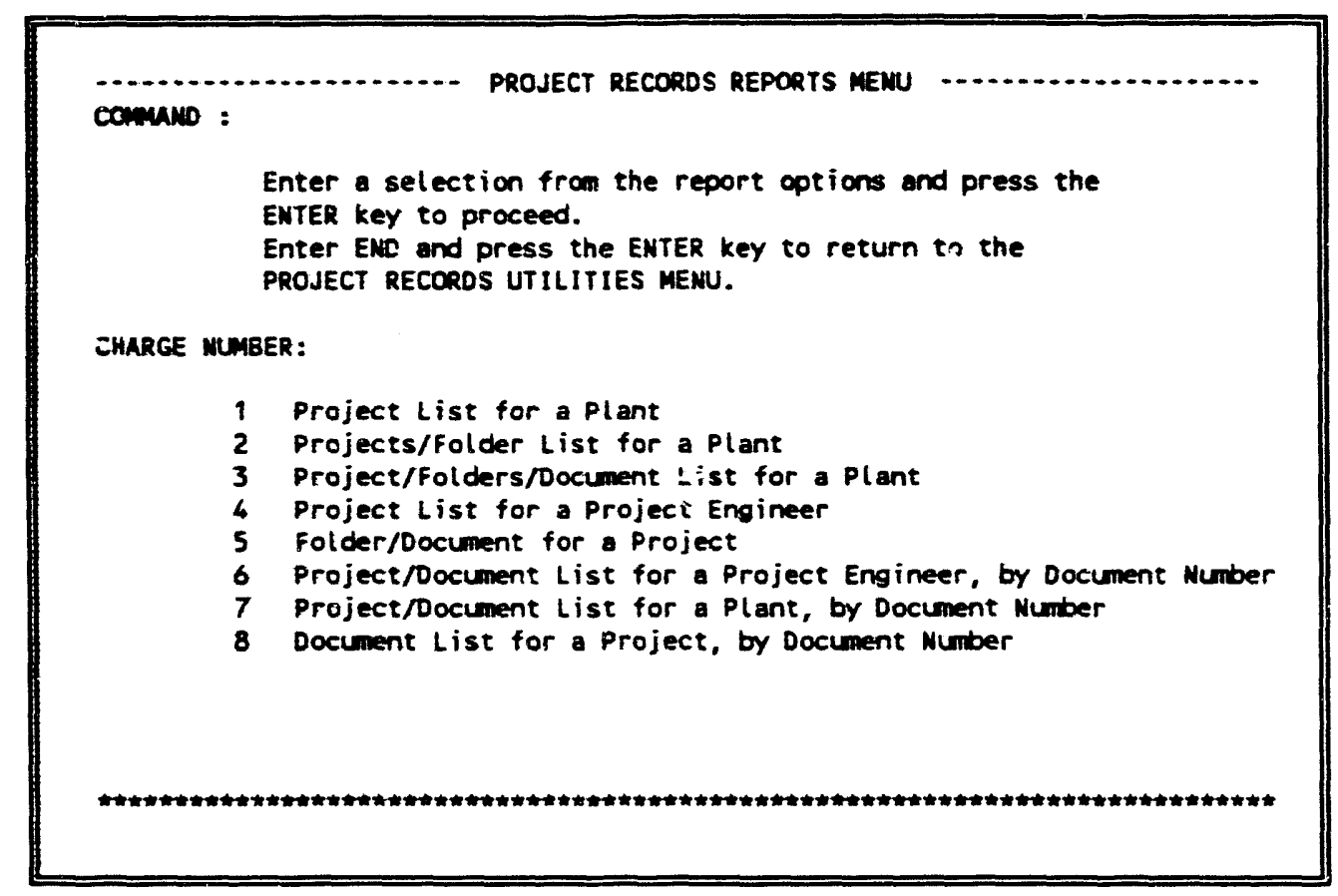

You must enter a charge number to be used for generating the reports. Then, select one of the eight report options listed on this menu by typing the report's number in the COMMAND line and pressing $<$ ENTER >. If no reports are desired, the END command will cancel this function and return you to the Project Record Utility Menu.

For some of the reports listed, you must supply additional information before the report can be gener ted. The requirements for each report are described in the following text. See Appendix $C$ for an example of tive format for each of these reports. 


\section{Reports $1,2,3$ and 7}

If you select report options $1,2,3$, or 7 , the following Plant List Screen will be displayed (with only those plants listed that are valid for PRIS) for you to selzct the desired plant for which to generate the report.

\section{PLANT LIST SCREEN}

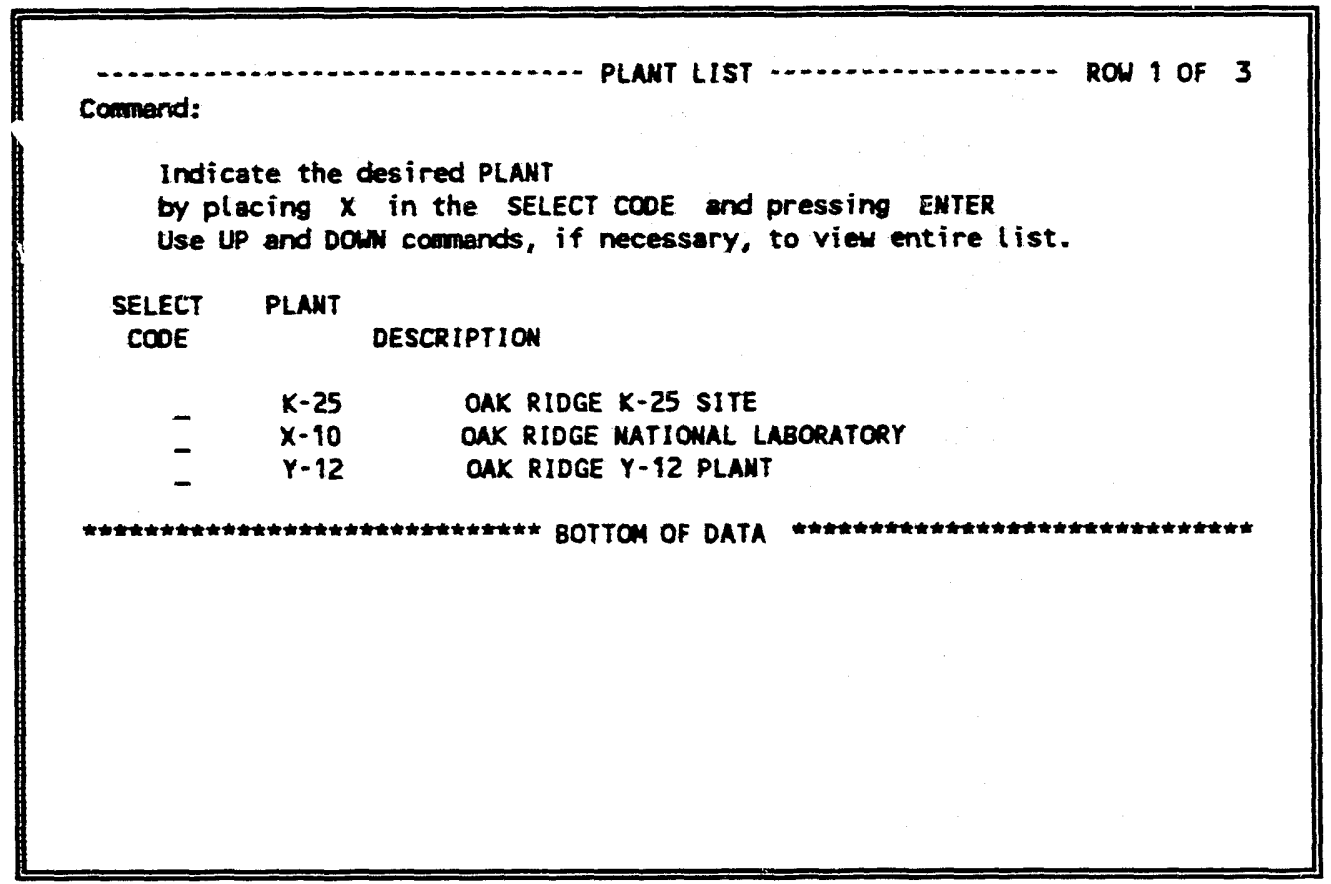

Place an $\mathrm{X}$ in the SELECT CODE field beside the desired plant and press <ENTER >. The report will be generated, printed on the mainframe printer, and will subsequently be delivered to your office. You will be returned to the Project Records Reports Menu.

If you enter END in the COMMAND line of this screen, generation of the report will be cancelled and you will be returned to the Project Records Reports Menu. 


\section{Report 4 and 6}

If you select report options 4 or 6, the system will display the Project Engineer Entry Screen, which will allow you to specify the desired project engineer's EMIS ID.

\section{PROJECT ENGINEER ENTRY SCREEN}

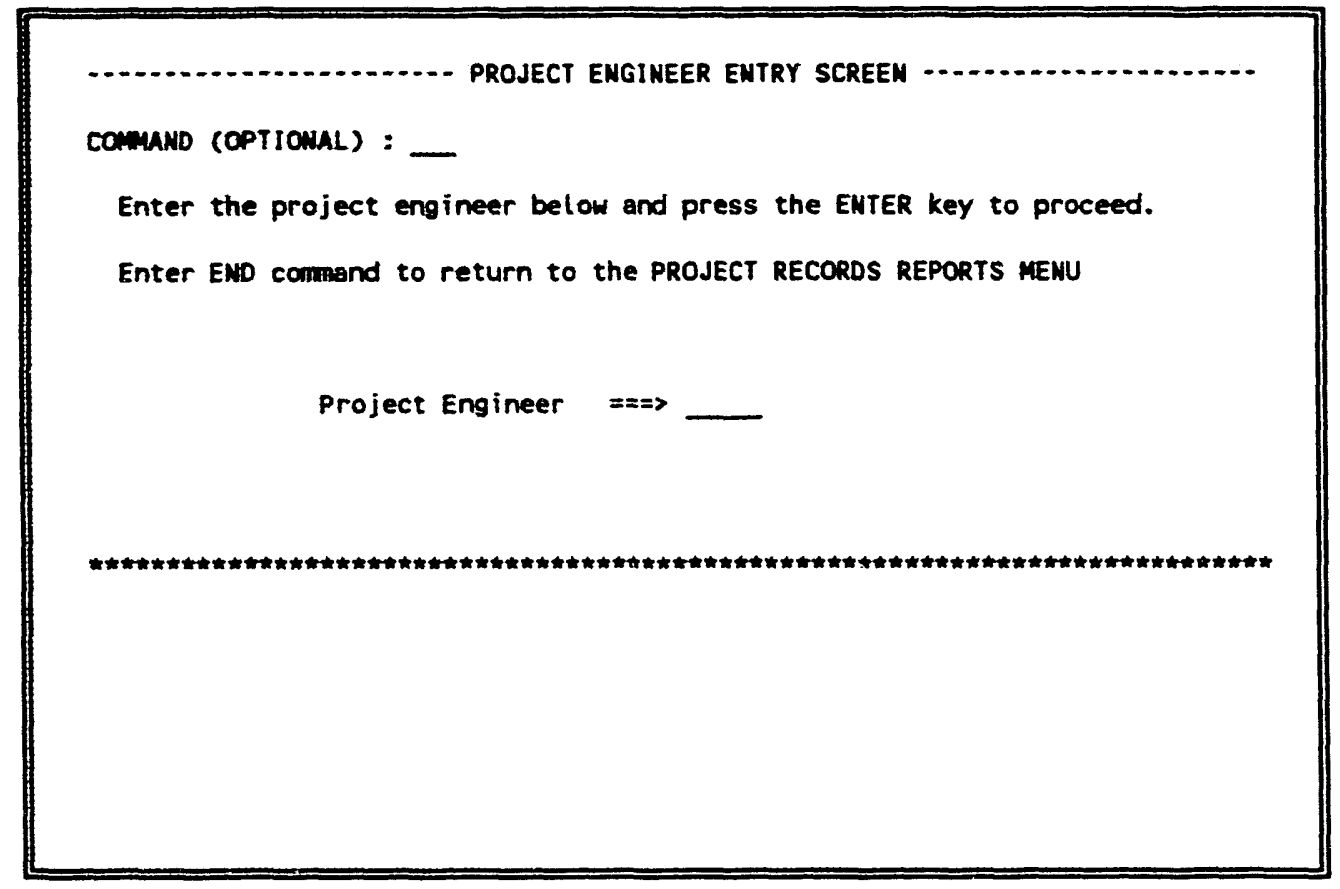

Enter a valid EMIS ID and press <ENTER>. If you do not know the EMIS ID of the project engineer, you may enter "?" in the input field and press <ENTER > to receive the Engineering Personnel Help screen. This screen allows you to enter search criteria consisting of a portion of a person's name and to receive a second screen listing the EMIS IDs and associated names of the persons that meet the search criteria you enter. (These screens are displayed in Appendix B.) When the desired EMIS ID is entered on the screen, the system will generate the report, it will be printed on the mainframe printer, and it will subsequently be delivered to your office. You will be returned to the Project Records Report Menu.

If you enter a project engineer ID for which there are no projects associated, this screen will be redisplayed with an error message.

If you enter END in the command field of this screen, the system will return to the Project Records Report Menu. 


\section{$\underline{\text { Report } 5 \text { and } 8}$}

If you select report options 5 or 8, the ISD Project Number Entry Screen will be displayed, which will allow you to specify the desired ISD Project Number for the report.

\section{ISD PROJECT NUMBER ENTRY SCREEN}

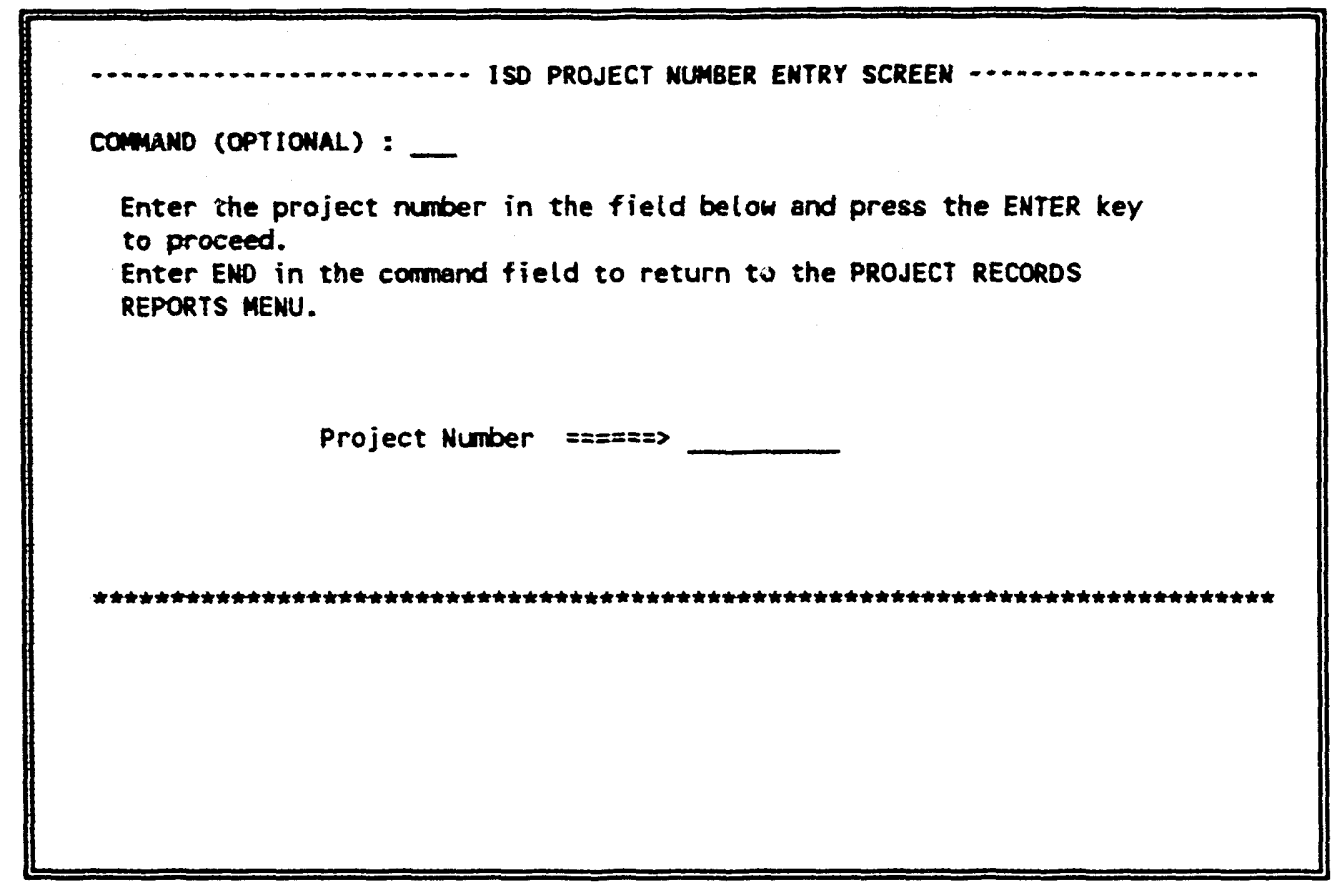

Enter a valid ISD Project Number and press <ENTER>. The report will be generated, printed on the mainframe printer, and subsequently delivered to your office. You will be returned to the Project Records Reports Menu.

If an invalid ISD project number is entered, this screen will be redisplayed with an error message.

If you enter END or $\mathrm{X}$ in the COMMAND line, generation of the report will be cancelled, and you will be returned to the Project Records Reports Menu. 


\subsubsection{Move documents or folders}

Option 2 on the PRIS Utilities Menu will allow you to move a document from one folder to another or move a folder from one project to another. If you select option 2, the following Document/Folder Movement Selection Screen will be displayed.

\section{DOCUMENT/FOLDER MOVEMENT SELECTION SCREEN}

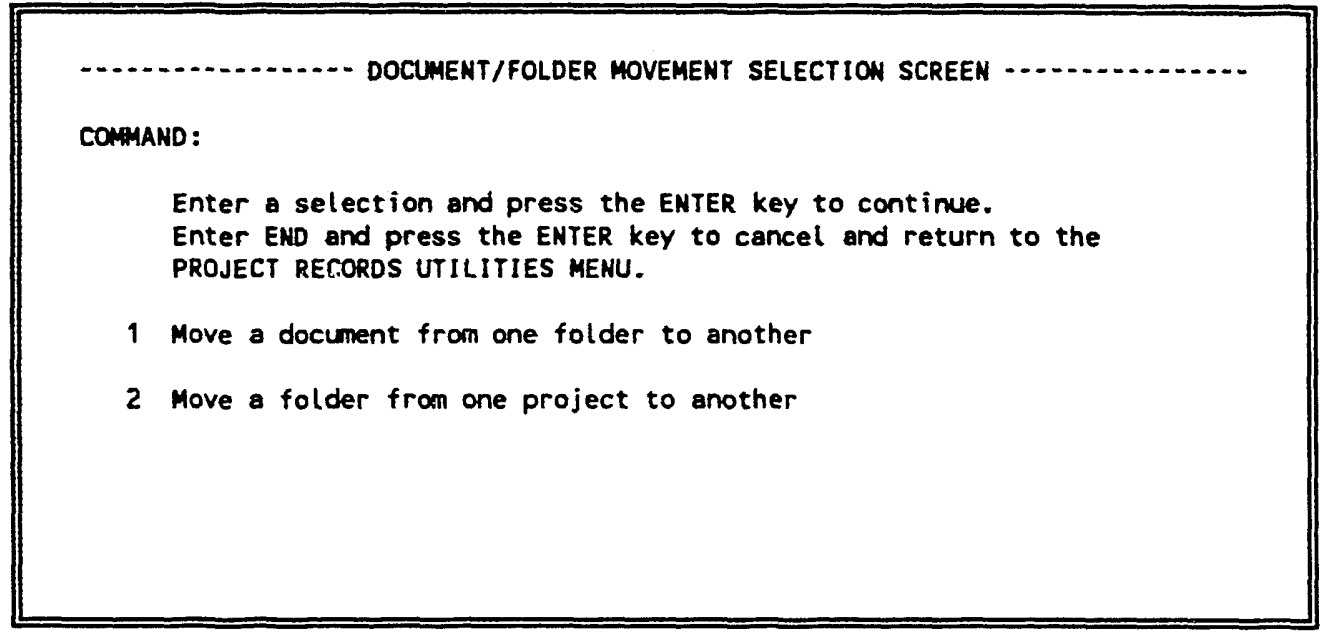

Enter either option 1 or 2 on the COMMAND line and press <ENTER>. These two options are discussed on the following page.

If you wish to cancel this function, type END and <ENTER> on the COMMAND line, and you will be returned to the Project Records Utilities Menu. 


\section{Move document from one folder to another}

If you select to move a document from one folder to another, the following Move Document Screen will be displayed for you to identify the document to be moved, along with the project and folder numbers of the folders involved in the movement.

\section{MOVE DOCUMENT SCREEN}

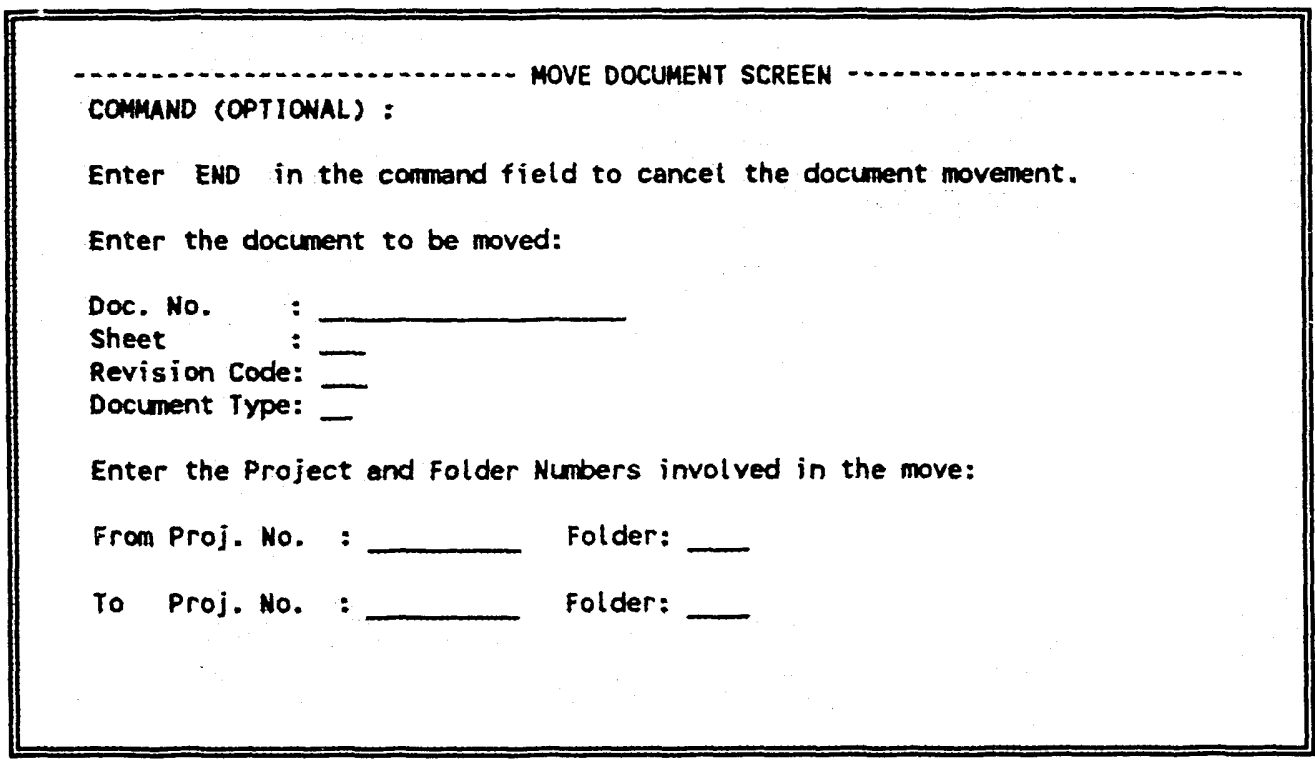

You can $\angle T A B\rangle$ to the entry fields to enter the requested information. The document, project, and folder numbers are required. You can enter "?" and <ENTER> in the document type field to receive a help list of types (see Appendix B). When all information is entered, press <ENTER $>$. The requested move will be performed, and you will be returned to the Document/Folder Movement Selection Screen with a confirmation message.

If the information you enter is not found in the database, you will be returned to this screen with an error meissage to reenter the valid information. Typing END in the COMMAND line will car.cel this function and return you to the Document/Folder Movement Selection Screen.

\section{Move a folder from one project to another}

If you select to move a folder from one project to another, the following Move Folder Screen will be displayed for you to identify the folder and projects involved in the move. 


\section{MOVE FOLDER SCREEN}

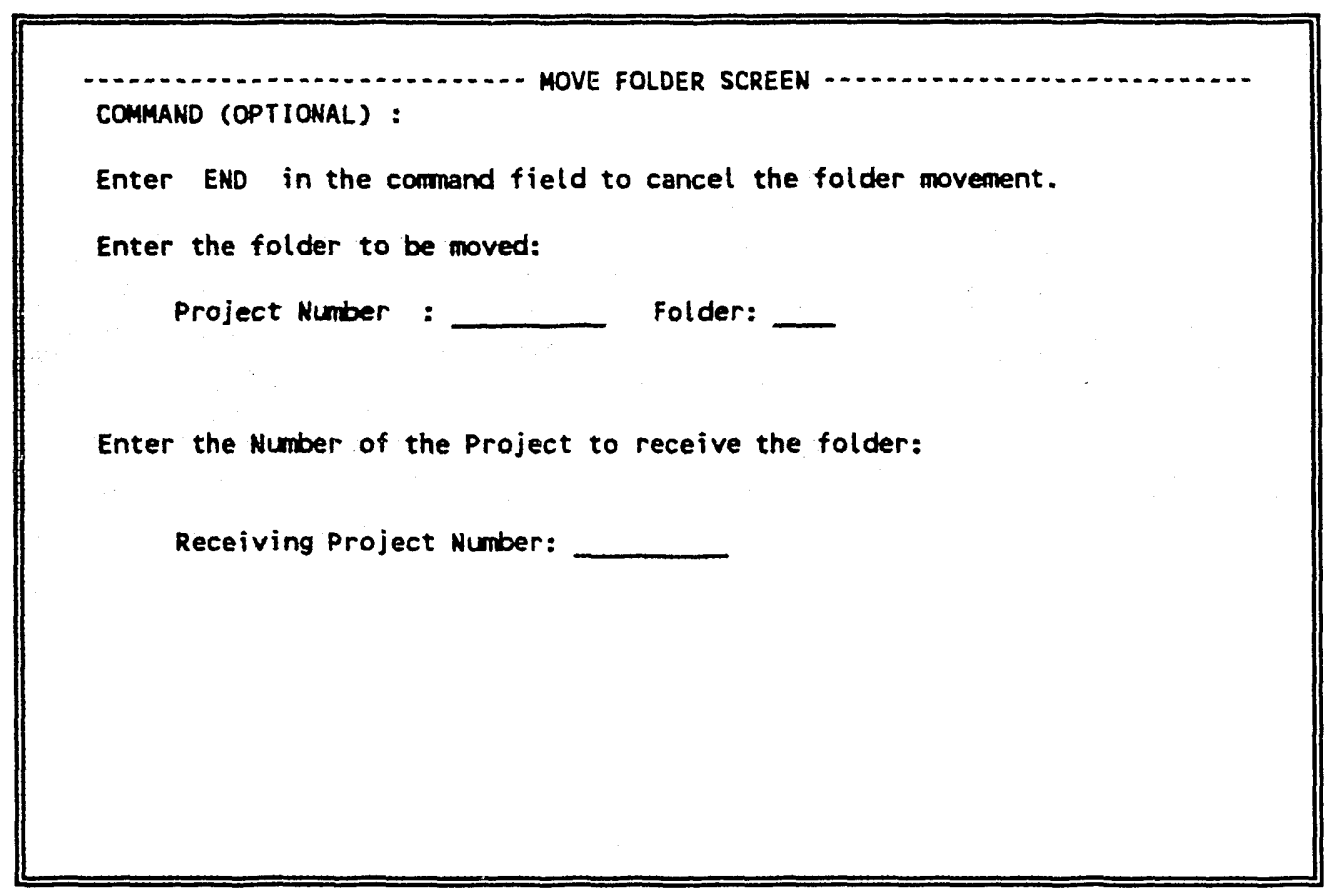

You may $\angle T A B>$ to the input fields to enter the project, folder, and receiving project numbers and press <ENTER>. The system will perform the requested move and return you to the Document/Folder Movement Screen with a confirmation message.

When a folder is moved from one project to another, the system will assign the next available folder number in the new project to the folder being moved. The system maintains a record of documents and folders moved. 
3.3.4.3 Select a project to be archived

This function is not available. 


$$
\ldots
$$




\section{DATA ELEMENT}

Access Date

Backup Location

Block 48

Block 50

Block 1

Block 49

Building

Change Date

Change Control Number

Classification

Classification Date

Classifier ID

Company

Configuration Control Number

Create Date

Creator

Design Date

Designer

Document ESO

\section{DESCRIPTION}

The date on which the document image was last accessed (modified or viewed). Automatically generated at access time.

A code indicating the backup storage location of a PRIS project.

A code that identifies the Engineering discipline to which the document (design drawing) belongs.

A code that signifies a subset of the type of work being performed.

A code representing the category of the work contained in the document.

A code that identifies the nature of the work contained in the document (applies to design drawing).

A code uniquely identifying the building with which the document is associated. (Abbreviated as Bldg.)

The date on which the document index was last modified.

The identifying number of the project change order for which the revision is made.

A code indicating the classification of the document. (Abbreviated as Class.)

The date on which the document's classification was approved. (Abbreviated as Class. Date.)

The EMIS ID of the person who approves the classification of the document. (Abbreviated as Class. ID.)

A code indicating the company responsible for the creation of the document.

A number that identifies the configuration control plan under which changes to the document are made.

The date of creation of a PRIS project.

The EMIS ID of the PRIS project creator.

The date on which the document was designed (applies to design drawings only).

The name of the designer of the original document (pertains to drawings only).

The ESO associated with a particular document (see ESO). 


\section{DATA ELEMENT}

Document Type

Document Number

Document Title

Draft Date

Draftsman

Drawing Size

ESO

Floor

Folder Number

Format Code

Format in EDIS

Index Date

Initial Store Date

ISD Project Number

Issue Date

Job Title

Last Store Date

\section{DESCRIPTION}

A code that identifies a category of documents to which the document belongs. (Abbreviated as Doc. Type.)

A number that uniquely identifies all documents referenced in the PRIS index. (Abbreviated as Doc. No.)

A title that describes the document. (Abbreviated as Doc. Title.)

The date on which the document was drafted (applies to design drawings only).

The name of the original drafter of the document (pertains to drawings only).

A code describing the size of the document (applies to drawings only).

The Engineering Service Order (ESO) to which specific revision work done on a document is charged.

A code describing the building floor to which the drawing or document refers.

The system-generated sequential number of a PRIS folder.

A code indicating the format of the document: CADAM - CADAM Electronic Format; ANVIL - Anvil Electronic Format; FILM - Aperture Card of Microfilm; MAN - Hard Copy or Manually Generated; UNCAD - Unspecified CAD Generated; OTHER - Unspecified. (Abbreviated as Format.)

A code indicating if the format of a document is stored in the EDIS repository.

The date on which the document was entered into the EDIS Index. Automatically generated at index time.

The date on which an electronic copy of the document was first stored in the EDIS repository. Automatically generated at store time. (Abbreviated as Initial Store.)

The ISD project number for a PRIS project.

The date on which the document was issued.

The job title on the transmittal that accompanies the documents sent to project records that describes the work package.

The date on which an electronic copy of the document was last stored in the EDIS Repository. (Abbreviated as Last Store.) 


\section{DATA ELEMENT}

Number of Sheets

Number of Models

Originator ID

Original Format

Originator Discipline

Originator's Company

Owner

Partfind

Plant

Plant Description

Principal Engineer

Project Acronym

Project Creator

Project Create Date

Project Engineer

Project Number

Project Status

\section{DESCRIPTION}

Indicates the total number of sheets included in a document. This number will be 1 for documents that are not of type DD (design drawing).

The number of models associated with a CADAM drawing.

The EMIS ID of the originator of the document. (Abbreviated as Orig. ID.)

The format of the document from which future revisions should be made; the format that is originally approved. All other formats are considered copies. (Abbreviated as Orig. Format.)

The EMIS discipline code associated with the EMIS ID of the originator of the document. (Abbreviated as Orig. Disc.)

The EMIS company code identifying the company of the originator of the document.

A code indicating the system ownership of the document index record.

$$
\begin{array}{ll}
1=\text { PRIS } & 4=\text { OTHER } \\
2=\text { ISD } & 5=\text { OTHER \& PRIS } \\
3=\text { PRIS \& ISD } & 6=\text { OTHER \& ISD } \\
& 7=\text { ALL }
\end{array}
$$

The partfind number of a CADAM drawing.

A code indicating the plant to which the drawing pertains.

A description of the plant to which the drawing pertains.

The EMIS ID of the principal engineer identified on the transmittal sent to project records. (Abbreviated as Principal Engr.)

The acronym assigned to a particular PRIS project. (Abbreviated as Proj. Acronym.)

The EMIS ID of the project creator.

The date of creation of a PRIS project.

The EMIS ID of a project engineer associated with a PRIS project. (Abbreviated as Project Engr.)

The EMIS project number with which the document is associated. (Abbreviated as Proj. No.)

A code indicating the status of a PRIS project. 


\section{DATA ELEMENT}

Project Storage Location

Project Title

Reserve Date

\section{Reserver ID}

Responsible ID

Responsible Discipline

Retention Period

Revision Code

Revision Date

Send to EFM

Sheet Number

Software Version

Status Code

Status Date

Storage Date

Storage Location

\section{DESCRIPTION}

A code indicating the default storage location for a PRIS project.

The title of a PRIS project. (Abbreviated as Proj. Title.)

The date the document number was reserved in EDIS. This is automatically generated at the time of reservation. (Abbreviated as Resv. Date.)

The EMIS ID of the person who last reserved the document. (Abbreviated as Resv. ID.)

The individual (normally the Eng. RED) responsible for the document. (Abbreviated as Resp. ID.)

The Engineering design discipline responsible for the document. (Abbreviated as Resp. Disc.)

The retention period required for a PRIS project. (Abbreviated as Ret. Period.)

A code that indicates the level of the document revision. Codes for revisions made by Martin Marietta are characters beginning at " $\mathrm{A}$; ; for architect/engineers, they are numbers beginning at "1." (Abbreviated as Rev. Code.)

A date that, in some cases, indicates a document's revision. Some text documents (maybe in a CADAM model) do not have revision codes. This field will be blank if an entry is made in the Revision code. (Abbreviated as Rev. Date.)

A code indicating if a copy of the document is to be sent to the EFM system.

The number of the sheet of a multiple sheet document. This is defaulted to '001' for all single sheet documents or documents that are not design drawings. (Abbreviated as Sheet.)

A code identifying the version of the software that created a particular electronic format of a document.

A code indicating the stage of development of the document. (Abbreviated as Status.)

The date the sheet revision was stored in its current state of development.

The date that a particular electronic format of a document was stored. The storage location of a particular format of a document. 


\section{DATA ELEMENT}

Subject Code

Transmittal EMIS Project Number

Transmittal ESO

Transmittal Number

Type

Vendor Code

Vendor Subject

Work Order

\section{DESCRIPTION}

A code indicating the subject of manufacturing or vendor data (document type MD).

The EMIS Project Number with which a particular transmittal or folder is associated (see Project Number).

The ESO associated with a particular transmittal or folder (see ESO).

The number identifying the transmittal that accompanies the documents sent to the project record (PRIS) files. (Abbreviated as Transmittal.)

Indicates the type of work to which the document is related (weapons, facilities, etc.). Refer to Eng. Standards for a list.

A code describing the vendor associated with document type MD (manufacturing or vendor data). A list of valid vendor codes is maintained by ISD.

A code describing the subject of document type MD (manufacturing or vendor data).

The EMIS work order number to which the creation of the document is charged. 
APPENDIX B: HELP AND ERROR SCREENS 
LIST OF VALID PRIS CODES

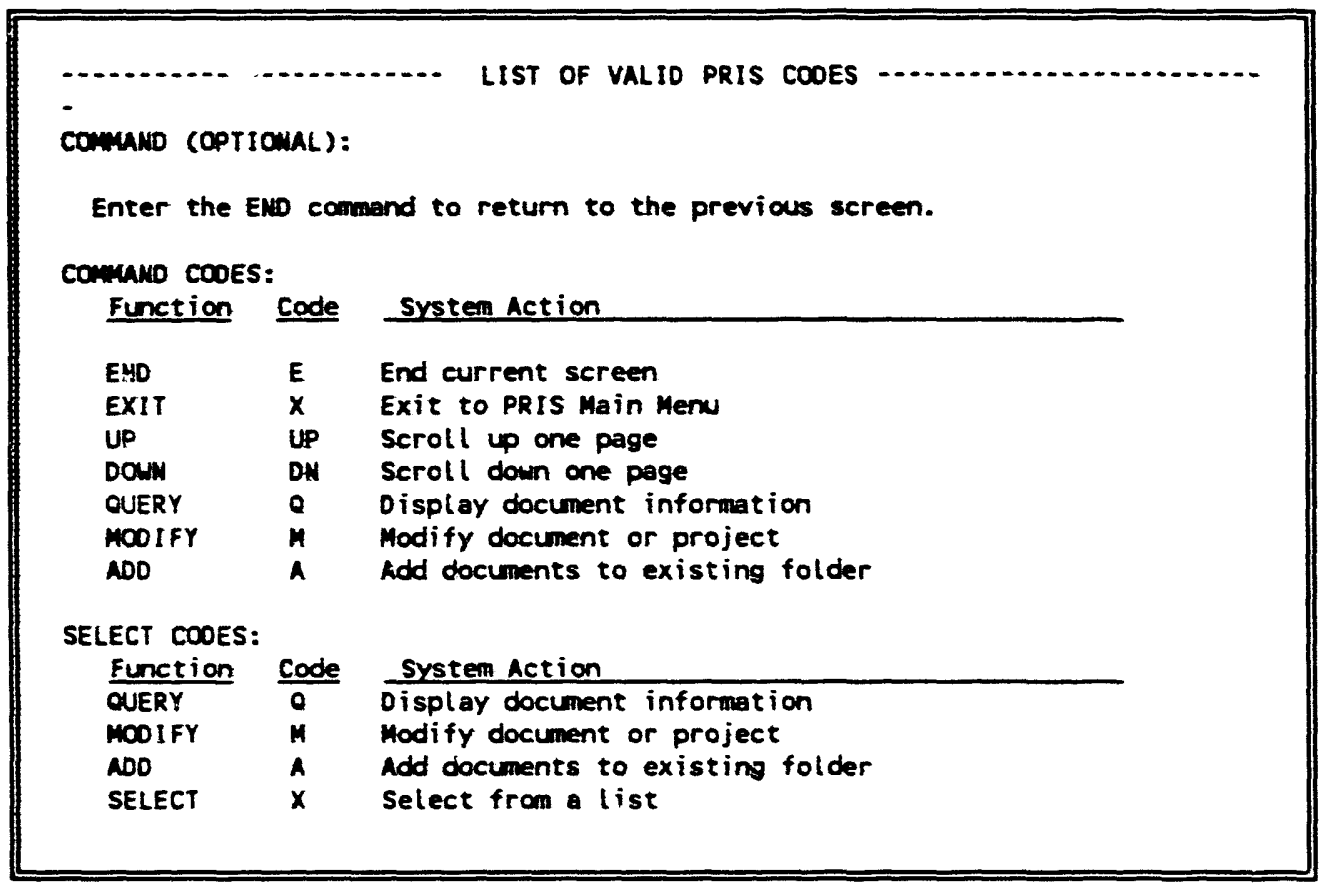




\section{CLASSIFICATION CODE LIST SCREEN}

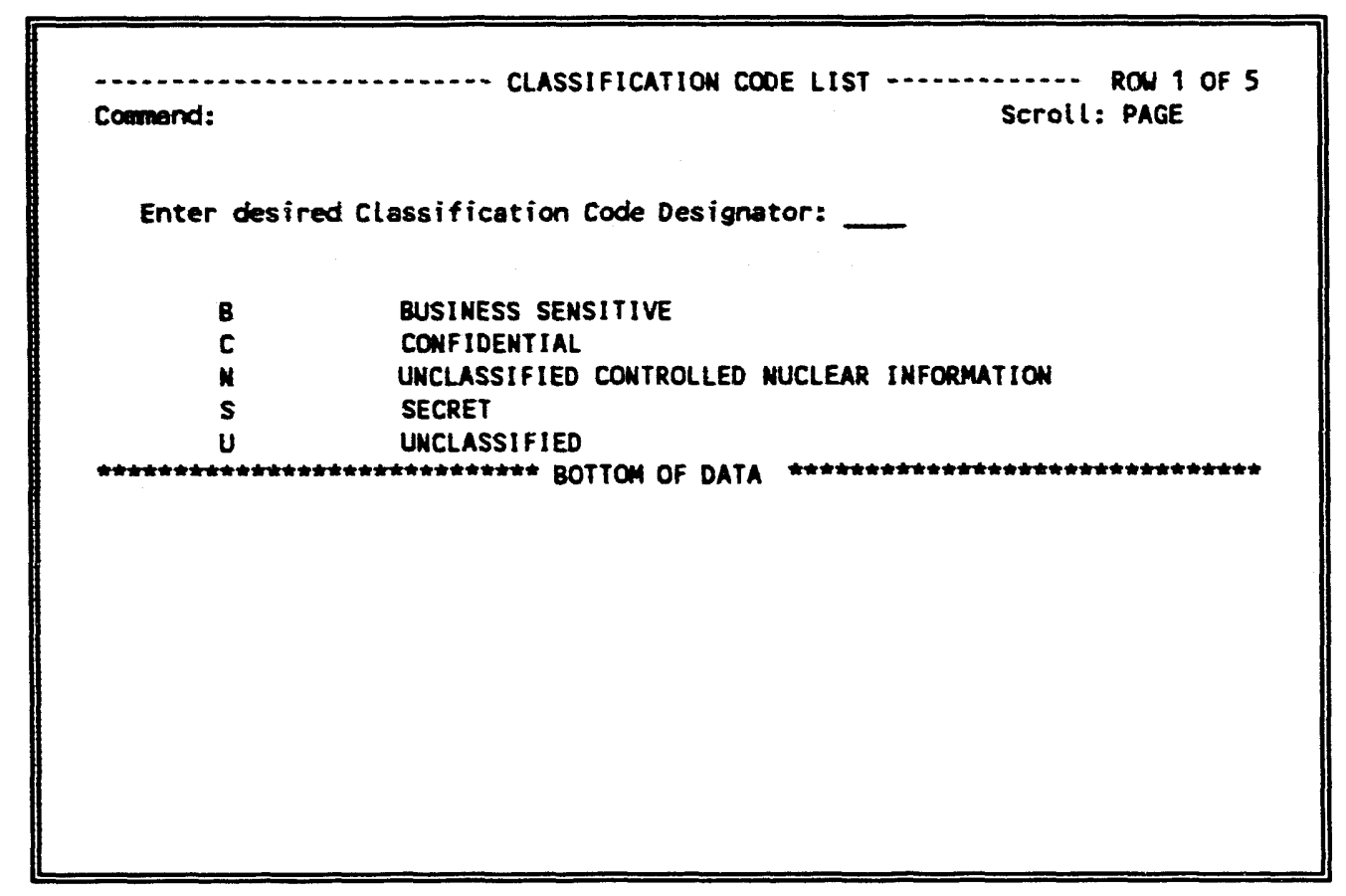




\section{SELECT BUILDING NUMBER SCREEN}

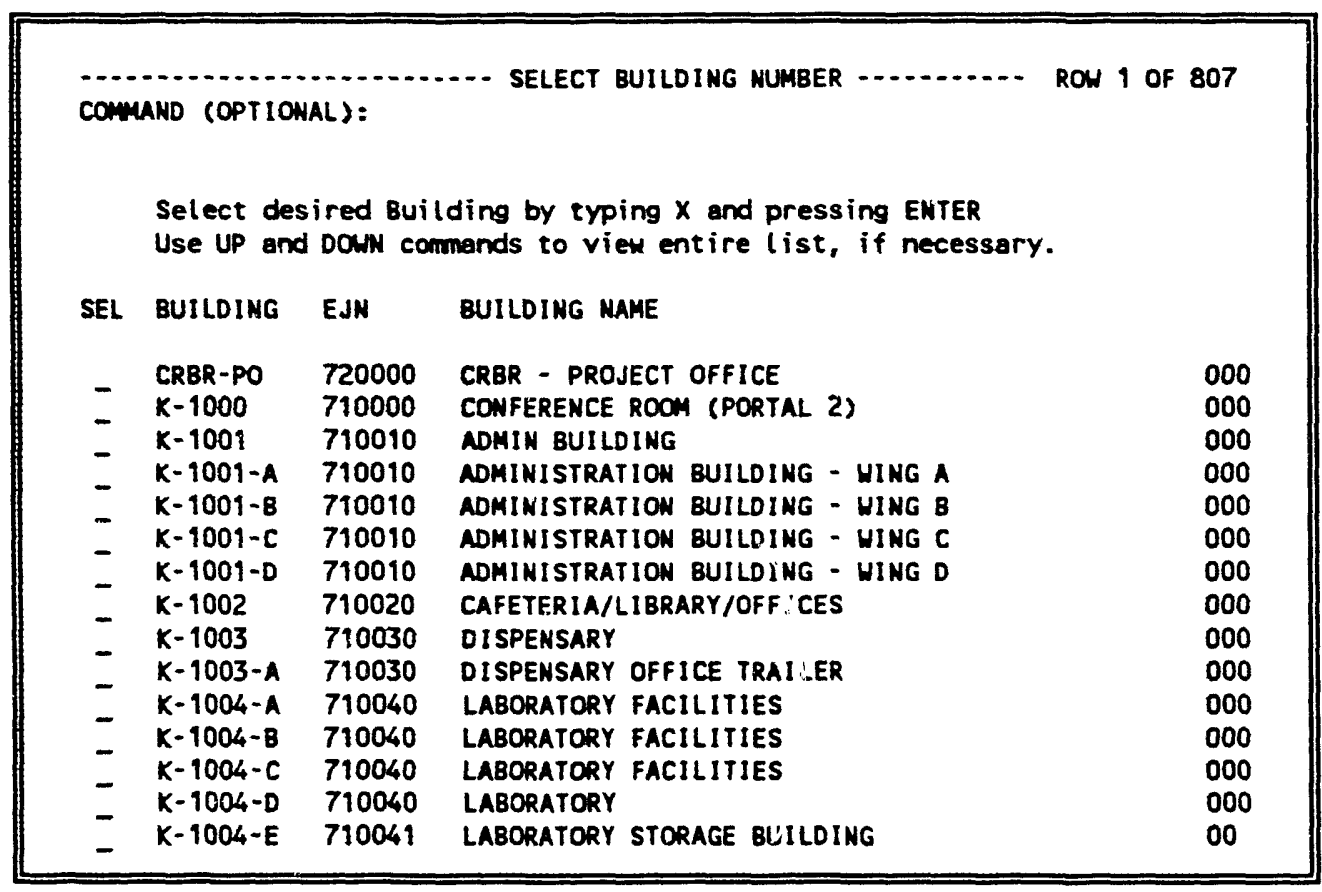




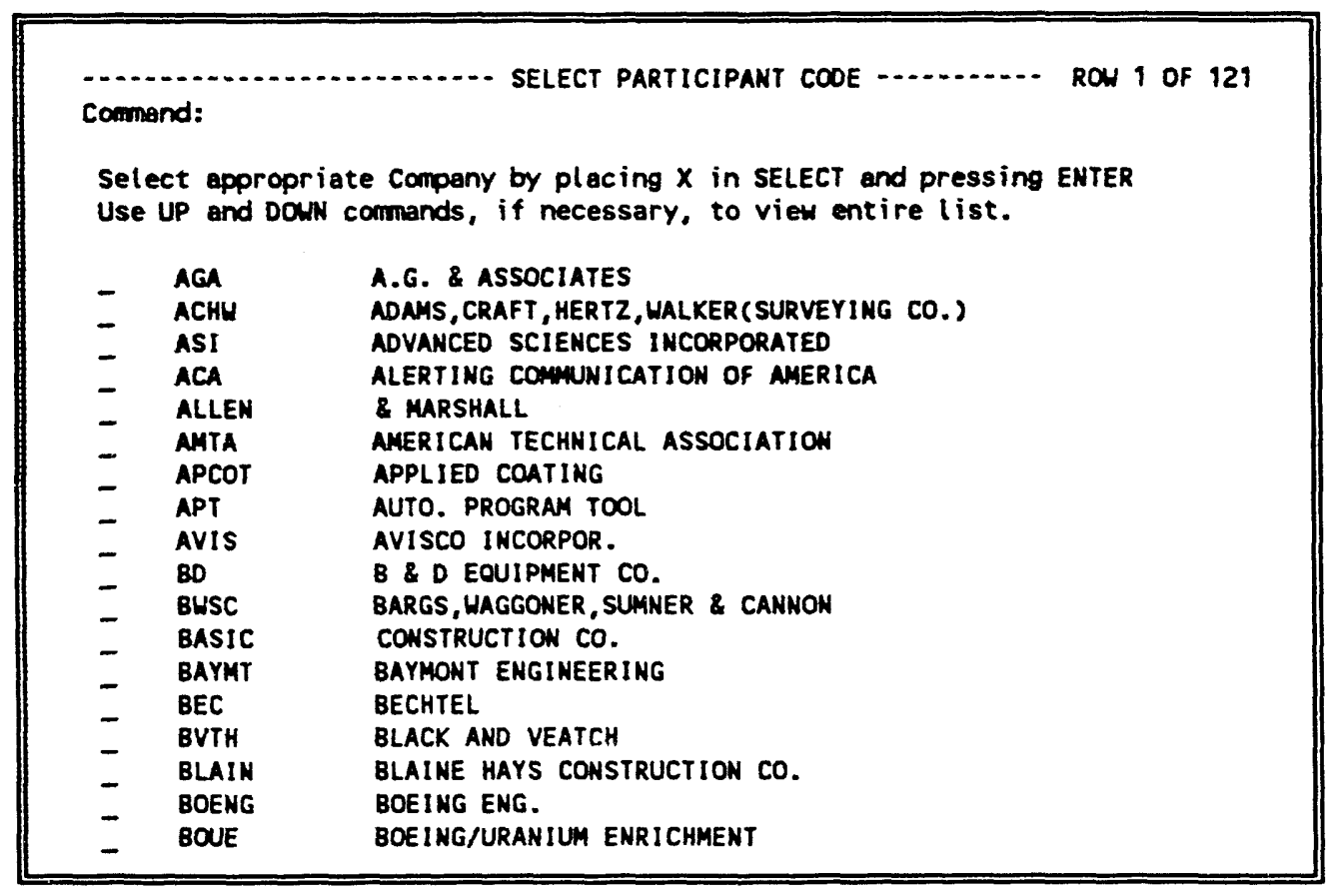


PERSONNEL HELP SCREEN

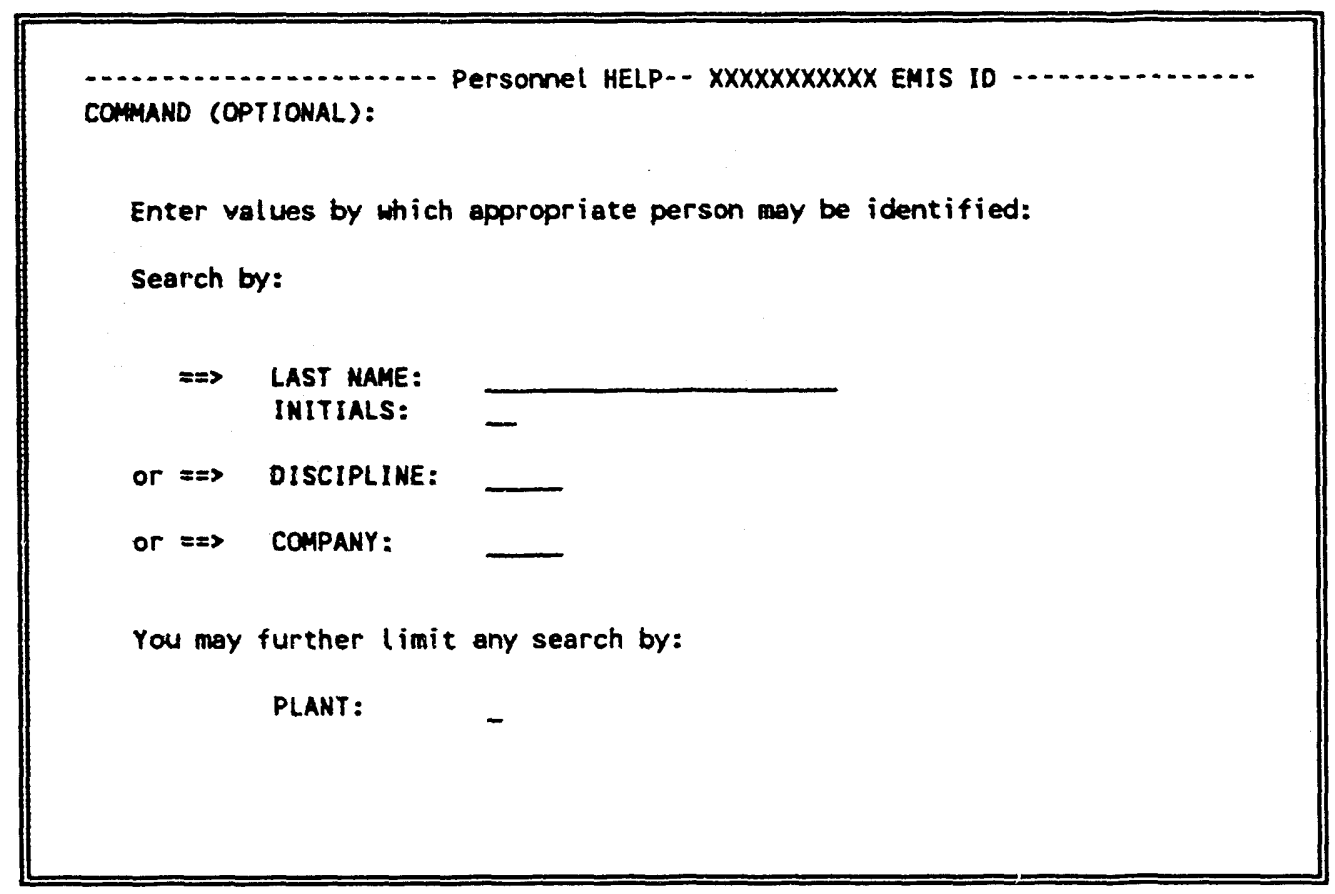


SELECT EMIS ID SCREEN

\begin{tabular}{|c|c|c|c|c|}
\hline \multicolumn{5}{|c|}{ COMNAND (OPTIONAL): } \\
\hline \multicolumn{3}{|c|}{$\begin{array}{l}\text { Indicate correct EMIS } 10 \\
\text { Use UP and DOWN commands }\end{array}$} & \multicolumn{2}{|c|}{$\begin{array}{l}\text { by placing } x \text { in SELECT and pressing Enter. } \\
\text { to view entire list, if necessary. }\end{array}$} \\
\hline SELECT & EMIS ID & NAME & & DISCIPLINE \\
\hline - & AWS & $A H$ & SMITH & YMD \\
\hline - & BGSOI & $B G$ & SMITH & XFT \\
\hline - & CBS & CB & SMITH & XPJ \\
\hline - & DES & DE & SMITH & YCP \\
\hline - & GSSO1 & GS & SHITH & XIE \\
\hline - & GSS & GS & SMITH & YMD \\
\hline - & HGS & HG & SMITH & $\mathrm{EE}$ \\
\hline - & JASO I & JA & SMITH & EE \\
\hline - & JMS & JM & SMITH & $A D$ \\
\hline - & $\begin{array}{l}\text { JPS } \\
\text { JWSO? }\end{array}$ & JP & SMITH & YEE \\
\hline - & $\begin{array}{l}\mathrm{JWSO2} \\
\mathrm{KDSO1}\end{array}$ & $J W$ & SHITH & $\mathrm{KDE}$ \\
\hline- & $\begin{array}{l}\text { KDSO1 } \\
\text { KES }\end{array}$ & KD & SMITH & YPJ \\
\hline- & $\begin{array}{l}\text { KES } \\
\text { KLS }\end{array}$ & KE & SHITH & $\begin{array}{l}\text { EM } \\
\text { krO }\end{array}$ \\
\hline 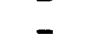 & MASO1 & $\begin{array}{l}\mathrm{KL} \\
M\end{array}$ & SMITH & XDE \\
\hline - & MASO2 & MA & SMITH & EM \\
\hline
\end{tabular}




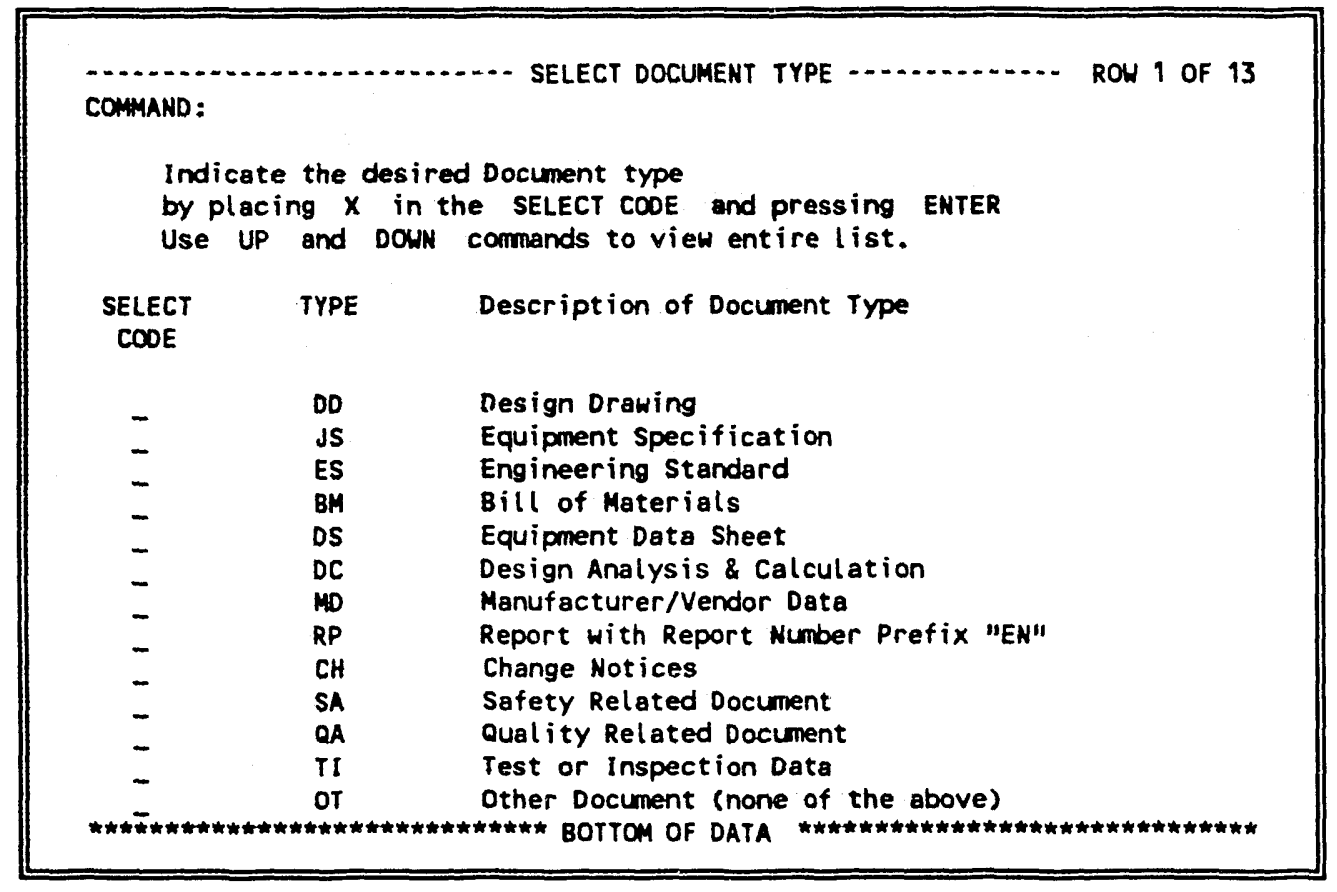


PLANT LIST SCREEN

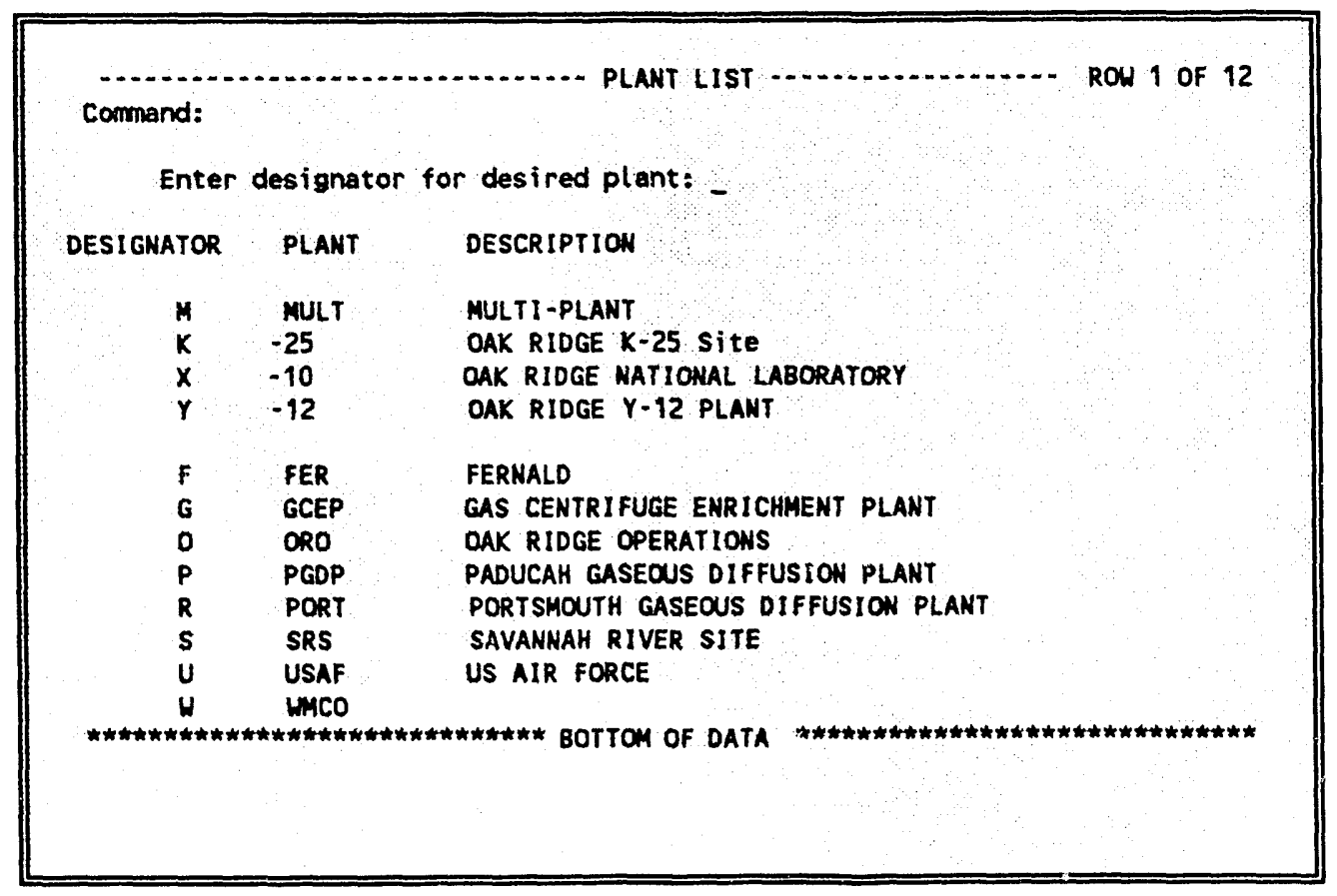




\section{DATABASE ERROR}

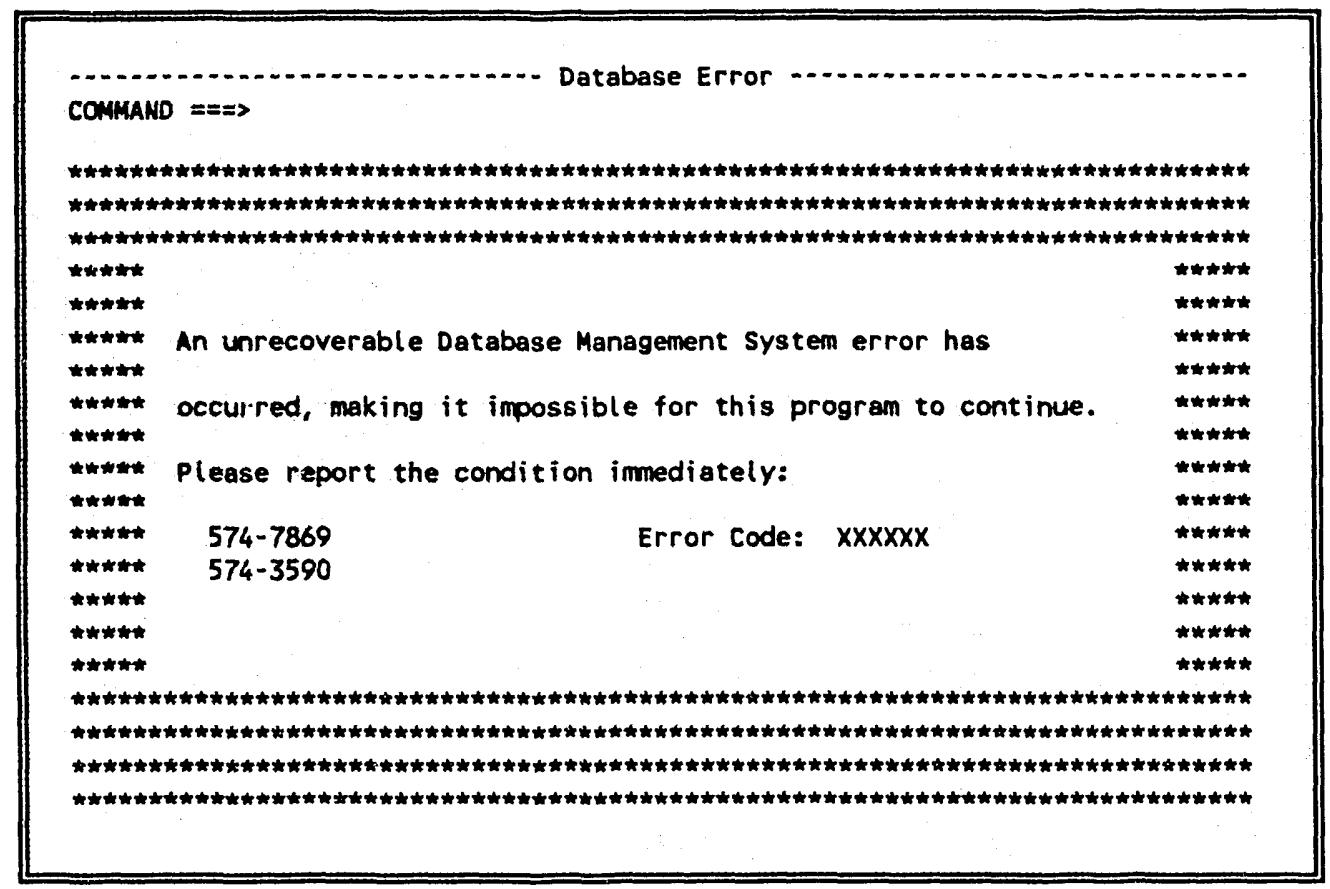


-

APPENDIX C: FRIS REPORT FORMATS

$\bullet$

- 


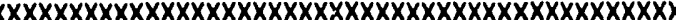
$X X X X X X X X X X X X X X X X X X X X X X X X X X X X X X X X X X X X X X X X X X X X X X X X X X X X X X$

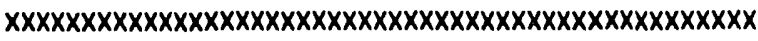
$x X X X X X X X X X X X X X X X X X X X X X X X X X X X X X X X X X X X X X X X X X X X X X X X X X X X X$ $x x x x x-x x x x$

$x x x x x-x x x x$ $x x x x x \quad x x x x x$

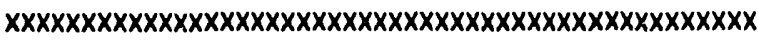

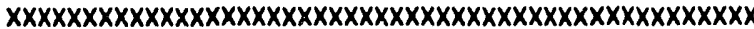
$x x x x x-x x x x$ $x X X X X$ $x x x x x \quad x x x x x$ $x x x x \quad x x x x x$ $X X X X X X X X X X X X X X X X X X X X X X X X X X X X X X X X X X X X X X X X X X X X X X X X X X X X$

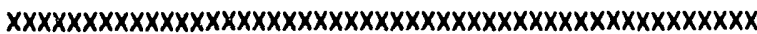

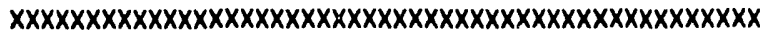
$x x x x x-x x x x$ $x x x x x \quad x x x x x$ $\begin{array}{lll}x X X X X-x X X X & X X X X X & X X X X X\end{array}$

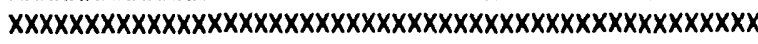
$x x X X X X X X X X X X X X X X X X X X X X X X X X X X X X X X X X X X X X X X X X X X X X X X X X X X X$

\begin{tabular}{|c|c|c|}
\hline DERIOD & DATE & STATUS \\
\hline$x x x$ & $x x x x-x x-x x$ & ACTIVE \\
\hline$x x x$ & $x x x x-x x-x x$ & ACT IVE \\
\hline$x x x$ & $x x x x-x x-x x$ & ACTIVE \\
\hline$x x x$ & $x x x x-x x-x x$ & ACTIVE \\
\hline$x x x$ & $x x x x-x x-x x$ & ACTIVE \\
\hline$x x x$ & $x x x x-x x-x x$ & ACTIVE \\
\hline$x x x$ & $x x x x-x x-x x$ & ACTIVE \\
\hline$x x x$ & $x x x x-x x-x x$ & ACT IVE \\
\hline$x x x$ & $x x x x-x x-x x$ & ACTIVE \\
\hline$x x x$ & $x x x x-x x-x x$ & ACTIVE \\
\hline$x x x$ & $x x x x-x x-x x$ & ACTIVE \\
\hline
\end{tabular}

Fig. C-1. PRIS Report 1 - PRIS Project Listing for a Given Plant. 
ISD PROJECT NUMBER : $X X X X X-X X X X$ PROJECT ENGINEER : $X X X X X$

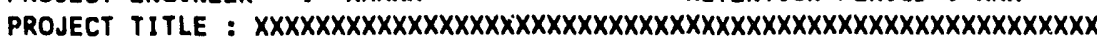

CREATE DATE : $X X X X-X X-X X$

STATUS : ARCHIVED

\begin{tabular}{|c|c|}
\hline FOLDER & TRANSMITTAL \\
\hline$x x x x$ & $x x x x x x x x x x x$ \\
\hline$x \mathbf{x x x}$ & $x X X X X X X X X X X$ \\
\hline$x x x x$ & $x x x x x x x x x x$ \\
\hline$x x x x$ & $x x x x x X X X X X X$ \\
\hline$x x x x$ & $x x x x x x x x x x x$ \\
\hline$x x x x$ & $x x x x x x x x x x x$ \\
\hline$x x x x$ & $X X X X X X X X X X X$ \\
\hline$x x x x$ & $x x x x x x x x x x x$ \\
\hline
\end{tabular}

JOB TITLE

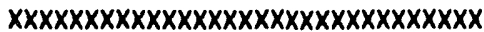

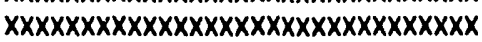

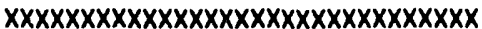

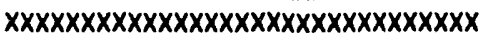

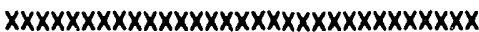

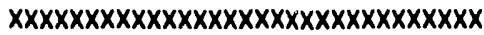

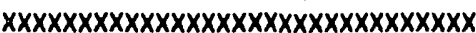

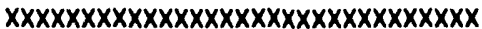

\begin{tabular}{|c|c|c|c|}
\hline $\begin{array}{l}\text { PRINCIPAL } \\
\text { ENGINEER }\end{array}$ & $\begin{array}{l}\text { ORIGINATOR/ } \\
\text { RECIPIENT }\end{array}$ & $\begin{array}{l}\text { EMIS } \\
\text { PROJECT }\end{array}$ & ESO \\
\hline$x x x x x$ & $X X X X X$ & $x x x x x x$ & $x x x x x x x x$ \\
\hline$x x x x x$ & $x x x x x$ & $x x x x x x$ & $x x x x x x x x$ \\
\hline$x x x x x$ & $X X X X X$ & $x x x x x x$ & $x x x x x x x x$ \\
\hline$x X X X X X$ & $x x x x x$ & $x x x x x x$ & $x x x x x x x x$ \\
\hline$x x x x x$ & $x x x x x$ & $x x x x x x$ & $x x x x x x x x$ \\
\hline$x x x x x$ & $x x x x x$ & $x x x x x x$ & $X X X X X X X X$ \\
\hline$x x x x x$ & $x x x x x$ & $x x x x x x$ & $x x x x x x x x$ \\
\hline$x x x x x$ & $x X X X X$ & $x x x x x x$ & $x x x x x x x x$ \\
\hline
\end{tabular}

Fig. C-2. PRIS Report 2 - Project/Folder Listing for a Given Plant. 


\begin{tabular}{|c|c|c|}
\hline 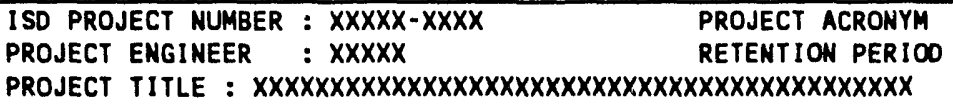 & $\begin{array}{l}: x \times x x x \\
0: x x x\end{array}$ & $\begin{array}{ll}\text { CREATE DATE : } & X X X X-X X-X X \\
\text { STATUS } & : \text { ARCHIVED }\end{array}$ \\
\hline 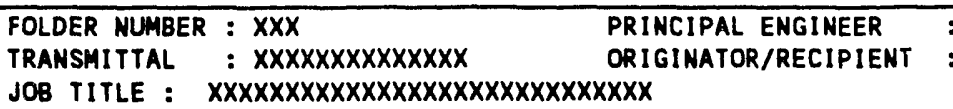 & $\begin{array}{l}: \quad X X X X X \\
: \quad x X X X X\end{array}$ & $\begin{array}{ll}\text { PROJECT NUMBER } & : X X X X X \\
\text { ESO } & : X X X X X X X X\end{array}$ \\
\hline
\end{tabular}

\begin{tabular}{|c|c|c|c|c|c|c|c|c|}
\hline DOCUMENT NUMBER & $\begin{array}{c}\text { DOCUMENT } \\
\text { TYPE }\end{array}$ & $\begin{array}{l}\text { REVISION } \\
\text { CODE }\end{array}$ & $\begin{array}{l}\text { SHEET } \\
\text { NUMBER }\end{array}$ & BUILDING & ISSUE DATE & STATUS DATE & CLASSIFICATION & ESO \\
\hline$X X X X X X X X X X X X X X X X X X X X X X$ & $x x$ & $\mathbf{X X X}$ & $x x x$ & $x x x x x x x x$ & $x x x x-x x-x x$ & $x x x x-x x-x x$ & $u$ & $x x x x x x x x$ \\
\hline 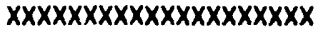 & $x x$ & & $x x x$ & $x X X X X X X X X$ & $x x x x-x x-x x$ & $x x x x-x x-x x$ & $u$ & $x x x x x x x x$ \\
\hline 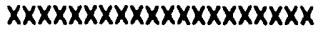 & $x x$ & $\mathbf{x X X}$ & $\mathbf{x x x}$ & $X X_{n} X X X X X$ & $x x x x-x x-x x$ & $x x x x-x x-x x$ & u & $x x x x x x x X$ \\
\hline 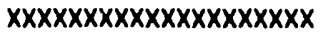 & $x x$ & & $x x x$ & $x x x x x x x x$ & $x x x x-x x-x x$ & $x x x x-x x-x x$ & $u$ & $x x x x x x x x$ \\
\hline 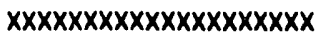 & $x x$ & & $x x x$ & $x x x x x x x x$ & $x x x x-x x-x x$ & $x x x x-x x-x x$ & u & $x x x x x x X X$ \\
\hline 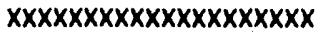 & $x x$ & $x x x$ & $x x x$ & $x x x x x x x x$ & $x x x x-x x-x x$ & $x x x x-x x-x x$ & $u$ & $x x x x x x x x$ \\
\hline
\end{tabular}

Fig. C-3. PRIS Report 3 - Project/Folder/Document Listing for a Given Plant. 
PRIS PROJECT LISTING

PROJECT ENGINEER : $X X X$

PLANT : $x-x x$
DATE : $X X / X X / X X$

PAGE : $x$

\begin{tabular}{|c|c|c|c|c|c|c|}
\hline $\begin{array}{l}\text { PROJECT } \\
\text { MUMBER }\end{array}$ & $\begin{array}{l}\text { PROJECT } \\
\text { ACRONYM }\end{array}$ & PROJECT TITLE & $\begin{array}{l}\text { RETENTION } \\
\text { PERIOO }\end{array}$ & $\begin{array}{l}\text { CREATE } \\
\text { DATE }\end{array}$ & CREATOR & STATUS \\
\hline$x x x x x-x x x x$ & $x \times x \times x$ & 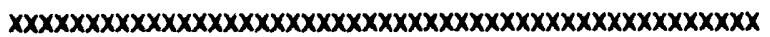 & $\mathbf{x x x}$ & $x x x x-x x-x x$ & $x \times x \times x$ & ACTIVE \\
\hline$x x x x x x-x x x x$ & $x \times x \times x$ & 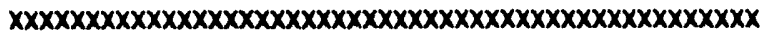 & $x \mathbf{x x}$ & $x x x x-x x-x x$ & $x x x x x$ & ACTIVE \\
\hline$x x x x x-x x x x$ & $x \times x \times x$ & 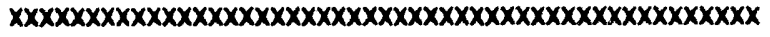 & $x \times x$ & $x x x x-x x-x x$ & $x \times x \times x$ & ACT IVE \\
\hline$x x x x x x-x x x x$ & $x \times x \times x x$ & 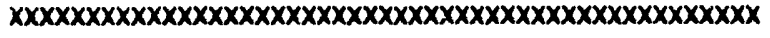 & $\mathbf{x x x}$ & $x x x x-x x-x x$ & $x \times x \times x$ & ACTIVE \\
\hline$x x x x x-x x x x$ & $x x x \times x$ & 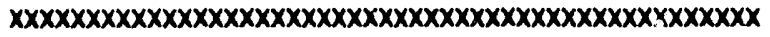 & $\mathbf{x x x}$ & $x x x x-x x-x x$ & $x x x x x$ & ACTIVE \\
\hline$x x x x x-x x x x$ & $x \times x \times x$ & 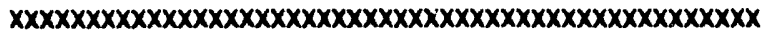 & $\mathbf{x x x}$ & $x x x x-x x-x x$ & $x x x x x$ & ACTIVE \\
\hline$x x x x x x-x x x x$ & $x \times x \times x x$ & 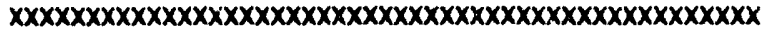 & $\mathbf{x x x}$ & $x x x x-x x-x x$ & $x x x x x$ & ACTIVE \\
\hline$x x x x x-x x x x$ & $x \times x \times x$ & 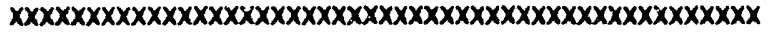 & $\mathbf{x x x}$ & $x x x x-x x-x x$ & $x \times x x x$ & ACTIVE \\
\hline$x x x x x-x x x x$ & $x \times x \times x \times$ & 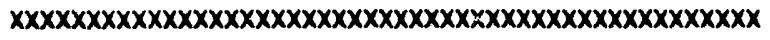 & $\mathbf{x x x}$ & $x x x x-x x-x x$ & $x x x x x$ & ACTIVE \\
\hline$x x x x x-x x x x$ & $x \times x \times x$ & 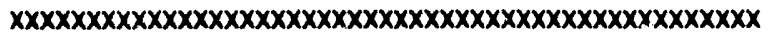 & $x \mathbf{x x}$ & $x x x x-x x-x x$ & $x x x x x$ & ACTIVE \\
\hline$x x x x x-x x x x$ & $x \times x x x$ & 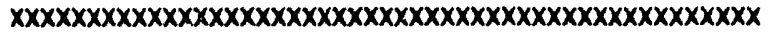 & $x x x$ & $x x x x-x x-x x$ & $x x x x x$ & ACTIVE \\
\hline
\end{tabular}

Fig. C-4. PRIS Report 4 - Project Listing for a Given Project Engineer. 


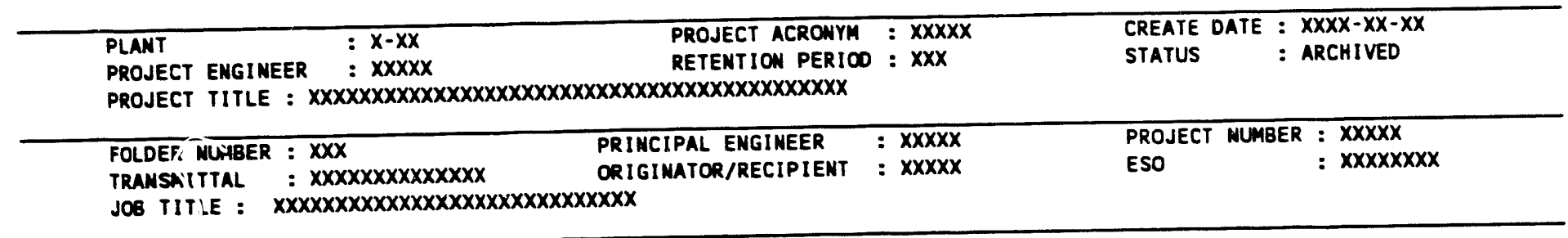

\begin{tabular}{|c|c|c|c|c|c|c|c|c|}
\hline DOCUMENT MUMBER & $\begin{array}{c}\text { DOCUMENT } \\
\text { TYPE }\end{array}$ & $\begin{array}{l}\text { REVISION } \\
\text { COOE }\end{array}$ & $\begin{array}{l}\text { SHEET } \\
\text { MUMBER }\end{array}$ & BUILDING & ISSUE DATE & STATUS DATE & CLASSIFICATION & ESO \\
\hline 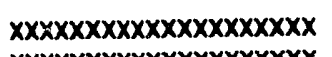 & $x x$ & $\mathbf{x x x}$ & $\mathbf{x x x}$ & $x x x x x \times x x$ & $x x x x-x x-x x$ & $x x x x-x x-x x$ & $\mathbf{u}$ & $x x x x x x x x$ \\
\hline 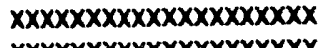 & $x x$ & & $\mathbf{x x x}$ & $x x x x x x x x x$ & $x x x x-x x-x x$ & $x x x x-x x-x x$ & $\mathbf{u}$ & $x x x x x x x x$ \\
\hline 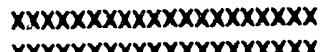 & $x x$ & $\mathbf{x x x}$ & $x \mathbf{x x}$ & $x x x x x x x x$ & $x x x x-x x-x x$ & $x x x x-x x-x x$ & $u$ & $x x x x x x x x$ \\
\hline 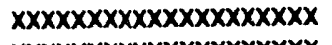 & $\mathbf{x x}$ & & $\mathbf{x x x}$ & $x x x x x x x x$ & $x x x x-x x-x x$ & $x x x x-x x-x x$ & $u$ & $x x x \times x \times x x$ \\
\hline 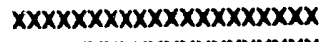 & $x x$ & & $x x x$ & $x x x x x x x x x$ & $x x x x-x x-x x$ & $x x x x-x x-x x$ & u & $x \times x \times x \times x \times x$ \\
\hline 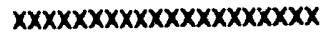 & $x x$ & $\mathbf{x x x}$ & $x x x$ & $x x x x x x x x$ & $x x x x-x x-x x$ & $x x x x-x x-x x$ & $\mathbf{u}$ & $x x x x x x x x$ \\
\hline
\end{tabular}

Fig. C-5. PRIS Report 5 - Folder/Document Listing for a Given Project. 


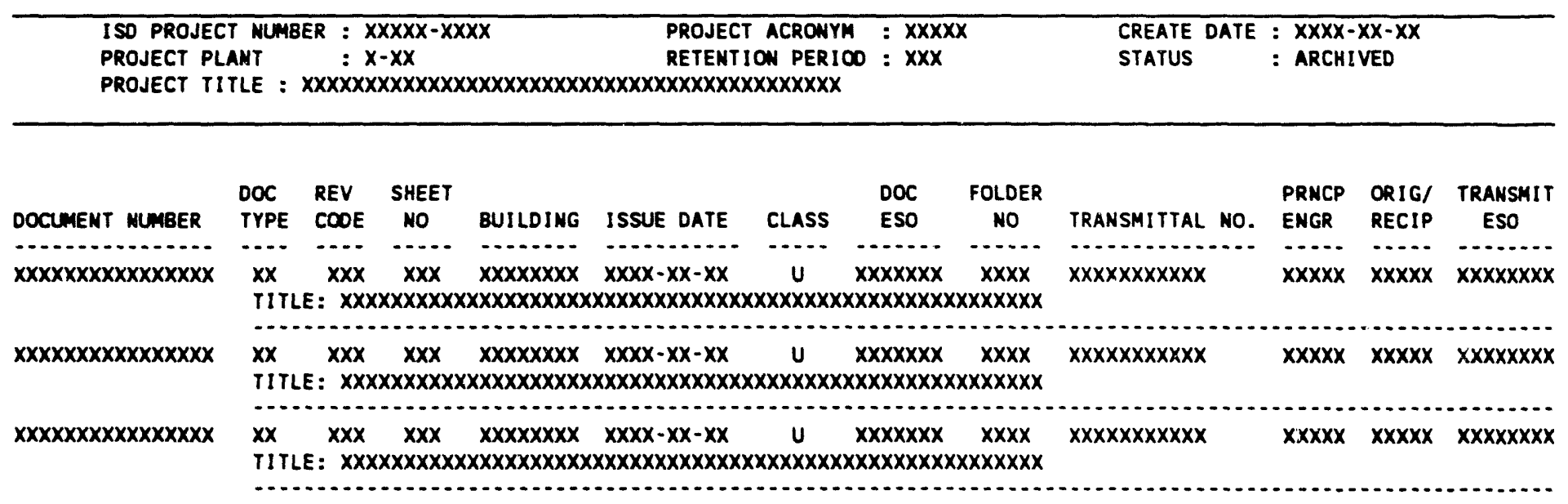

Fig. C-6. PRIS Report 6 - Project/Document List For a Given Project Engineer. 


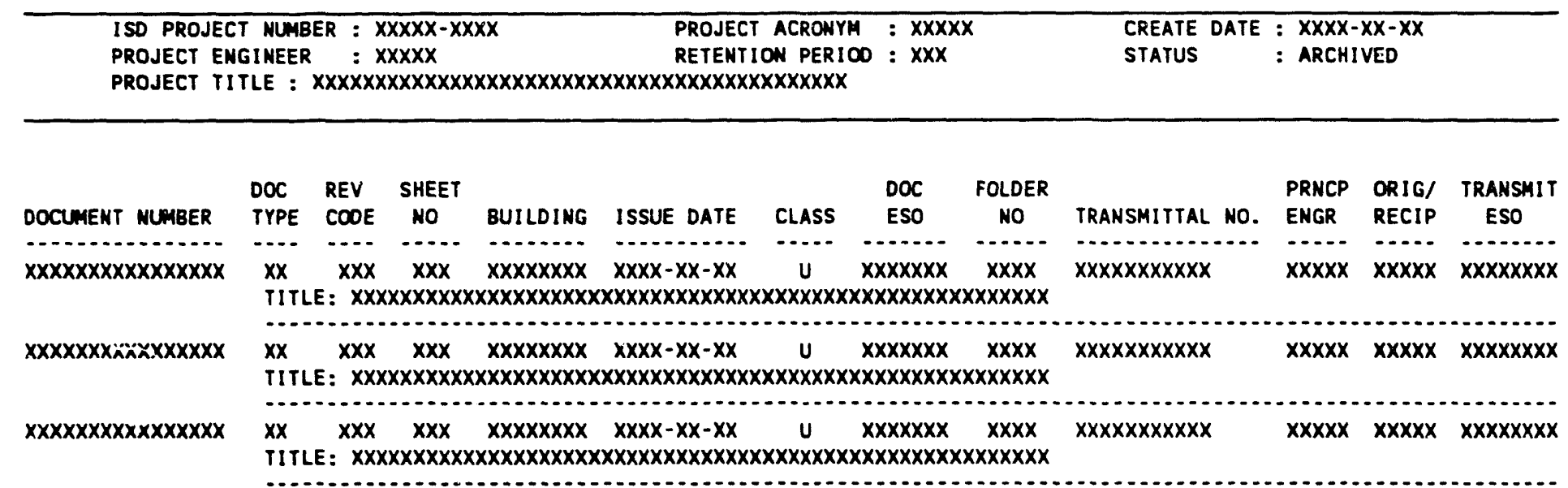

Fig. C-7. PRIS Report 7 - Project/Document List For a Given Plant. 


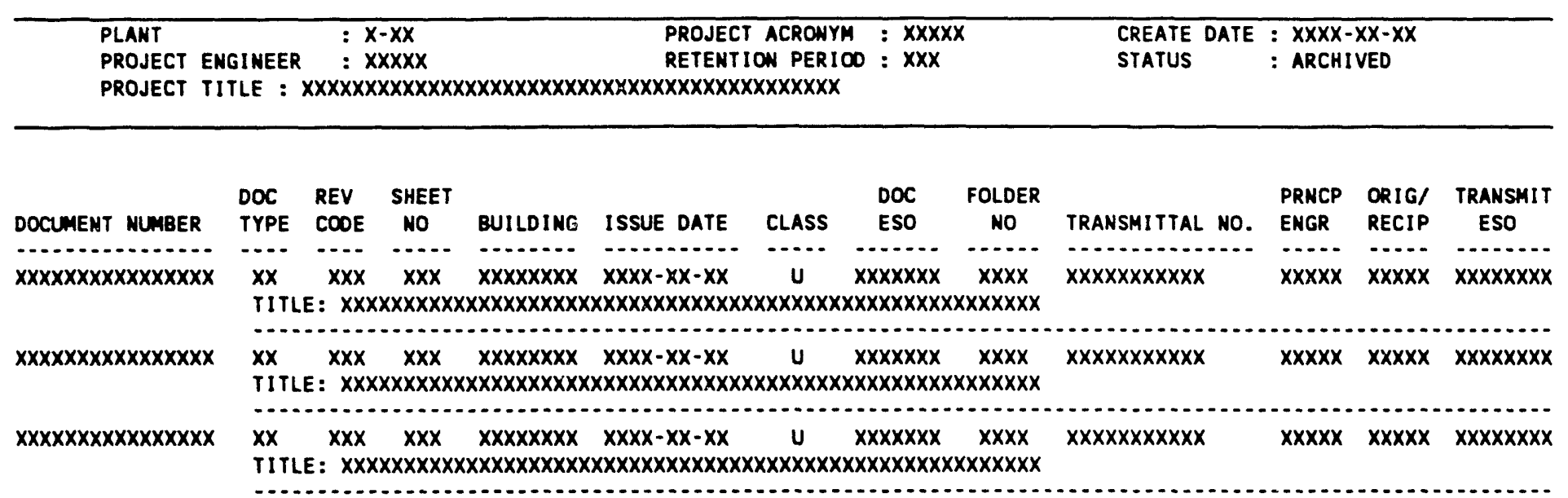

Fig. C-8. PRIS Report 8 - Document List For a Given Project. 
APPENDIX D: PRIS PRIMARY MENU STRUCTURE DIAGRAM 

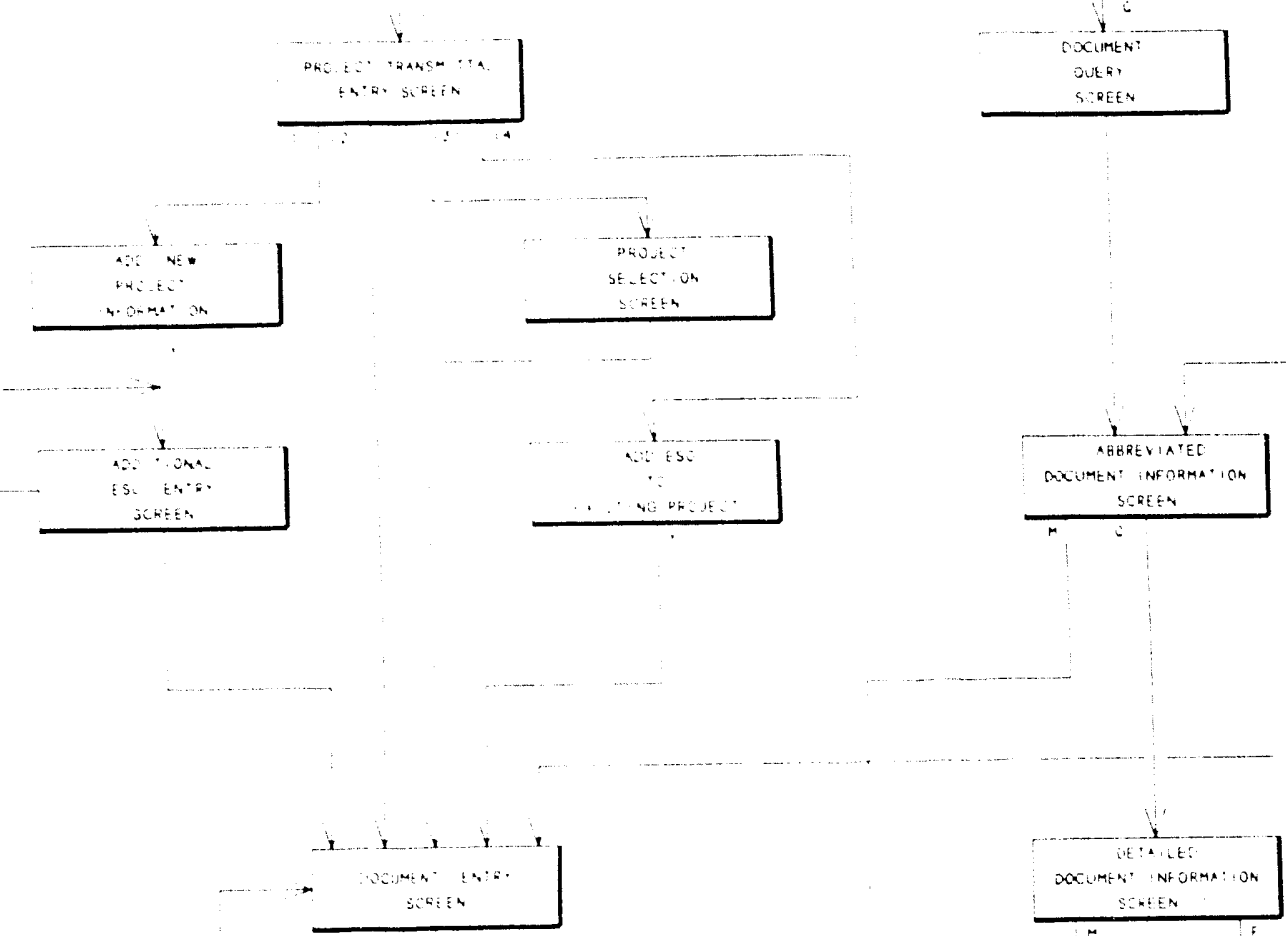

NOTES:

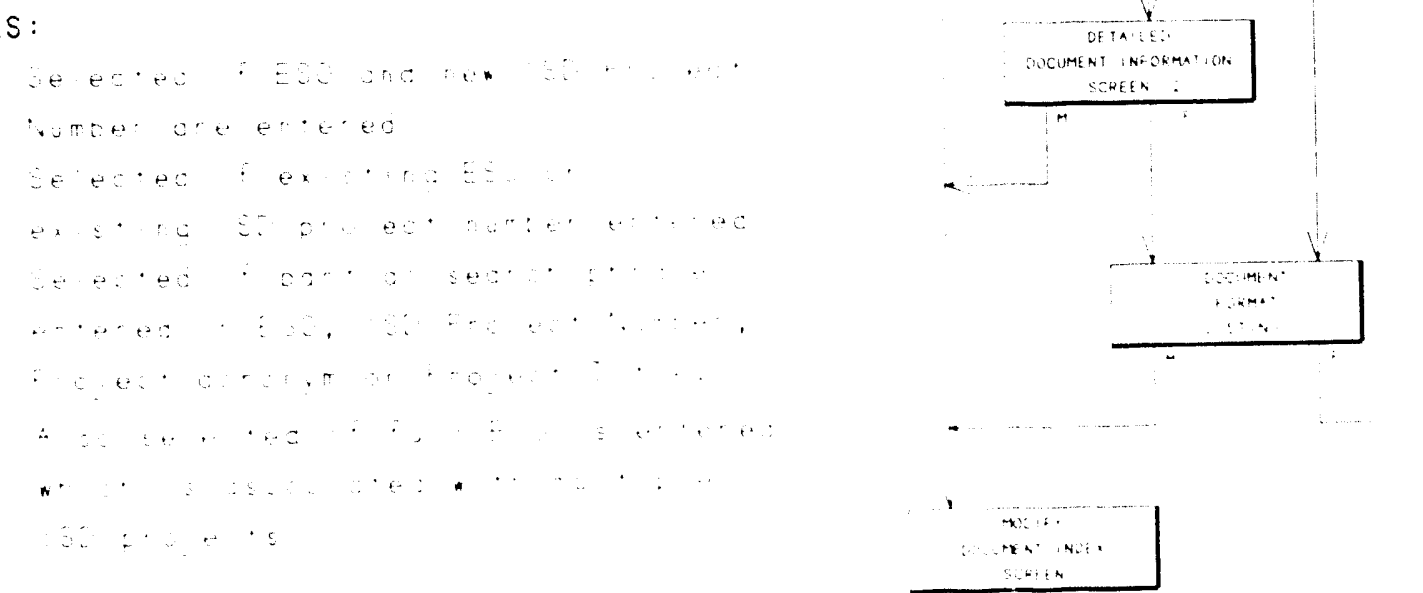

NOTES:

Project Records Infi PRIMARY ME 

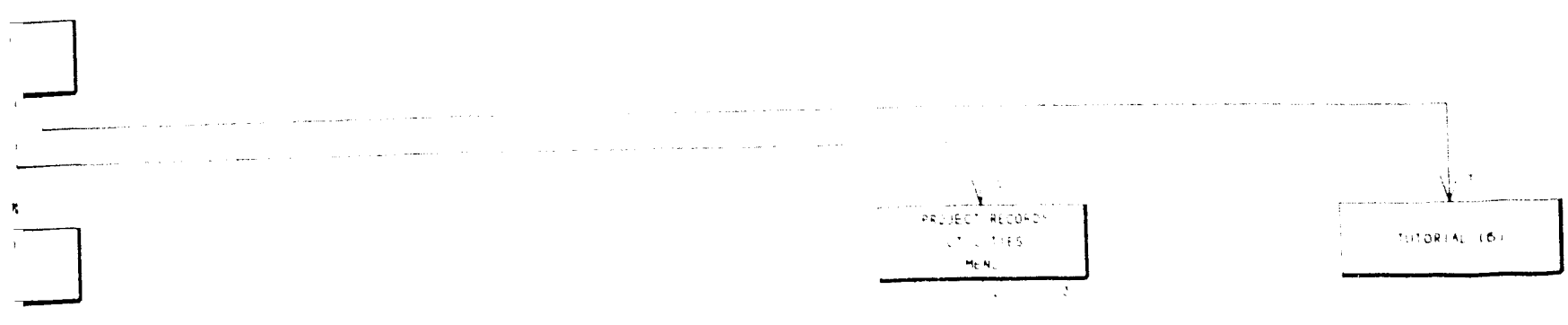

$\square$
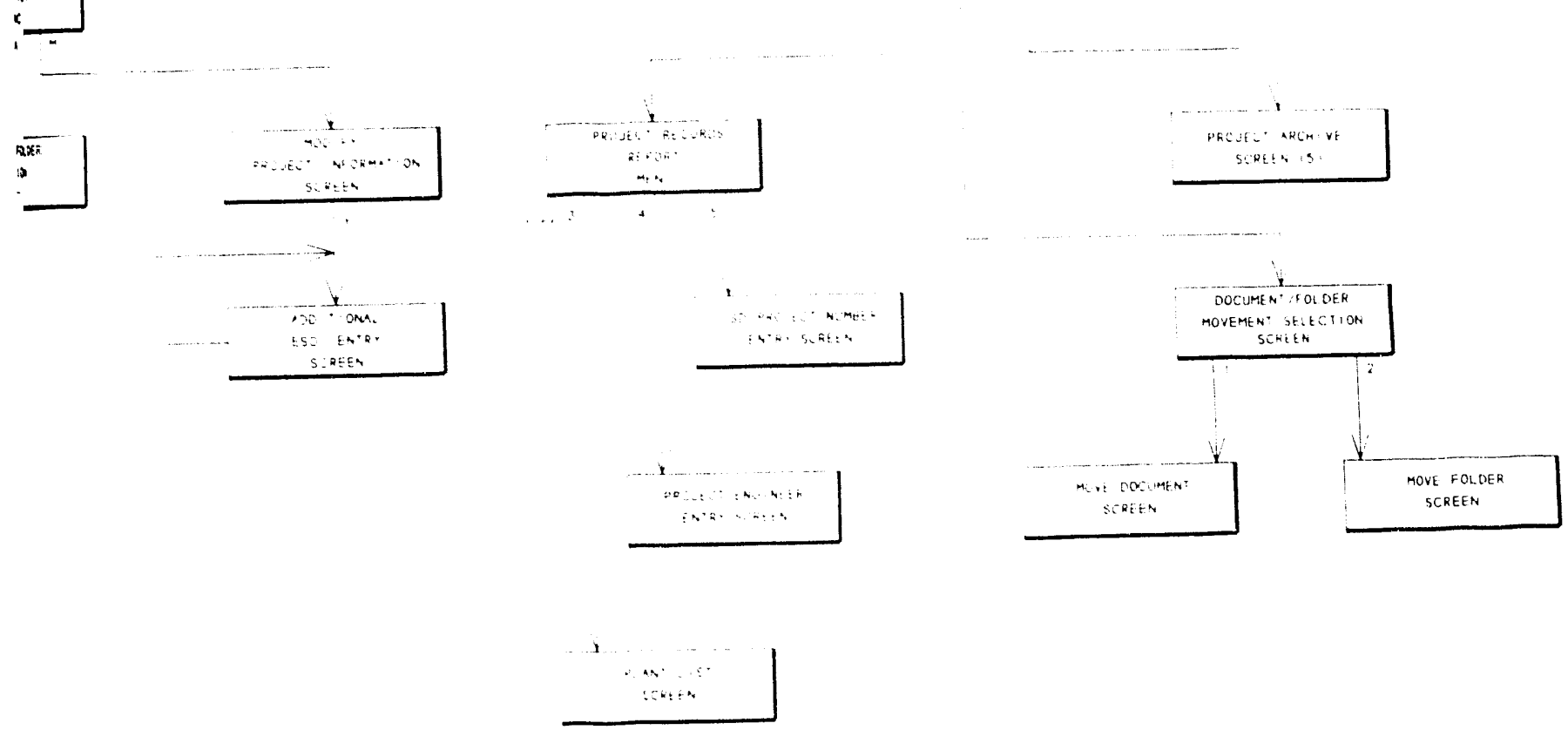

\begin{tabular}{|clll|}
\hline USER RESPONSE & LEGEND \\
\hline D DELETE & $F$ & FORWARD \\
1 & INPUT & $M$ & MODIFY \\
O & OUERY & $U$ & UTILITIES \\
$Y$ & YES & PO & PROJECT OUERY \\
\hline
\end{tabular}

rmation System (PR/S)

N STRUCTURE 
K/CSD/TM-93/R1

Dist. Category UC-505

\section{DISTRIBUTION}

\section{1-20. P. S. Smith}

21. Applied Technology Library

22. K-25 Site Records Department - RC

23-34. Department of Energy -

Office of Scientific and Technical Information 

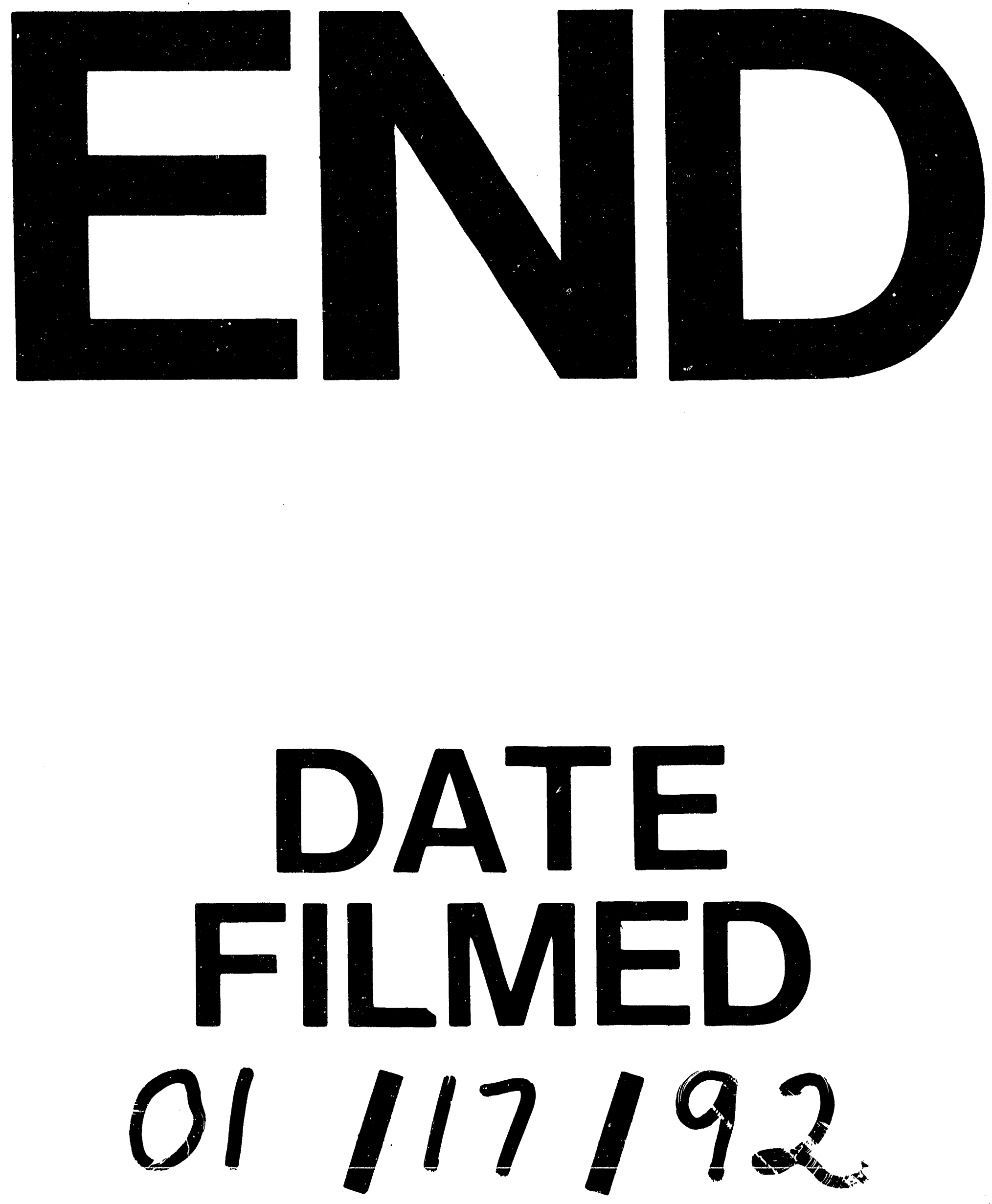

I 
